\title{
Plant-Based Antidiabetic Nanoformulations: The Emerging Paradigm for Effective Therapy
}

\author{
Saikat Dewanjee ${ }^{1, *(\mathbb{D}}$, Pratik Chakraborty ${ }^{1}\left(\mathbb{D}\right.$, Biswajit Mukherjee ${ }^{2}\left(\mathbb{D}\right.$ and Vincenzo De Feo ${ }^{3, *}$ \\ 1 Advanced Pharmacognosy Research Laboratory, Department of Pharmaceutical Technology, Jadavpur \\ University, Kolkata 700032, India; pratik.chakraborty88@yahoo.com \\ 2 Pharmaceutics Research Laboratory, Department of Pharmaceutical Technology, Jadavpur University, \\ Kolkata 700032, India; biswajit.mukherjee@jadavpuruniversity.in \\ 3 Department of Pharmacy, University of Salerno, 84084 Fisciano, Italy \\ * Correspondence: saikat.dewanjee@jadavpuruniversity.in (S.D.); defeo@unisa.it (V.D.F.); \\ Tel.: +91-33-42452-32043 (S.D.); +39-089-969-751 (V.D.F.)
}

Received: 26 February 2020; Accepted: 19 March 2020; Published: 23 March 2020

\begin{abstract}
Diabetes mellitus is a life-threatening metabolic syndrome. Over the past few decades, the incidence of diabetes has climbed exponentially. Several therapeutic approaches have been undertaken, but the occurrence and risk still remain unabated. Several plant-derived small molecules have been proposed to be effective against diabetes and associated vascular complications via acting on several therapeutic targets. In addition, the biocompatibility of these phytochemicals increasingly enhances the interest of exploiting them as therapeutic negotiators. However, poor pharmacokinetic and biopharmaceutical attributes of these phytochemicals largely restrict their clinical usefulness as therapeutic agents. Several pharmaceutical attempts have been undertaken to enhance their compliance and therapeutic efficacy. In this regard, the application of nanotechnology has been proven to be the best approach to improve the compliance and clinical efficacy by overturning the pharmacokinetic and biopharmaceutical obstacles associated with the plant-derived antidiabetic agents. This review gives a comprehensive and up-to-date overview of the nanoformulations of phytochemicals in the management of diabetes and associated complications. The effects of nanosizing on pharmacokinetic, biopharmaceutical and therapeutic profiles of plant-derived small molecules, such as curcumin, resveratrol, naringenin, quercetin, apigenin, baicalin, luteolin, rosmarinic acid, berberine, gymnemic acid, emodin, scutellarin, catechins, thymoquinone, ferulic acid, stevioside, and others have been discussed comprehensively in this review.
\end{abstract}

Keywords: bioavailability; diabetes; drug delivery; nanoformulation; natural products; phytochemicals

\section{Introduction}

Nanoscience and nanotechnology have progressed rapidly in recent years with the scope of various applications. Nanotechnology has spread its applications in several fields including medical and health sciences. In the field of medical science, nanosized formulations offer an unprecedented success in drug delivery systems over conventional formulations via enhancing clinical efficacy of therapeutic agents through improving their biopharmaceutical attributes, pharmacokinetic profiles, and target specificity [1]. The development of nanocarrier-assembled drug nanoparticles, such as polymeric nanoparticles, liposomes, dendrimers, niosomes, nanomicelles, metallic nanoparticles, stimuli-responsive nanoparticles, nanostructured lipid carriers, and nanofabricated devices have been found to produce great success over conventional drug delivery systems in terms of effectiveness, stability, bioavailability, biodistribution, and drug release [1]. Combinations of nanocarriers with ligands make them more targeted with the consequent advantage of the protection of entrapped drugs 
against degradation. Increased success of nanostructured drug delivery system has gained the interest of many scientists to develop novel formulations against different diseases, such as different types of cancer, inflammatory disorders, cardiovascular diseases, infectious diseases, etc. [2]. Nanoformulations were also found to be efficacious against common metabolic syndrome, such as diabetes mellitus to deliver insulin and oral hypoglycaemic agents. Nanocarrier-assembled nanoparticles of hypoglycaemic agents promote the functionalization of the antidiabetic agents via improving drug penetration to the specific target, prolonging the hypoglycaemic effect, and minimizing the risk of side effects.

Over the years, several pieces of research yielded a number of target-specific small molecules from natural resources including plant phenolics to be effective against diabetes [3]. Many of these have been found to exhibit exciting antidiabetic activity in vitro [3]. However, a gap exists between the in vitro observations and the in vivo effects, which reduce their clinical usefulness [4]. Poor water solubility, rapid metabolism, poor bioavailability, and high P-glycoprotein (P-gp) efflux have been found to be accountable for their in vivo ineffectiveness $[3,5]$. To overcome the pharmaceutical incompetence of these compounds and to utilize their beneficial effects against diabetes, different pharmaceutical approaches, such as hydrotrophy, micronization, lipid-based emulsion systems, solid dispersions, etc. have been proposed by different scientists over the years [6]. However, nanocarrier-assembled nanosized drug delivery has been found to exhibit remarkable prospects over other dosage forms to deliver naturally occurring antidiabetic agents possessing poor pharmaceutical attributes [1]. Nowadays, the nanodrug delivery system is progressively gaining more attention in the formulation development research to achieve better therapeutic efficacy by reducing dosing frequency, enhancing bioavailability, achieving sustained-release properties, promoting selectivity, and reducing other undesirable biopharmaceutical attributes [6]. This review emphasized the distinctive features of nanoformulations of antidiabetic agents from natural sources.

\section{Diabetes Mellitus: General Overview}

Diabetes mellitus is a serious and pervasive metabolic syndrome characterized by high glucose levels in blood. It can be classified into two major types: type 1 and type 2 diabetes mellitus. Over the past few decades, the prevalence of diabetes has climbed exponentially [7]. In 2014, approximately 422 million people constituting $8.5 \%$ of the total global population were diagnosed diabetic $[8,9]$. Among them, $7 \%$ of people with diabetes were categorized as type 2 diabetic patients [9]. It has been predicted that approximately 642 million people will suffer from diabetes mellitus by 2040 [10]. Diabetes is a silent killer which can provoke a number of slowly or rapidly developing pathogenesis, such as nephropathy, retinopathy, neuropathy, cardiomyopathy, peripheral arterial disease, coronary artery disease, and stroke [11-15]. Glycaemic control has been regarded to be the principal therapeutic intervention in diabetes mellitus. However, multiple risk factors in diabetes, lethal complications, and establishment of vasculopathy before diagnosis necessitate developing novel therapeutic strategies for the effective management of diabetes [12]. Insulin, a polypeptide hormone, is secreted from $\beta$ cells of islets of Langerhans in the pancreas and regulates the uptake and utilization of glucose by the tissues to produce energy [16]. For type 1 diabetic patients, typical treatment includes injections of long-acting insulin to maintain a basal level of insulin, in combination with bolus injections of fast-acting insulin at mealtimes [17]. Several hypoglycaemic agents singly or in combination with insulin are clinically used to treat type 2 diabetes mellitus $[9,14]$. However, the clinically available antidiabetic agents disappoint both clinicians and patients owing to their untoward effects, which increasingly shifted the focus toward the discovery of novel antidiabetic agents. On the other hand, many naturally occurring phytochemicals have shown huge prospects against diabetes and diabetic complications in preclinical assays via aiming at multiple targets [3,9]. 


\section{Plant-Derived Small Molecules as Antidiabetic Agents}

Many plant-derived secondary metabolites were reported to possess significant antidiabetic activities. Plant secondary metabolites have been revealed to exhibit antidiabetic effect via multiple mechanisms, which include suppression of glucose absorption, restoration of the functional mass of $\beta$ cells, improvement of insulin expression, reversal of insulin resistance, promotion of glucose utilization, and regulation of carbohydrate and lipid metabolism (Figure 1).

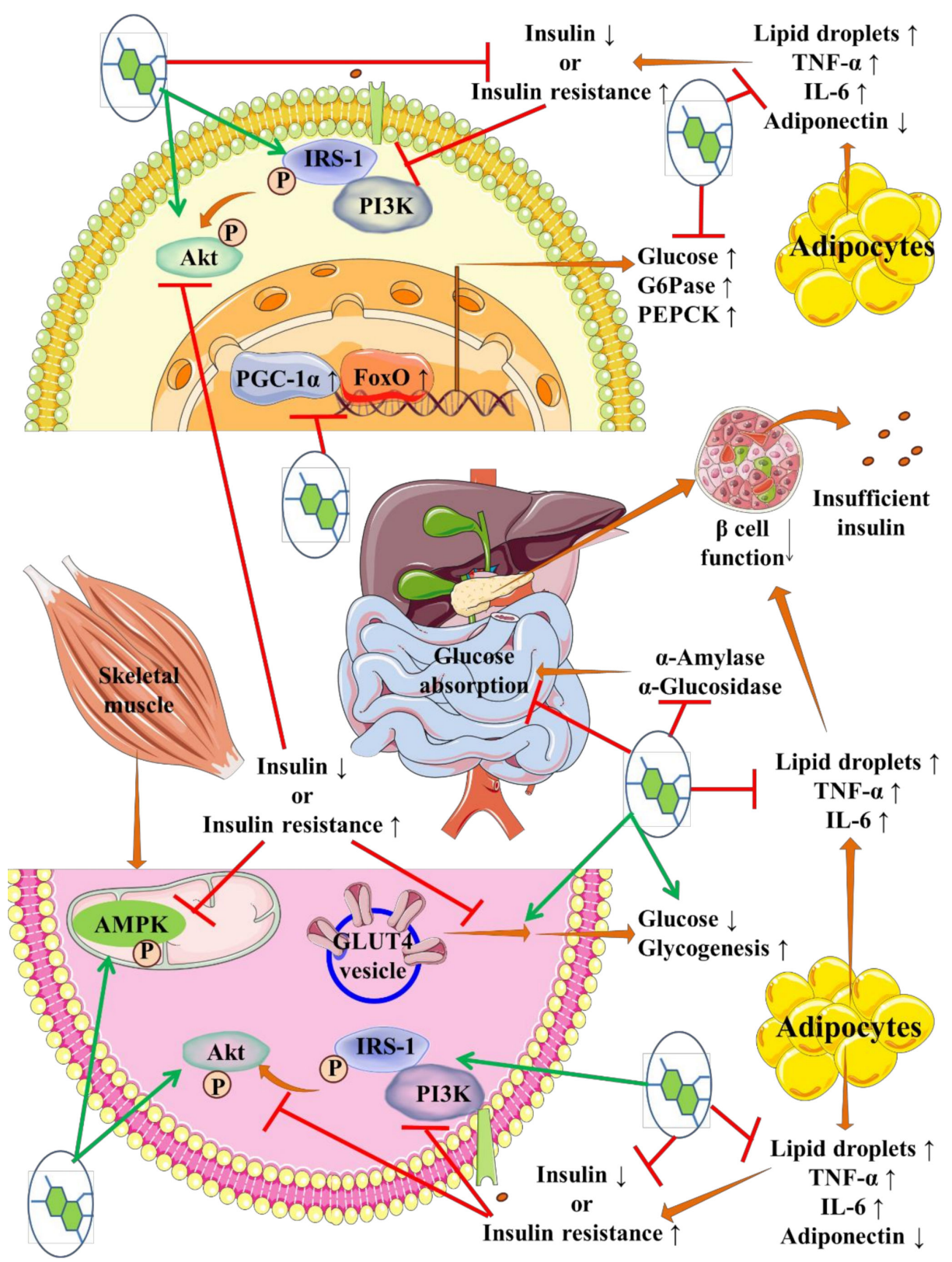

Figure 1. Multiple therapeutic targets of plant secondary metabolites in diabetes management. Orange arrows indicate downstream cellular events; upward arrows indicate upregulation; downward arrows indicate downregulation; green arrows indicate activation; red lines indicate inhibition. Akt: protein kinase A, AMPK: 5' AMP-activated protein kinase, FoxO: forkhead box protein O, G6Pase: glucose 6-phosphatase, GLUT: glucose transporter, IL: interleukin, IRS-1: insulin receptor substrate-1, PEPCK: phosphoenolpyruvate carboxykinase, PGC-1 $\alpha$ : peroxisome proliferator-activated receptor- $\gamma$ coactivator- $1 \alpha$, PI3K: phosphoinositide 3-kinase, TNF- $\alpha$ : tumour necrosis factor- $\alpha$. 
Several phytochemicals have been found to suppress postprandial hyperglycaemia by interrupting carbohydrate digestion and retarding glucose absorption through inhibition of intestinal carbohydrate digesting enzymes, such as $\alpha$-amylase, $\alpha$-glucosidase, and $\beta$-glucosidase [18]. Resveratrol, myricitrin, baicalin, apigenin, quercetin, naringenin, curcumin, luteolin scutellarin, ferulic acid, gallic acid, rosmarinic acid, and some anthocyanins can inhibit intestinal carbohydrate-digesting enzymes [18-24].

Progressive functional loss of $\beta$ cells in diabetic milieu caused by high lipids, high glucose, inflammatory mediators secreted by the adipose tissue, and endoplasmic reticulum stress can decrease insulin secretion, thereby developing persistent hyperglycaemia [25]. Curcumin, gymnemic acids, silymarin, quercetin, resveratrol, and berberine have been proposed to restore functional mass of pancreatic $\beta$ cells via multiple targeting, thus can attribute to the prospective therapeutic strategy in diabetes [25]. Curcumin and resveratrol can improve $\beta$ cell function by suppressing pathologic signalling events through inhibition of the phosphodiesterases in $\beta$ cells [26]. Resveratrol can restore $\beta$ cell function by endorsing sirtuin 1 (SIRT1) activation, which subsequently endorses pancreatic and duodenal homeobox 1 (PDX1)-triggered insulin expression and abolishes forkhead box O1 (FoxO1)-governed transcriptional actions [27]. Mangiferin can stimulate $\beta$ cell function via dipeptidyl peptidase-IV (DPP-4) inhibition [28]. Gymnemic acid has been proposed to protect $\beta$ cells against oxidative damage and stimulate glucose-induced insulin secretion by recruiting glucose transporter type (GLUT)2 signalling [29]. Stevioside can directly target pancreatic $\beta$ cells and promote insulin secretion [30]. In addition, it improves $\beta$ cell function by potentiating the transient receptor potential cation channel subfamily melastatin member 5 (TRPM5) channel activity [31]. Asiatic acid can preserve $\beta$ cell population by endorsing protein kinase B (Akt) and B-cell lymphoma-extralarge (Bcl-xL) expressions [32]. Flavonoids ensure $\beta$ cell survival against high glucose, high lipids, and pro-inflammatory cytokines by inhibiting nuclear factor kappa-light-chain-enhancer of activated $\mathrm{B}$ cells (NF-KB) activation, endorsing phosphoinositide 3-kinase (PI3K)/Akt signalling, inhibiting nitric oxide production, and decreasing oxidative stress [33]. In addition, flavonoids can restore the secretory function of $\beta$ cells through phospholipase C (PLC), protein kinase C (PKC), protein kinase A (PKA), cyclic adenosine monophosphate (cAMP) regulation [33]. Naringenin can restore the function of $\beta$ cells via activating GLUT2, PDX1, Akt, insulin receptor substrate (IRS), B-cell lymphoma 2 (Bcl2), and heat shock protein (Hsp)70/90 genes [34]. In addition, it can prevent $\beta$ cell loss by suppressing pro-apoptotic genes such as Bcl-2-associated X protein (Bax), caspase 3 , and acetyl-CoA carboxylase (Acc1) [34]. Silymarin, a flavonoid, was found to endorse $\beta$ cell neogenesis and insulin production by triggering Nkx6.1 and insulin mRNA activation [35]. Gallic acid prevents high gluco-lipid-induced $\beta$ cell dysfunction via inhibiting apoptosis and restoring PDX1 and insulin expressions [36].

Insulin resistance primarily hampers glucose utilization in type 2 diabetes [37]. Restoration of insulin signalling is a therapeutic approach to reciprocate insulin resistance [37]. Insulin receptor (IR), insulin receptor substrate (IRS)-1, PI3K, Akt, and GLUT4 are the key components of insulin signalling in skeletal muscle [9,15]. Phosphorylation of IRS1 at Tyr 895 activates PI3K, which subsequently endorses phosphorylation of Akt at Ser 473 and Thr308 resulting in GLUT4 translocation into the membrane $[9,15]$. GLUT4 translocation can facilitate glucose uptake and utilization. 5' AMP-activated protein kinase (AMPK) regulates cellular energy homeostasis in this process $[9,15]$. In addition, phosphorylated Akt can prevent FoxO1 activation via inhibiting the phosphorylation of FoxO1, thus abrogate the expression of hepatic gluconeogenic genes, such as phosphoenolpyruvate carboxykinase (PEPCK), and glucose-6-phosphatase (G6Pase) [38]. AMPK can also suppress PEPCK and G6Pase activities in the liver [39]. Several phytochemicals have been proposed to regulate glucose utilization through stimulation of GLUT4 translocation to membrane, thus improve postprandial glucose uptake [40]. Resveratrol [24,41], curcumin [42], naringenin [34], quercetin [43], apigenin [44], rosmarinic acid [22], berberine [45], stevioside [46], asiatic acid [47], glycyrrhizin [48], gallic acid [49], thymoquinone [50] can elicit insulin-provoked glucose uptake into skeletal muscle by endorsing IRS-1/PI3K/Akt/GLUT4/AMPK signalling. 
Peroxisome proliferator-activated receptor (PPAR) subtypes have been regarded as the key metabolic regulators. PPAR- $\alpha$ and PPAR- $\beta / \delta$ are implicated in fatty acid uptake and fatty acid oxidation; while, PPAR- $\gamma$ promotes glucose and lipid uptake, glucose oxidation, and insulin responsiveness [51]. Several phytochemicals have been reported to activate PPARs, thereby playing important roles in the management of diabetes. Curcumin [52], berberine [53], glycyrrhizin [54], and scutellarin [55] were found to activate glucose and lipid metabolism by activating PPAR- $\alpha$ in the adipose tissue; while, naringenin [56], myricetin [57], quercetin [58], mangiferin [59], ferulic acid [60], bixin [61], silymarin [62], $\alpha$-eleostearic acid [63], glycyrrhizin [54], and asiatic acid [64] can endorse hepatic lipid metabolism via endorsing PPAR- $\alpha$ activation. Gymnemic acid was found to endorse fatty acid oxidation and reciprocate insulin resistance in the liver, skeletal muscle and adipose tissue through PPAR- $\delta$ activation [65]. Plant phenolics can maintain energy homeostasis by triggering PPAR- $\delta$ activation [66]. Several naturally occurring small molecules, such as curcumin [52], resveratrol [67], naringenin [34], luteolin [68], quercetin [43], apigenin [44], emodin [68], berberine [69], baicalin [70], gallic acid [49], and catechin [71] were reported to elicit glucose and lipid metabolism via endorsing transcriptional activity of PPAR- $\gamma$ in adipose tissue.

In addition, plant-derived small molecules have proven their therapeutic effectiveness against diabetes-mediated vascular complications, such as nephropathy, retinopathy, cardiomyopathy, neuropathy, adipose tissue dysfunctions, hepatic disorder, and other vascular diseases via multiple mechanisms. Precisely, hyperglycaemia can elicit oxidative stress by triggering free radical production and impairing endogenous redox defense system [9,12,14,15,72]. Oxidative stress simultaneously endorses inflammation, fibrosis, autophagic dysfunction, and apoptosis via endorsing mitogen-activated protein kinase (MAPK)/PKC/NF- $\mathrm{KB} /$ transforming growth factor $\beta 1$ (TGF- $\beta 1$ )/mothers against decapentaplegic homolog (Smad) 2, 3 and $4 / \alpha$-smooth muscle actin $(\alpha-\mathrm{SMA}) / \mathrm{collagen}$ signalling [12-14]. In contrast, plant-derived antidiabetic agents can alleviate diabetic complications through glycaemic control, antioxidant mechanism, and inhibition of pathological signal transductions involved in inflammation, fibrosis, and apoptosis (Figure 2). Curcumin [73], resveratrol [74], naringenin [34], quercetin [75], apigenin [76,77], myricitrin [78,79], baicalin [80,81], luteolin [82,83], mangiferin [59,84,85], emodin [86,87], rosmarinic acid [88], berberine [89], stevioside [90,91], asiatic acid [92-94], glycyrrhizin [95-98], baicalin [99,100], silymarin [101], gallic acid [102-104], catechins [105,106], thymoquinone [107], and ferulic acid [108-110] have been revealed to attenuate diabetic vascular complications via modulating multiple molecular targets.

Despite the aforementioned plant-derived molecules exhibited excellent opportunity to alleviate diabetes and associated complications in preclinical assays, but poor systemic availability owing to undesirable molecular size, low water solubility, poor lipophilicity, rapid metabolism, less penetrability, and high P-gp efflux largely restricts their clinical usefulness as therapeutic agents in diabetes management $[3,111]$. Table 1 depicts pharmaceutical incompetence of plant-derived antidiabetic molecules. Thus, formulation designers are actively involved to extract their best therapeutic output through developing novel formulations. In this issue, nanotechnology-based formulation designing has been emerging as a solution to eradicate the pharmaceutical incompetence and improve patient compliance. 


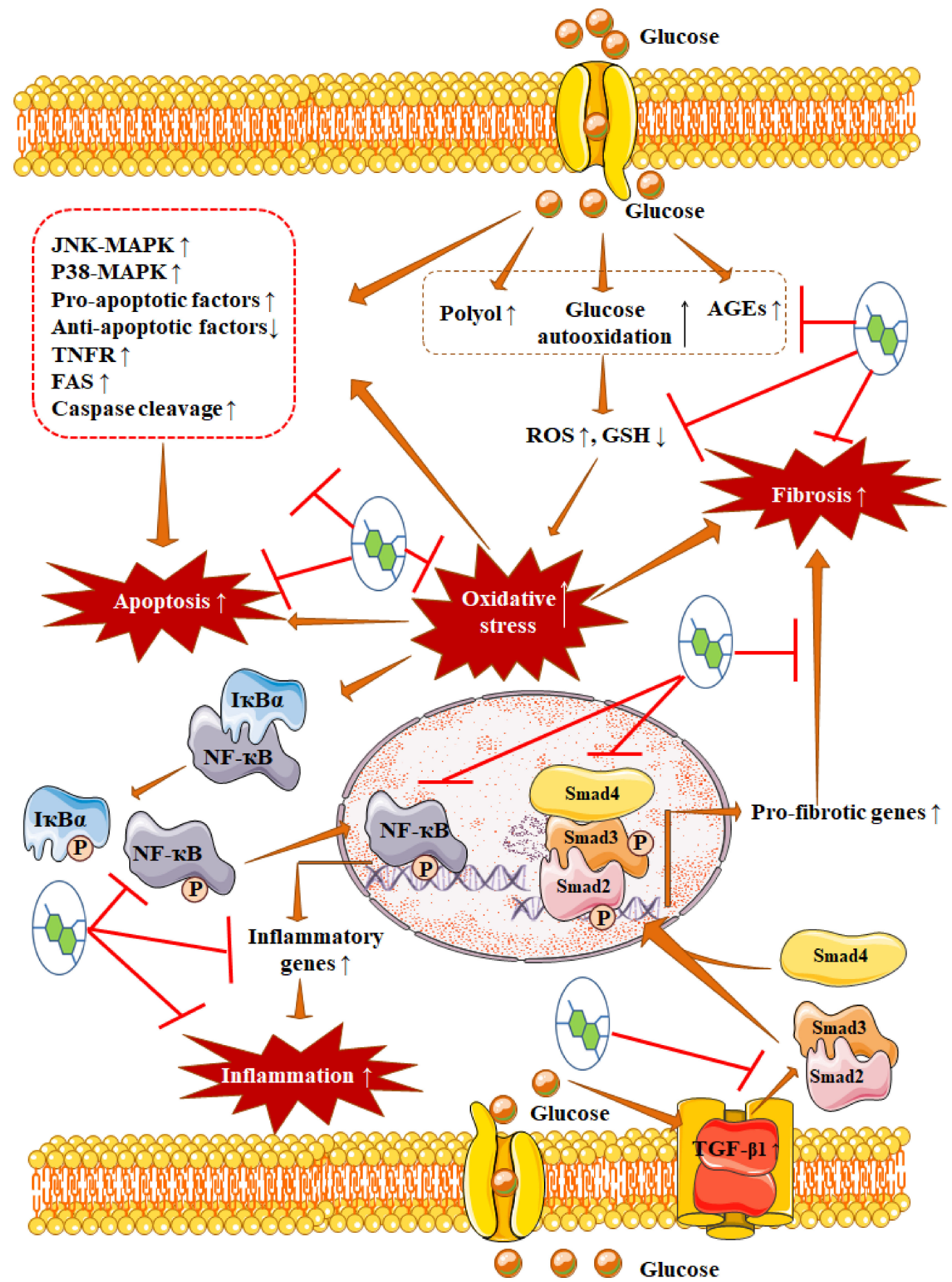

Figure 2. Overall protective mechanism of plant secondary metabolites in diabetic complications. Orange arrows indicate downstream cellular events; upward arrows indicate upregulation; downward arrows indicate downregulation; red lines indicate inhibition. AGEs: advanced glycation end products, FAS: Fas cell surface death receptor, IкB $\alpha$ : nuclear factor of kappa light polypeptide gene enhancer in B-cells inhibitor $\alpha$, JNK: c-Jun N-terminal kinases, MAPK: mitogen-activated protein kinase, NF-kB: nuclear factor kappa-light-chain-enhancer of activated B cells, ROS: reactive oxygen species, Smad: mothers against decapentaplegic homolog, TGF- $\beta 1$ : transforming growth factor $\beta 1$, TNFR: tumour necrosis factor receptor. 
Table 1. Pharmaceutical limitations of plant-derived antidiabetic molecules.

\begin{tabular}{|c|c|c|c|}
\hline S No. & Compounds & Pharmaceutical Limitations & References \\
\hline 1 & Curcumin & $\begin{array}{l}\text { Water solubility } \sim 8 \mathrm{mg} / \mathrm{L} \text {, poor chemical stability, low } \\
\text { penetrability, poor absorption, rapid metabolism, high faecal } \\
\text { excretion, elimination half-life } \sim 2 \mathrm{~h} \text {. }\end{array}$ & [112-114] \\
\hline 2 & Resveratrol & $\begin{array}{l}\text { Water solubility } \sim 30 \mathrm{mg} / \mathrm{L} \text {, rapid metabolism, rapid } \\
\text { elimination, low plasma concentration, limited systemic } \\
\text { distribution, oral bioavailability } \sim 1-5 \% \text {, poor physicochemical } \\
\text { stability, rapid trans to cis (less active) isomerization. }\end{array}$ & $\begin{array}{l}{[111,115,} \\
116]\end{array}$ \\
\hline 3 & Naringenin & $\begin{array}{l}\text { Water solubility } \sim 9.8 \mathrm{mg} / \mathrm{L} \text {, low absorption, rapid metabolic } \\
\text { transformation by the hepatic and gastric enzymes, oral } \\
\text { bioavailability } \sim 5 \% \text {, high intestinal P-gp efflux. }\end{array}$ & $\begin{array}{l}{[111,117,} \\
118]\end{array}$ \\
\hline 4 & Quercetin & $\begin{array}{l}\text { Water solubility } \sim 10 \mathrm{mg} / \mathrm{L} \text {, poor chemicobiological stability, } \\
\text { low absorption, fast metabolism, rapid elimination, poor oral } \\
\text { bioavailability } \sim 1 \% .\end{array}$ & {$[119,120]$} \\
\hline 5 & Apigenin & $\begin{array}{l}\text { Water solubility } \sim 16 \mathrm{mg} / \mathrm{L} \text {, poor lipid solubility, high } \\
\text { metabolic transformation, poor oral bioavailability, high } \\
\text { inter-individual variability. }\end{array}$ & [121] \\
\hline 6 & Myricitrin & $\begin{array}{c}\text { Water solubility } 300 \mathrm{mg} / \mathrm{L} \text {, poor gastrointestinal stability, rapid } \\
\text { conversion into poorer soluble myricetin (solubility } \sim 17 \mathrm{mg} / \mathrm{L} \text { ) } \\
\text { by colonic microflora, very low absorption, poor } \\
\text { bioavailability. }\end{array}$ & {$[122,123]$} \\
\hline 7 & Baicalin & $\begin{array}{l}\text { Water solubility } 91 \mathrm{mg} / \mathrm{L} \text {, poor absorption, high biliary } \\
\text { excretion, high metabolic conversion, poor bioavailability }(\sim 3 \\
\% \text { in rats). }\end{array}$ & {$[124,125]$} \\
\hline 8 & Luteolin & $\begin{array}{l}\text { Water solubility } 140 \mathrm{mg} / \mathrm{L} \text {, low absorption, rapid first pass } \\
\text { effect, bioavailability } \sim 4 \% .\end{array}$ & [126] \\
\hline 9 & Mangiferin & $\begin{array}{l}\text { Water solubility } \sim 300 \mathrm{mg} / \mathrm{L} \text {, poor absorption, high first-pass } \\
\text { property, rapid metabolism (by cytochrome P-450), high P-gp } \\
\text { efflux, oral bioavailability } \sim 1.5-5 \% .\end{array}$ & [127] \\
\hline 10 & Gymnemic acid & $\begin{array}{l}\text { Poor water solubility, poor lipid solubility, very poor oral } \\
\text { bioavailability. }\end{array}$ & {$[128,129]$} \\
\hline 11 & Emodin & $\begin{array}{l}\text { Water solubility } \sim 222 \mathrm{mg} / \mathrm{L} \text {, poor intestinal absorption, faster } \\
\text { metabolism, rapid elimination, low bioavailability. }\end{array}$ & {$[130,131]$} \\
\hline 12 & Rosmarinic acid & $\begin{array}{l}\text { Poor biological stability, poor absorption, rapid metabolic } \\
\text { transformation, poor bioavailability } 0.9-1.7 \% \text {. }\end{array}$ & {$[132,133]$} \\
\hline 13 & Berberine & $\begin{array}{l}\text { Poor water solubility } \sim 2.1 \mathrm{~g} / \mathrm{L} \text {, high } \mathrm{P} \text {-gp efflux, low plasma } \\
\text { concentration, rapid biotransformation, large intestinal and } \\
\text { hepatic first-pass, poor oral bioavailability }<1 \% \text {. }\end{array}$ & [134-137] \\
\hline 14 & Stevioside & $\begin{array}{l}\text { Poor intestinal absorption, low persistence, rapid metabolic } \\
\text { degradation by human microflora, low bioavailability. }\end{array}$ & [138-140] \\
\hline 15 & Asiatic acid & $\begin{array}{l}\text { Poor water solubility } \sim 158 \mathrm{mg} / \mathrm{L} \text { (in saturated saline), rapid } \\
\text { hepatic metabolism, poor oral bioavailability }(\sim 16 \% \text { in rats) }\end{array}$ & {$[92,141]$} \\
\hline 16 & Glycyrrhizin & $\begin{array}{l}\text { Poor absorption, prosystemic hydrolysis by gastric fluid and } \\
\text { by gastrointestinal flora, rapid hepatic metabolism, low oral } \\
\text { bioavailability. }\end{array}$ & [142] \\
\hline 17 & $\alpha$-Eleostearic acid & $\begin{array}{l}\text { Poor chemical stability, high metabolic conversion, low oral } \\
\text { bioavailability. }\end{array}$ & {$[143,144]$} \\
\hline 18 & Scutellarin & $\begin{array}{l}\text { Water solubility } \sim 15 \mathrm{mg} / \mathrm{L} \text {, poor lipid solubility, poor } \\
\text { membrane permeability, very low absorption, rapid } \\
\text { metabolism, rapid faecal elimination, poor oral bioavailability } \\
(<0.75 \% \text { in } \mathrm{dog})\end{array}$ & {$[145,146]$} \\
\hline
\end{tabular}


Table 1. Cont.

\begin{tabular}{|c|c|c|c|}
\hline S No. & Compounds & Pharmaceutical Limitations & References \\
\hline 19 & Silymarin & $\begin{array}{l}\text { Poor water solubility }<50 \mathrm{mg} / \mathrm{L} \text {, poor intestinal permeability, } \\
\text { rapid metabolism, rapid excretion, poor oral bioavailability. }\end{array}$ & {$[147,148]$} \\
\hline 20 & Gallic Acid & $\begin{array}{l}\text { Fast gastrointestinal absorption, fast systemic metabolism, } \\
\text { rapid elimination, poor oral bioavailability. }\end{array}$ & [149] \\
\hline 21 & Catechins & $\begin{array}{l}\text { Poor stability, slow intestinal absorption, rapid P-gp efflux, } \\
\text { fast metabolism, rapid clearance, poor oral bioavailability } \sim \\
5 \% \text {, poor cellular permeability }\end{array}$ & [150] \\
\hline 22 & Pelargonidin & $\begin{array}{l}\text { Low water solubility, poor stability, rapid metabolic } \\
\text { degradation, poor bioavailability. }\end{array}$ & {$[151]$} \\
\hline 23 & Thymoquinone & $\begin{array}{l}\text { Poor aqueous solubility, high lipophilicity, slow absorption, } \\
\text { fast metabolism, rapid elimination, low bioavailability, poor } \\
\text { physicochemical stability. }\end{array}$ & {$[152,153]$} \\
\hline 24 & Ferulic acid & $\begin{array}{c}\text { Poor water solubility, poor gastrointestinal stability, rapid } \\
\text { metabolism, low bioavailability } \sim 3 \% .\end{array}$ & {$[154,155]$} \\
\hline 25 & Betulin & $\begin{array}{l}\text { Low aqueous solubility, high permeability, low and variable } \\
\text { bioavailability }\end{array}$ & {$[156,157]$} \\
\hline 26 & $\begin{array}{l}\text { Trans-cinnamic } \\
\text { acid }\end{array}$ & Rapid absorption, rapid elimination, quick metabolism. & [158] \\
\hline 27 & Trigonelline & Moderate absorption rate, fast elimination. & [159] \\
\hline 28 & Crocetin & $\begin{array}{c}\text { Water solubility } \sim 1.2 \mathrm{mg} / \mathrm{L}, \text { instability, rapid absorption, low } \\
\text { oral bioavailability. }\end{array}$ & {$[160,161]$} \\
\hline 29 & Rhein & $\begin{array}{c}\text { Low hydrophilicity, aqueous solubility }<1 \mathrm{mg} / \mathrm{L} \text {, low oral } \\
\text { absorption, fast metabolic degradation, poor oral } \\
\text { bioavailability } \mathrm{t}_{1 / 2} \sim 15 \mathrm{~min} .\end{array}$ & {$[162,163]$} \\
\hline 30 & $\begin{array}{l}\text { 14-Deoxy 11, } \\
\text { 12-didehydro } \\
\text { andrographolide }\end{array}$ & $\begin{array}{l}\text { Poor aqueous solubility, rapid absorption, fast metabolism, } \\
\text { poor oral bioavailability. }\end{array}$ & [164] \\
\hline 31 & Fisetin & $\begin{array}{l}\text { Water solubility } \sim 10.5 \mathrm{mg} / \mathrm{L} \text {, pro-systemic metabolism, rapid } \\
\text { first pass metabolism, high P-gp efflux, low oral } \\
\text { bioavailability. }\end{array}$ & {$[165,166]$} \\
\hline 32 & Astaxanthin & $\begin{array}{l}\text { High lipophilicity, poor water solubility, poor stability, low } \\
\text { oral bioavailability. }\end{array}$ & {$[167,168]$} \\
\hline 33 & Lycopene & $\begin{array}{l}\text { Extensively isomerized after dosing, chemical instability, } \\
\text { rapidly metabolized into polar metabolites, rapid excretion. }\end{array}$ & [169] \\
\hline 34 & Bixin & Poor water solubility, very poor chemical stability. & [170] \\
\hline 35 & Lutein & $\begin{array}{l}\text { High lipophilicity, poor water solubility, poor physic-chemical } \\
\text { stability, low oral bioavailability. }\end{array}$ & {$[171,172]$} \\
\hline 36 & Fucoxanthin & $\begin{array}{l}\text { Poor aqueous solubility, poor physic-chemical stability, low } \\
\text { oral bioavailability. }\end{array}$ & [173] \\
\hline 37 & $\begin{array}{l}\text { 16-Hydroxycleroda } \\
\text {-3,13-dine-16,15 } \\
\text {-olide }\end{array}$ & Poor water solubility, low oral bioavailability. & [174] \\
\hline 38 & $\gamma$-Oryzanol & $\begin{array}{l}\text { Poor water solubility, rapid metabolism, poor oral } \\
\text { bioavailability. }\end{array}$ & [175] \\
\hline 39 & Escin isomers & $\begin{array}{l}\text { Poor water solubility, Extensive metabolism in the gut, low } \\
\text { bioavailability. }\end{array}$ & {$[176,177]$} \\
\hline 40 & $\begin{array}{l}\text { Docosahexaenoic } \\
\text { acid }\end{array}$ & $\begin{array}{c}\text { Poor water solubility, hydrophobic, low absorption, low } \\
\text { bioavailability, redox instability, age-related differential } \\
\text { responses. }\end{array}$ & {$[178,179]$} \\
\hline
\end{tabular}




\section{Nanocarrier-Based Drug Delivery: A Contemporary Promise}

The prefix 'nano' has been derived from Latin 'nanus', which means dwarf. Nanoscience deals with the objects with dimensions of $10^{-9}-10^{-7} \mathrm{~m}$. In recent years, nanotechnology has gained immense interest in medical science both in diagnosis and in therapy. It has been shown that nanoscaled materials acquire some special physical, chemical and biological properties, which make them attractive for biomedical applications [180]. Curative agents at the nanoscale dimension have been found to break the barrier between therapeutic effects and pharmaceutical incompetence. The development of different types of nanocarriers (Figure 3), such as nanoparticles, liposomes, dendrimers, niosomes, and micelles has become a novel approach in drug delivery over conventional drug delivery systems in terms of effectiveness, stability, bioavailability, target specificity, and release of drugs [181]. Nanocarrier-based drug colloidal nanoparticles with a dimension of less than $500 \mathrm{~nm}$ offer a high surface area to volume ratio [181]. Excellent active target specificity of nanocarrier-based formulation can be achieved through functionalization of their surface with synthetic polymers or conjugating with appropriate ligands (Figure 4). Nanocarriers can deliver a wide range of drugs with versatile physicochemical properties [182-184]. In contrast, some challenges exist in nanocarrier-based drug delivery, which include poor drug loading capacity, missing cellular uptake ability, toxicity, and questionable biodegradability and ligand-tagging ability [185]. However, formulation scientists have mentioned several approaches to mitigate these limitations and to achieve real-world applications of nanocarrier-based drug delivery. A recent report revealed that the global market of drug nanoformulations is rising progressively with an annual growth rate of $22 \%$ [185].

$\mathbf{a}$

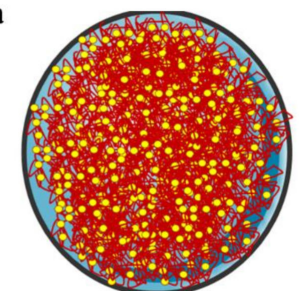

c

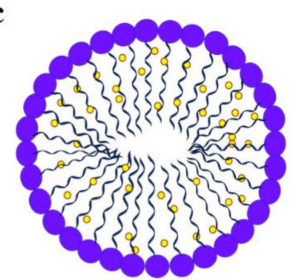

e

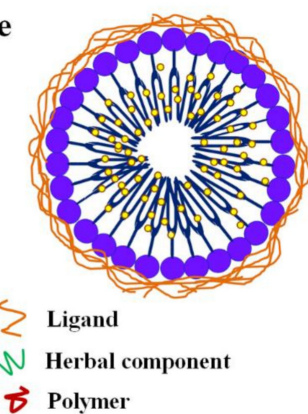

b

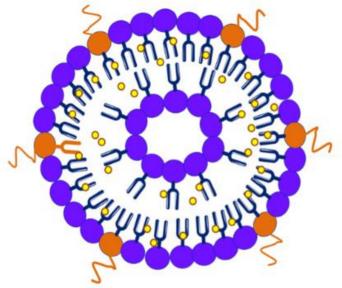

d

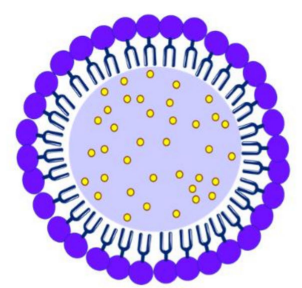

f

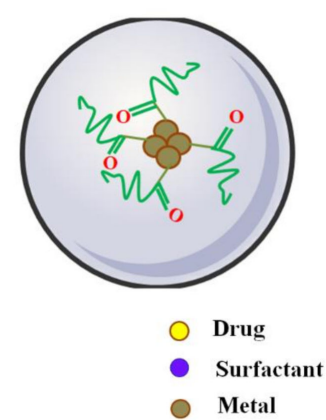

Figure 3. Different types of nanoscale formulations of plant-derived small molecules to achieve better therapeutic efficacy: (a) polymeric nanoparticles; (b) functionalized capped liposomes; (c) non-polymeric micelle; (d) solid lipid nanoparticles; (e) nanoemulsion; (f) herbo-metallic nanoparticles with organic core to improve stability. 


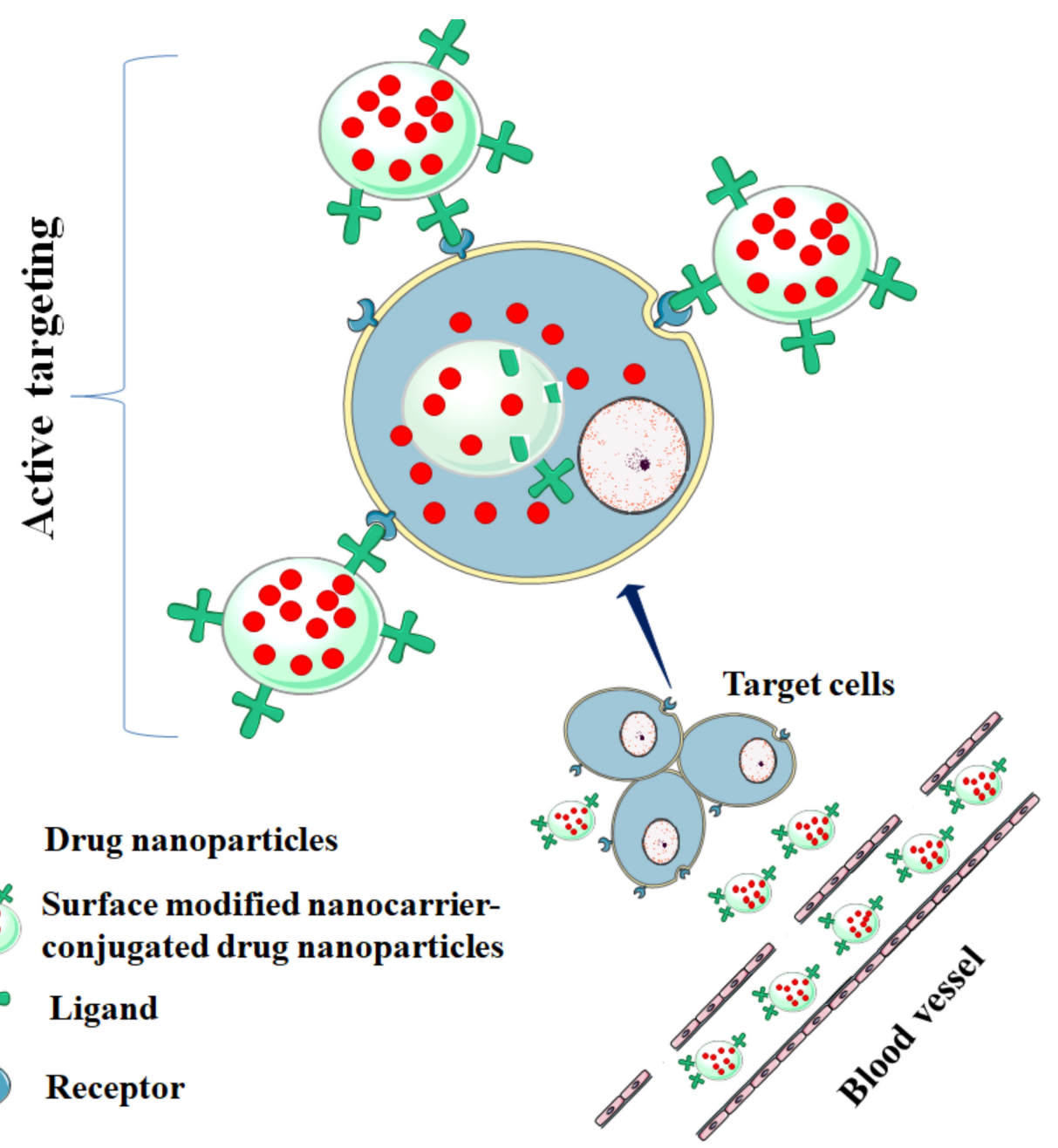

Figure 4. Active targeting by nanocarrier-based formulation by functionalization of their surface with synthetic polymers or conjugating with appropriate ligands. The blue arrow indicates subsequent event.

\section{Nanoformulations in Diabetes Treatment}

Nanotechnology-based approaches offer improved therapeutic management of diabetes mellitus with a minimized risk of acute and chronic complications [1]. A myriad of nanoformulations with varying architectures have been fabricated for the treatment of diabetes mellitus [186]. Nanocarrier-based formulations ensure the efficient delivery of drugs to the target site with the desired release pattern $[1,186]$. In addition, nanoformulations allow the delivery of drugs through various routes [186,187]. Fabrication of nanocarriers with suitable ligands makes them more targeted and can enhance the systemic availability and stability of drugs. Fabrication of nanocarriers can also reduce the dose of drug and frequency of administration. Finally, fabricated nanoformulations can reduce the risk of toxic manifestations $[1,188]$. Thus, suitably designed nanoformulations of hypoglycaemic agents may offer improved therapeutic management of diabetes in the near future. The subsequent section of this review emphasized the advancement and effectiveness of nanobased formulations of antidiabetic agents from plant sources.

\subsection{Curcumin}

The development of curcumin nanoformulations has emerged as one of the most prospective approaches to improve solubility, stability, bioavailability, and therapeutic efficacy of curcumin as an antidiabetic agent. Allam and co-workers formulated a curcumin-loaded self-nanophospholipid 
dispersion using Phosal ${ }^{\circledR} 53$ and miglyol 812 at different surfactant ratio [189]. Phosal ${ }^{\circledR} 53$ MCT is a phosphatidyl-choline from soybean lecithin, which can serve as an excellent solvent for lipophilic compounds [189]. Curcumin-self-nanophospholipid dispersions were reported to enhance oral bioavailability of curcumin over conventional formulations in rats [189]. Curcumin nanoparticles prepared by a modified emulsion-diffusion-evaporation method was found to reduce fasting blood glucose and glycosylated hemoglobin levels significantly via increasing the expression of insulin and insulin receptor (IR) mRNAs in diabetic rats [190]. Curcumin-ZnO (10 mg/kg, for 21 days) nanoparticles were claimed to be more effective than curcumin nanoparticles $(50 \mathrm{mg} / \mathrm{kg}$, for 21 days) in diabetes therapy in terms of reduction of blood glucose, improvement in serum insulin, and activation of GLUT2 and glucokinase genes in pancreas and liver of type 2 diabetic rats [191]. Nanocarrier constituted with poly-( $\gamma$-benzyl l-glutamate), poly-(ethylene glycol), and poly-( $\gamma$-benzyl 1-glutamate) has been shown to improve the bioactivity and water solubility of curcumin [192]. The design of this nanocarrier offered high loading capacity, gradual release, and low cytotoxicity [192]. Curcumin-encapsulated multi-polymeric nanocarrier achieved better pharmacological effects in cross-regulation of $\mathrm{Ca}^{2+} /$ calmodulin, calcium-sensing receptor gene and endogenous cystathionine $\gamma$-lyase/ $\mathrm{H}_{2} \mathrm{~S}$ over conventional curcumin formulations in the management of diabetic cardiomyopathy in rats [192]. Curcumin-encapsulated poly(lactic-co-glycolic acid) (PLGA) nanoparticles were found to be effective in enhancing the relative oral bioavailability (5.6-fold to native curcumin) and improving biological half-life of curcumin via improving water solubility, triggering drug release in the intestinal juice, enhancing permeation, inhibiting P-gp efflux, and increasing residence time in the intestinal cavity [193]. Self-nanoemulsification of curcumin has been revealed to prolong plasma acquaintance and improve oral bioavailability of curcumin [194]. Thus, self-nanoemulsified curcumin formulation exhibited better therapeutic effect than native curcumin against experimentally induced diabetic neuropathy in terms of reversing functional, behavioral, and biochemical deficits in rats [194]. Curcumin-entrapped PLGA-PVA (polyvinyl alcohol) nanoparticles were found to improve oral bioavailability of curcumin and thus, achieved better therapeutic effect over free curcumin in delaying cataract formation in diabetic rats [195]. This nanoformulation of curcumin showed superior ability to interfere with the pathological events in the diabetes-mediated cataract formation, such as oxidative stress, polyol pathway, protein insolubilization, protein glycation, and crystallin distribution [195]. Oral delivery of curcumin-loaded pluronic nanomicelles has been shown to attenuate hyperglycaemia, hyperlipidaemia, oxidative stress, and hypoinsulinemia via suppressing $\beta$ cell damage, promoting $\beta$ cell regeneration, and triggering the activation of PDX-1 and NK6 homeobox-1 (NKx6.1) genes beyond the values of controls [196]. Devadasu and co-workers formulated curcumin-loaded PLGA nanoparticles for oral delivery, which exhibited improved bioavailability of curcumin and better therapeutic efficacy in the management of hyperlipidaemia, and inflammation in diabetic rats [197]. An amphiphilic polymer prepared by the polymerization of methyaluminoxane (MAO), poly-(ethylene glycol) methacrylate (PEGMA), and 2-(dimethylamino)ethyl methacrylate (DMAEMA) was found to be a potential nanocarrier for encapsulating curcumin [198]. The curcumin-loaded nanoparticles were found to attenuate diabetic neuropathy via suppressing interleukin-1 $\beta$ (IL-1 $\beta$ ), connexin 43 , and phosphorylated protein kinase $\mathrm{B}(\mathrm{Akt})$ expressions in dorsal root ganglia and downregulating purinergic 2 (P2) Y12 receptor mRNA expression in satellite glial cells of diabetic rats [198]. Curcumin-loaded polylactic acid (PLA)-polyethylene glycol (PEG) polymeric nanoparticles were found to be effective through the oral route in reciprocating hyperglycaemia, hypoinsulinemia, and diabetes-provoked hepatotoxicity more effectively than free curcumin [199]. Curcumin-PLA-PEG nanoparticles could attenuate hepatotoxicity by mitigating hepatic oxidative stress, inflammation, and fibrosis through suppression of respective signalling events [199]. Curcumin-loaded chitosan nanoparticles were found to improve muscle cell glucose uptake capacity of curcumin in vitro via enhancing its solubility [200]. The curcumin-nanoparticle-loaded topical hydrogel was found to improve aqueous solubility and skin permeability of curcumin [201]. Thus, the nanocurcumin hydrogel improved the wound healing process in diabetic skin of type 1 diabetic rats as compared with normal curcumin hydrogel [201]. In another 
study, self-assembled curcumin nanoparticles were encapsulated within gelatine microspheres to respond to matrix metalloproteinase 9 (MMP-9) which is commonly over-expressed at diabetic wound sides [202]. Thermosensitive hydrogel in the structure of curcumin-assembled gelatine microspheres was found to improve the capacity of drug release in a sustained manner to the diabetic wound and promoted the efficacy of healing via reducing redox stress and reversing MMP-9-provoked inhibition of cell migration in diabetic mice [202]. Katas and co-researchers formulated a pluronic F-127-based gel containing curcumin-PGT (prostaglandin transporter) DsiRNA chitosan nanoparticles to treat diabetic wounds [203]. Curcumin-loaded chitosan nanoparticles encapsulated into collagen-alginate complex have been designed for the treatment of diabetic wounds. This nanohybrid scaffold offered improvement in stability, porosity, sustainability, biocompatibility, and tissue-regenerating ability to achieve a potential therapeutic option in the management of diabetic wounds [204]. Several clinical trials have reported that nanoformulations of curcumin exhibit improved bioavailability and pharmacokinetic attributes and provided a strong rationale for therapeutic applications of nanocurcumin [205]. In a double-blind randomized clinical trial, type 2 diabetic patients $(n=35)$ receiving curcumin nanomicelles ( $80 \mathrm{mg} /$ day) for three months showed a significant reduction in the levels of fasting blood glucose, glycosylated haemoglobin, low-density lipoprotein (LDL)-cholesterol, triglycerides, and body mass index when compared with placebo control patients [206]. In another double-blind randomized placebo-controlled clinical trial, nanocurcumin $(80 \mathrm{mg} /$ day, orally) for three months was reported to decrease the levels of fasting blood glucose, glycosylated hemoglobin, triglycerides, LDL-cholesterol, homeostatic model assessment-insulin resistance (HOMA-IR), inflammation markers in the obese patients $(n=42)$ with nonalcoholic fatty liver disease as compared with placebo control patients [207]. Nonalcoholic fatty liver disease is very closely related to obesity and type 2 diabetes.

\subsection{Resveratrol}

Poor pharmacokinetic and biopharmaceutical properties of resveratrol have been implicated in dose escalation and frequent dosing to achieve desired therapeutic effects [24]. Several strategies, such as chemical modifications, inclusion of bioenhancers, development of resveratrol prodrugs and development of novel pharmaceutical formulations can address the pharmaceutical incompetence of resveratrol [24]. However, nanoencapsulation of resveratrol in lipid nanocarriers, nanoemulsions, micelles, polymeric particles, solid dispersions, and nanocrystals have been demonstrated to be advantageous over other approaches to achieve better stability, improved bioavailability, specific targeting, advanced therapeutic efficacy and improved patient compliance [24,116]. Resveratrol-loaded layer-by-layer nanoformulation consists of 5.5 bilayers of polyallylamine hydrochloride and dextran sulphate and resveratrol nanocores were found to enhance the stability and systemic availability of resveratrol following oral administration [208]. Thus, the formulations represent potential drug delivery tools for resveratrol [208]. Multilayered resveratrol nanoliposome prepared by dry film hydration process and its PEG-amalgamated (PEGylated) modification have been reported to improve glycaemic status, redox status, insulin level in glucose or streptozotocin-treated $\beta$-TC cells [209]. The formulations produced a sustained effect up to $24 \mathrm{~h}$ in vitro as compared to native resveratrol [209]. Resveratrol-loaded nanocochleates exhibited similar results in glucose or streptozotocin-exposed $\beta$-TC cells [210]. Thus, resveratrol-loaded nanoliposome, PEGylated modification of resveratrol-loaded nanoliposome, and resveratrol-loaded nanocochleates could be the effective formulations in the management of type 2 diabetes and associated microvascular complications [209,210]. Resveratrol-loaded casein nanoparticles have been found to be an effective tool for the oral delivery of resveratrol and the formulation exhibited $\mathrm{pH}$ resistance, faster penetration, and sustained drug release properties. This formulation was shown to result in a 10-fold increment of oral bioavailability of resveratrol [115]. Resveratrol nanoemulsion (Life Enhancement, California, USA) has been claimed to be effective in reducing hyperglycaemia and oxidative stress in type 2 diabetic rats [211]. Resveratrol-loaded solid lipid nanoparticles have been reported to enhance the therapeutic effect of resveratrol following oral treatment in diabetic rats [212]. The formulation 
allowed an initial burst followed by a gradual release under normal conditions and improve the oral bioavailability of resveratrol [212]. The formulation has been found to be significantly effective over free resveratrol in reversing insulin resistance through the activation of synaptosomal-associated protein 23 (Snap23), syntaxin-4 (Stx-4), and vesicle-associated membrane protein 2 (Vamp2) mRNAs in muscle and reduction of oxidative stress in sera of type 2 diabetic rats [212]. Resveratrol-loaded PLGA nanoparticles exhibited an excellent and stable delivery with remarkable improvement in encapsulation efficiency, drug loading capacity, solubility, absorption, bioavailability, and sustained release of resveratrol to attenuate nonalcoholic fatty liver disease, which is very closely associated with type 2 diabetes [213]. Galactosylated PLGA has also been found to be a potential nanocarrier for the oral delivery of resveratrol to achieve improved bioavailability and therapeutic efficacy [214]. Oral treatment with resveratrol-assembled gold nanoparticles exhibited excellent inhibitory effects on the activation of vascular endothelial growth factor (VEGF)-1, monocyte chemotactic proteins-1 (MCP-1), intercellular adhesion molecule-1 (ICAM-1), extracellular signal-regulated kinase (ERK) 1/2, NF- $\mathrm{kB}$, $\mathrm{TNF} \alpha$, IL-6, IL-1 $\beta$ genes in the retina of diabetic rats [215]. The nanoformulations could also trigger the activation of retinal pigment epithelium-derived factor (PEDF) mRNA [216]. Thus, resveratrol assembled gold nanoparticles would be a potential therapeutic agent in diabetic retinopathy [215]. To date, there is no such report on the clinical trial of resveratrol nanoformulation on diabetic humans.

\subsection{Naringenin}

Various pharmaceutical strategies, such as formulating with solubility enhancers, P-gp inhibitor, and metabolic inhibitors have been undertaken to improve the pharmacokinetic and biopharmaceutical properties of naringenin in achieving the clinical relevance [118]. However, nanotechnology-based formulation designing has emerged as a prospective strategy over others to eliminate pharmaceutical incompetencies and to achieve better therapeutic efficacy of naringenin. Development of naringenin nanoemulsification using PVP (polyvinylpyrrolidone) K-90 as stabilizer has been found to improve gastrointestinal absorption, dissolution, and oral bioavailability of naringenin over native naringenin [117]. Self-nanoemulsified naringenin delivery system has been found to improve drug release, absorption, and oral bioavailability naringenin as compared to free drug suspension [216]. Naringenin-loaded soluthin-maltodextrin nanocarrier was found to enhance oral bioavailability ( 116 fold) and to reduce toxicity ( 21 fold) of naringenin compared to free naringenin [217]. Naringenin-loaded liposomal nanoformulation has been found to increase solubility and oral bioavailability (13.44 fold) of naringenin, thus improving its clinical applications [218]. Despite several nanoformulations of naringenin have been claimed to improve oral bioavailability and therapeutic efficacy against different diseases; however, their potential role in diabetes management is still limited [219]. Naringenin-loaded chitosan core-shell nanoparticles coated with alginate have been found to be effective for oral delivery naringenin ensuring significant drug entrapment (> $90 \%$ ) and $\mathrm{pH}$-responsive slow and sustained release of naringenin [220]. Naringenin-encapsulated core-shell polymeric nanoparticles were found to exhibit better therapeutic effect than free naringenin in reversing hyperglycaemia, dyslipidaemia, and oxidative stress in diabetic rats [220]. In addition, naringenin-loaded core-shell polymeric nanoparticles have been revealed to be a safe formulation for oral therapy [220].

\subsection{Quercetin}

Nanofabrication of quercetin has offered excellent opportunities in improving oral bioavailability, target specificity, therapeutic efficacy, and compliance. Quercetin-loaded on PLGA nanoparticles was observed to increase the oral bioavailability of quercetin ( $>$ five-fold) than free quercetin [221]. This quercetin nanoformulation offered a prolonged release of quercetin up to six days [221]. Thus, the formulation improves therapeutic compliance by reducing the therapeutic dose and frequency of administration [221]. Quercetin-PLGA nanoparticles at the dose of $150 \mathrm{mg} / \mathrm{kg}$ in every fifth day could significantly reciprocate hyperglycaemia and oxidative stress (kidney, 
and pancreas) in diabetic rats and the effect was found to be superior to that of free quercetin at the dose of $150 \mathrm{mg} / \mathrm{kg} /$ day [221]. Quercetin nanorods offered an efficient delivery of quercetin with improved pharmaceutical attributes in reciprocating hyperglycaemia, changes in glucose-metabolizing enzymes, and oxidative stress (liver, kidney, and pancreas) in diabetic mice [222]. Nanorods have been proven to enhance the efficiency of diabetes management via improving cellular uptake and bio-distribution of quercetin in the target sites [222]. Quercetin-loaded PEG-block-[poly-(ethylenediaminel-glutamate)-graft-poly-( $\varepsilon$-benzyloxy-carbonyl-l-lysine)] nanocarrier remarkably promoted the therapeutic potential of quercetin than free quercetin in the management of diabetes and associated nephropathy via improving the serum content of quercetin in rats [223]. Quercetin-loaded solid lipid nanoparticles exhibited increase in the absorption and the oral bioavailability of quercetin as compared to native quercetin [223]. Oral delivery of quercetin-succinylated chitosan-alginate core-shell-corona structured nanoparticles remarkably improved oral hypoglycaemic effect of quercetin in diabetic rats compared to native oral quercetin [224]. Quercetin-loaded Soluplus micelles have been found to improve the oral bioavailability ( $>16 \%$ ) of quercetin and maintained a prolonged release pattern in the management of diabetes in rats [225]. Oral delivery of quercetin-conjugated superparamagnetic iron oxide nanoparticles has been found to ameliorate diabetes-provoked memory impairment in rats at a much lower dose compared to free quercetin [226]. Several nanoformulations of quercetin have been claimed to improve oral bioavailability and therapeutic efficacy against diabetes; however, clinical reports on the antidiabetic potential of quercetin nanoformulation are yet to be published.

\subsection{Apigenin}

Several nanoformulations have been proposed to increase the therapeutic efficacy of apigenin, which have not only improved the bioavailability but also simultaneously ensured specific targeting. Microwave-synthesized apigenin-pluronic F127 nanoparticles were found to enhance dissolution rate and oral absorption of apigenin and thus, improved the oral bioavailability to $>$ three-fold compared with the marketed capsule [121]. An apigenin-loaded nanomixed micelles system comprising Soluplus and pluronic F127 polymers has been claimed to improve oral bioavailability ( $>$ four-fold), achieve a sustained release, and promote gastrointestinal absorption of apigenin than free apigenin in rats [227]. Apigenin nanomixed micelles significantly improved water solubility and cellular uptake of apigenin [227]. Carbon nanopowder-based solid dispersion of apigenin improved stability and bioavailability of apigenin [228]. Apigenin-loaded nanoliposomes were claimed to inhibit apoptosis of myocardial cells in diabetic cardiomyopathy rats [229]. However, there is no available literature on the antidiabetic efficacy of apigenin nanoparticles till today.

\subsection{Myricitrin}

Several nanoformulations of myricitrin have been revealed to improve the oral bioavailability and the therapeutic efficacy of myricitrin. The solid lipid nanocarrier system has been found to be an excellent platform for the oral delivery of myricitrin to treat type 2 diabetes and diabetes-provoked oxidative stress in mice [79]. Myricetin-loaded solid lipid nanoparticles achieved a sustained release of myricetin from the formulation and exhibited excellent therapeutic effect in reciprocating hyperglycaemia, insulin resistance, impairment of glucose uptake by myotubes, and apoptosis of pancreas in vitro and in vivo [79]. The myricetin nanoparticles were found to be more effective than that of metformin at much lower dose [79]. The same group has also reported that myricetin-loaded solid lipid nanoparticles can attenuate hyperglycaemia-triggered oxidative stress, inflammation, fibrosis, and apoptosis in high glucose-exposed proximal tubules of mouse in vitro. Thus, the formulation would be equally effective against diabetic nephropathy or other diabetic complications. 


\subsection{Baicalin}

Development of nanoscale formulations of baicalin has emerged as a potential approach to enhance the bioavailability of baicalin in achieving better clinical efficacy $[125,230]$. Baicalin-entrapped nanoliposome has been reported to be an excellent formulation for the oral delivery exhibiting improved stability, biodistribution and oral bioavailability of baicalin [231]. Similarly, baicalin-loaded nanomicelle containing pluronic P123 copolymer and sodium taurocholate showed improvement of absorption, circulation time and oral bioavailability ( $>1.5$-fold) of baicalin compared to baicalin suspension in rats and thus can serve as a promising approach of oral delivery of baicalin [232]. Different nanoformulations of baicalin were found to improve oral bioavailability of baicalin; however, only one literature is available regarding the therapeutic benefit of baicalin in diabetes management. Baicalin-loaded nanostructured lipid carriers have been presented as stable for oral delivery offering a sustained release of baicalin and have been proven to increase the antidiabetic efficacy of baicalin [232]. At the same dose, the nanostructured baicalin-lipid complex was found to be more effective to control hyperglycaemia and hyperlipidaemia in diabetic rats as compared with free baicalin and metformin [232].

\subsection{Luteolin}

Fabrication of nanoformulation of luteolin has been found to improve the oral bioavailability of luteolin [233,234]. Luteolin-assembled poly(E-caprolactone)-PLGA-nature oil has been found to be a suitable nanocarrier for increasing its dispersion in the aqueous medium and thereby improve the oral bioavailability [233]. Luteolin-loaded solid lipid nanoparticles were reported to enhance solubility, biological half-life and bioavailability (4.8-fold) of luteolin and thus improved its therapeutic efficacy [235]. However, the effect of luteolin nanoparticles on diabetic animals is yet to be explored.

\subsection{Mangiferin}

The development of nanoparticle-based drug delivery systems has been proposed to be an excellent tool over other mangiferin formulations in improving biopharmaceutical attributes and therapeutic efficacy of mangiferin [5,127]. Mangiferin-loaded self-assembled phospholipidic nanomicelles were reported to improve the biopharmaceutical attributes of mangiferin [127]. Vitamin E-TPGS (D- $\alpha$-tocopheryl polyethylene glycol 1000 succinate) co-loaded self-assembled phosholipidic nanomixed micelles systems could enhance the intestinal permeability and oral bioavailability of mangiferin [5]. Mangiferin-encapsulated $\beta$-lactoglobulin nanoparticles have been formulated to deliver mangiferin through oral route to achieve target specificity, pepsin resistance, protection against the probiotic strains in the intestine, and sustained release properties [236]. However, the effect of mangiferin nanoparticles on diabetes is yet to be explored.

\subsection{Gymnemic Acid}

Nanoscale formulations of gymnemic acid have been found to improve its pharmacokinetic, pharmacodynamic and therapeutic potentials. To enhance the oral bioavailability, Ravichandran developed lyophilized nanocrystals of gymnemic acid, which enhanced the gastrointestinal absorption and oral bioavailability of gymnemic acid [237]. The redispersion of gymnemic acid nanocrystals in water was also claimed to be equally effective and offered improved oral bioavailability of gymnemic acid [238]. The developed gymnemic acid nanocrystals-loaded tablets were found to exhibit significant antihyperglycaemic activity and even produced considerable hypoglycaemia in diabetic and glucose-loaded rats [129]. Gymnemic acid nanocrystals-loaded tablets were able to reduce blood glucose levels in diabetic rats after $3 \mathrm{~h}$ of treatment [129]. Biocompatible gymnemic acid-reduced gold nanoparticles have been found to enhance the glucose uptake capacity of 3T3-L1 adipocytes through the insulin-dependent/independent pathway than free drug and the glucose uptake efficacy was found to be similar to that of pioglitazone [239]. In addition, gymnemic acid-reduced gold 
nanoparticles exhibited significant stability and low toxicity at the therapeutic doses in vitro [239]. Thus, gymnemic-acid-reduced gold nanoparticles would be a potential oral formulation for the treatment of diabetes. Gymnemic-acid-chitosan nanoparticles prepared by emulsion-droplet coalescence method allowed a controlled release of gymnemic acid continuously for $24 \mathrm{~h}$ and claimed to be effective in the management of diabetes mellitus [240]. However, more research is required to formulate a potential antidiabetic nanoformulation of gymnemic acid to achieve better antidiabetic efficacy.

\subsection{Emodin}

Several pharmaceutical attempts were taken to improve the biopharmaceutical potential of emodine; however, emodine nanoformulations have emerged as the most promising approach to improve compliance and bioavailability of emodin. Emodin-loaded nanoemulsion has been found to improve oral bioavailability of emodin effectively via prolonging its residence time, improving tissue distribution, and reducing clearance [241]. Several emodin nanoformulations enhanced the biopharmaceutical competence of emodin for oral delivery. However, adequate literation is not available to reveal the potential application of emodin nanoformulation in diabetes management. Emodin-loaded poly-PEGMA-DMAEMA-MAM nanoparticles have been found to attenuate diabetes-provoked neuropathic pain via suppressing purin 2 X3 (P2X3) receptor expression, TNF- $\alpha$ level, and ERK1/2 activation in dorsal root ganglia of type 2 diabetic rats [242].

\subsection{Rosmarinic Acid}

Several nanoformulations can successfully address the major pharmaceutical obstacles of rosmarinic acid. Madureira and co-workers formulated physico-chemically stable and biocompatible solid lipid nanoparticles of rosmarinic acid using carnauba waxes [132]. The same group also formulated rosmarinic acid-assembled solid lipid nanoparticles using carnauba wax [132]. Both the nanoformulations were found to be safe and biocompatible for the oral delivery of rosmarinic acid. In addition, the rosmarinic acid-solid lipid nanoparticles did not exhibit any sign of genotoxicity and cytotoxicity in vitro [132]. Polyacrylamide-cardiolipin-PLGA grafted with surface 83-14 monoclonal antibody has been designed as a potential nanocarriers to deliver rosmarinic acid to the brain for protecting $\beta$-amyloid-insulted neurons [243]. Similarly, polyacrylamide-chitosan-PLGA grafted with cross-reacting material 197 and apolipoprotein E nanocarriers was found to be effective in delivering rosmarinic acid to the brain for alleviating neurotoxicity-mediated through $\beta$-amyloid [244]. Both these nanocarriers allowed rosmarinic acid to cross blood-brain barrier, improve cellular uptake, and attenuate $\beta$-amyloidosis. An earlier report revealed that diabetes neuropathy is often associated with an increase in $\beta$-amyloid in neurones [245]. Thus, the therapeutic effect of both these formulations may be evaluated against diabetic neuropathy. Rosmarinic acid-chitosan nanoparticles and rosmarinic acid-loaded solid lipid (Witepsol H15) nanoparticles have been found to exhibit excellent thermal stability, in vitro release, and efficient antioxidant effect without incidence of aggregation [246,247]. Instillation of rosmarinic acid-chitosan-sodium tripolyphosphate nanoparticles have been found to enhance the retention of formulation on ocular mucosa and claimed to be an effective drug delivery system to attenuate oxidative damage in the eyes without exhibiting any toxicity on retinal and corneal cells [248]. Rosmarinic acid-assembled chitosan nanoparticles-loaded hydrogel is a biocompatible topical dosage form, which exhibited a higher degree of wound healing than the rosmarinic acid -gel formulation [248]. In addition, rosmarinic acid-chitosan nanoparticles-loaded hydrogel allows sustained release of drug release for a period of $14 \mathrm{~h}$ [248]. Considering antioxidant, compatible and sustained release properties, rosmarinic acid-chitosan nanoparticles may be evaluated against diabetic retinopathy and wound. To date, no report is available to expose the effectiveness of rosmarinic acid nanoformulation on diabetes. However, considering the improvement of therapeutic effectiveness, biopharmaceutical attributes, and pharmacokinetic profiles of different rosmarinic acid nanoformulations for treating various pathological events, they may be subjected to preclinical assays against diabetes and diabetic complications. 


\subsection{Berberine}

Several pharmaceutical tactics, such as formulation with permeability enhancers, P-gp inhibitors, muco-adhesive agents have been attempted to eradicate pharmaceutical incompetence of berberine; however, application of nanotechnology has been found to be the most promising tool to improve oral bioavailability and therapeutic efficacy of berberine [249]. Dendrimers-encapsulated berberine, berberine-assembled polymer-lipid hybrid nanoparticles, and chitosan-coated nanoliposomes of berberine have been reported to facilitate oral delivery of berberine with improved pharmaceutical attributes [250-252]. Berberine-loaded anhydrous reverse micelle formulated by lyophilisation of water in oil (W/O) emulsion employing soy phosphatidylcholine as emulsifier has been found to improve the oral bioavailability and hypoglycaemic efficacy of berberine [253]. Berberine-assembled solid lipid nanoparticles have been found to enhance oral bioavailability, stability and antidiabetic potential of berberine compared to the free drug [253]. Oral administration of nanoparticles remarkably reduced hyperglycaemia, body-weight gain, and insulin resistance in type 2 diabetic mice compared to native berberine [254]. In addition, berberine-assembled solid lipid nanoparticles have been found to achieve maximum drug concentration in the liver ( 20-fold higher than in plasma) and significantly attenuated diabetes-provoked hepatosteatosis in type 2 diabetic mice [255]. Ortho-hexadecyl-dextran-encapsulated berberine chloride nanoparticles exhibited an improved bioavailability and controlled release of berberine [256]. The nanoberberine was found to alleviate hyperglycaemic stress in murine hepatocytes via inhibiting glucose-provoked ROS production, oxidative stress, and apoptosis [256]. The nanoberberine formulation was found to exhibit a similar effect as free berberine but at much $(\sim$ 20-fold lower) lower concentration [256]. The study implicated the therapeutic usefulness of berberine nanoformulation against diabetic complications at a much lower dose. Berberine-TPGS nanosuspension has been found to achieve better hypoglycaemic potential than native berberine in diabetic mice [257]. Berberine-assembled nanostructured lipid carriers coated with selenium have been found to trigger therapeutic efficacy of berberine in diabetes management than berberine-assembled nanostructured lipid carriers and berberine solution [258]. Selenium modification of nanostructured lipid formulation enhanced intestinal absorption, oral bioavailability, and controlled release of berberine [258]. In addition, selenium-modified nanostructures enhanced the transport of berberine into the enterocytes to achieve better glucose uptake in diabetic rats [258]. Oral delivery of berberine nanoformulations has already been proven to be preclinically effective against diabetes and subsequent complications; however, the extensive clinical investigation is required to deliver effective nanoformulations of berberine for therapeutic purpose.

\subsection{Stevia Glycosides}

Stevia glycosides possess impressive antidiabetic effect in preclinical assays; however, they could not impress in clinical studies [140]. It has been revealed that the doses were not sufficient to achieve anticipated pharmacological effect [140], which may be correlated to that of poor bioavailability issue of Stevia glycosides. Over the year, several nanoformulations of Stevia glycosides have been formulated, which were found to enhance the oral bioavailability, target specificity, and therapeutic efficacy of the Stevia glycosides [111]. Stevioside-assembled PEG-PLA nanoparticles achieved a burst release of stevioside at $2 \mathrm{~h}$ followed by a controlled release up to 21 days and have been claimed to be safe and effective for the management of diabetes [111]. Pluronic-F-68 copolymer-based stevioside- PLA nanoparticles have been claimed to be an effective antidiabetic nanoformulation for oral delivery [138]. The formulation was found to increase stability, intestinal absorption, biocompatibility, and oral bioavailability of stevioside with an additional success of achieving sustained release pattern [138]. Rebaudioside A-PLA nanoparticles have been claimed to be superior antidiabetic nanoformulation than stevioside-PLA nanoparticles due to their capacity of high drug-loading and sustained release of rebaudioside A [259]. In addition, rebaudioside A has been reported to possess nanocarrier-alike characteristics by self-assembling into micelles in aqueous solutions. Thus, encapsulation of hydrophobic hypoglycaemic agents in rebaudioside A nanomicelles would 
improve the bioavailability of hydrophobic drugs and can intensify the antidiabetic potential through synergy [260].

\subsection{Asiatic Acid}

Application of nanotechnology has been found to be an effective tool to alleviate pharmaceutical limitations, improve compliance, and achieve better therapeutic efficacy of asiatic acid [92]. Asiatic acid tromethamine salt-loaded solid lipid nanoparticles have been found to improve the oral bioavailability (2.5-fold) of asiatic acid than free asiatic acid in rats [141]. PEGylated asiatic acid-loaded nanostructured lipid carriers exhibited enhanced penetration and transport capacities of asiatic acid in the small intestine of rats [261]. The PEG-modified nanoformulation was found to improve oral bioavailability of asiatic acid evidenced from the increase ( two-fold) in elimination half-life [261]. However, the effect of asiatic acid nanoparticles on diabetes is yet to be explored.

\subsection{Glycyrrhizin}

Various non-vascular administration routes have been proposed to improve the bioavailability of glycyrrhizin; however, the development of nanoscale formulation most suitably addressed the biopharmaceutical incompetence of glycyrrhizin. Incorporation of glycyrrhizin in insulin-loaded poly(ethylcyanoacrylate) nanospheres has been reported to enhance oral absorption of insulin by inhibiting proteolytic enzymes in the digestive tract [262]. The presence of glycyrrhizin may simultaneously synergize the antidiabetic effect of insulin. Glycyrrhizin-assembled sodium deoxycholate-phospholipid-mixed nanomicelles have been proven to be a good nanoformulation for oral delivery of glycyrrhizin with improved pharmacokinetic attributes [142]. Glycyrrhizin-assembled chitosan-gum-arabic nanoparticles have been reported to achieve improved bioavailability and sustained release property [263]. The polymeric nanoformulation could entrap $\sim 25 \%$ of pure glycyrrhizin [263]. Glycyrrhizin nanoparticles were found to be more effective at a much lower dose in the management of hyperglycaemia and dyslipidaemia in type 2 diabetic rats [263]. However, glycyrrhizin nanoparticles in combination with thymoquinone nanoparticles have been revealed to exhibit better therapeutic efficacy in the management of hyperglycaemia and dyslipidaemia in type 2 diabetic rats than glycyrrhizin nanoparticles [264].

\subsection{7. $\alpha$-Eleostearic Acid}

Development of a redox stabilized nanoformulation of $\alpha$-eleostearic acid or bitter gourd oil can improve its stability and therapeutic efficacy of $\alpha$-eleostearic acid [144]. $\alpha$-Eleostearic acid-enriched nanoemulsion of bitter melon seed oil has been found to enhance absorption, biocompatibility, cellular uptake, bioavailability, and antioxidant effect more efficiently than conventional emulsion of $\alpha$-eleostearic acid $[265,266]$. In addition, the nanoemulasion exhibited excellent improvement in stability up to 12 weeks as evidenced from the restoration of particle size distribution, hydrodynamic mean diameter, and zeta potential $[265,266]$. Nanoemulsion of $\alpha$-eleostearic acid-enriched bitter melon seed oil has been found to reduce blood glucose level and hyperglycaemia-triggered oxidative stress more effectively than the conventional emulsion in type 1 diabetic rats [265]. In another report, nanoemulsion of $\alpha$-eleostearic acid-enriched bitter melon seed oil showed better cellular penetration to inhibit oxidative stress and inflammation in ex vivo and in vivo models [144]. Thus, nanoemulsion of $\alpha$-eleostearic acid-enriched bitter melon seed oil would be an improved therapeutic formulation to tackle diabetes and associated toxicosis.

\subsection{Scutellarin}

Scutellarin-loaded hydroxypropyl- $\beta$-cyclodextrin-chitosan nanoparticles have been found to enhance drug loading efficiency, solubility, bioavailability, and tissue uptake of scutellarin and thus, be proven to be a potential drug delivery system to achieve a therapeutic effect at the target site [146]. Scutellarin-loaded bovine serum albumin nanoparticles have been found to enhance bioavailability 
and to achieve sustained release profile of scutellarin following parenteral administration [267]. Scutellarin-loaded amphiphilic chitosan derivatives nanoparticles were found to enhance oral bioavailability (roughly two- to three-fold), elimination half-life, and cellular uptake of scutellarin than free scutellarin [268]. In addition, the nanoformulation could attenuate diabetic retinopathy via suppressing VEGF, VEGF receptor 2 (VEGFR2), and von Willebrand factor (vWF) expressions without affecting hyperglycaemia [268]. However, more research is required to optimize a suitable nanoformulation for the oral delivery of scutellarin.

\subsection{Silybum Flavonolignans}

Considering the poor bioavailability of Silybum flavonolignans, they require an escalation in the dose and dosing frequency to achieve desirable therapeutic effects [148]. On the other hand, higher doses of silymarin have been contraindicated in diabetes treatment as high doses of silymarin have been proposed to induce insulin resistance [148]. Further, Silybum flavonolignans can impart antidiabetic effects through the liver- and pancreas-centric mechanisms $[148,269]$. Thus, to attain desire therapeutic efficacy, special attention is required not only to improve the biopharmaceutical and pharmacokinetic aspects but also to ensure target specificity. In these regards, nanoformulations can serve better to reverse the biopharmaceutical and pharmacokinetic limitations of Silybum flavonolignans to achieve better compliance and therapeutic efficacy at much lower dose [270]. Silymarin-loaded Soluplus-TPGS nanomicelles have been found to be suitable for oral delivery as the silymarin nanomicelles exhibited improved water solubility, biological stability, P-gp inhibition, gastrointestinal absorption, and cellular uptake of silymarin [271]. Silymarin-PLGA nanoparticles synchronized as microencapsulation, silymarin-loaded solid lipid nanoparticles, and silymarin-loaded nanostructured lipid carriers have also exhibited better pharmacokinetic attributes than silymarin [272,273]. Silymarin-loaded PLGA-pluronic nanomicelles have been reported to be an efficacious oral formulation to treat diabetes and associated complications than free silymarin [148]. The therapeutic effect of silymarin nanomicelles was found to be associated with the activation of insulin, PDX1 and Nkx6.1 genes, inhibition of $\beta$ cell apoptosis, stimulation of $\beta$ cell regeneration, suppression of oxidative stress, and reciprocation of dyslipidaemia [148]. The therapeutic superiority of silymarin nanomicelles has been correlated to that of improved in vivo bioavailability, and the sustained release profile of silymarin [148]. Chitosan-modified silybin-loaded solid lipid nanoparticles were found to possess good stability, pronounced mucoadhesive property, sustained release, better absorption, and enhanced cellular uptake of silybin following oral absorption [274]. Carbon nanotube-based drug delivery system and lipid-silybin conjugate nanoparticles have also been found to offer better pharmacokinetic attributes of silybin $[275,276]$. Pluronic F-68-PLGA-based chitosan-assembled silybin nanoparticles have achieved an improved therapeutic outcome in the management of diabetes than native silybin via enhancing bioavailability, improving tissue targeting, and attaining a sustained release profile of silybin [269]. This engineered nanoformulation significantly reciprocated hyperglycaemia, dyslipidaemia, formation of advanced glycation end products (AGEs), and oxidative stress with superior effect as compared with free silybin [269]. However, extensive research is required to formulate clinically effective nanoparticles of Silybum flavonolignans for the management of diabetes mellitus.

\subsection{Gallic Acid}

Various nanostructured systems have been proven to be prospective delivery strategies to improve the bioavailability and therapeutic efficacy of gallic acid [277,278]. Gallic-acid-encapsulated chitosan nanoparticles showed improvement in $\alpha$-glucosidase inhibitory effect and would be a suitable antidiabetic nanoformulation [279]. Hydroxyapatite nanoparticles carrying insulin and gallic acid have been found to be an effective oral formulation to mitigate hyperglycaemia [280]. The insulin-gallic-acid nanoparticles were found to improve hepatic glucose utilization via triggering PI3K/Akt/GLUT4 activation in vitro [280]. The developed formulation has been claimed to be a stable, non-toxic, 
and efficacious agent for oral delivery of insulin-gallic acid combination for the management of diabetes [280].

\subsection{Catechins}

Earlier reports revealed the nanoscale formulations of catechins can improve stability, gastrointestinal absorption, bioaccumulation, oral bioavailability, and therapeutic efficacy of catechins [150,281-285]. Catechin-grafted inulin and catechin-grafted chitosan nanoparticles were reported to exhibit improved antidiabetic potential in terms of $\alpha$-glucosidase and $\alpha$-amylase inhibitory effects than free catechins and acarbose [286,287]. In addition, catechin-grafted chitosan nanoparticles exhibited better antioxidant potential than the native catechins [287]. Solid lipid nanoparticles and nanostructured lipid carriers have been developed to enhance solubility, stability, sustained release capacity, and cyto-compatibility of epigallocatechin-3-gallate [288]. Epigallocatechin-3-gallate-loaded chitosan-peptides nanoparticles improve cellular uptake and antioxidant potential than the native of epigallocatechin-3-gallate than free drug [289]. Epigallocatechin gallate-loaded cationic lipid nanoparticles have been reported to exhibit promising effects to mitigate ocular inflammation and oxidative stress, which revealed the probable effectiveness of epigallocatechin-3-gallate in diabetic complications [290]. In addition, self-assembled gelatin-epigallocatechin gallate nanoparticles were found to inhibit ocular angiogenesis remarkably via targeting integrin $\alpha v \beta 3$ [291]. The aforementioned reports predicted that the efficacious roles of catechins nanoformulations against diabetes and associated complications. However, extensive research is required to develop a novel catechin nanoformulation to achieve better therapeutic management in diabetes.

\subsection{Pelargonidin}

Development of pelargonidin nanostructured formulations has been anticipated to address the biopharmaceutical and pharmacokinetic incompetence of pelargonidin. Roy and co-workers formulated pelargonidin-assembled PLGA nanoparticles to improve the stability and therapeutic efficacy of pelargonidin [292]. Intravenous injection of pelargonidin-PLGA nanoparticles at an interval of three days was found to be effective in alleviating hyperglycaemia, dyslipidaemia, and oxidative stress in diabetic rats [292]. Pelargonidin-PLGA nanoparticles exhibited a better therapeutic effect compared to native pelargonidin [292]. Pelargonidin-PLGA nanoparticles have also been found to attenuate hyperglycaemia-triggered apoptosis, oxidative stress, DNA damage, and impairment in glucose utilization in L6 skeletal muscle cells more efficiently and at a much low dose ( 10-fold less) than native pelargonidin [293,294]. In addition, pelargonidin-PLGA nanoparticles exhibited more stability and sustained release profile of pelargonidin [293,294]. Thus, pelargonidin-PLGA would have the possibility in advanced management of diabetes and associated complications.

\subsection{Thymoquinone}

Several thymoquinone nanoformulations have been recommended, which can eliminate its poor pharmaceutical qualities to achieve better therapeutic efficacy. Thymoquinone-loaded pluronic F127 nanoparticles, PLGA-PEG-thymoquinone nanoparticles and thymoquinone-assembled mesoporous silica core-shell nanoformulation were found to exhibit better biopharmaceutical attributes and suitable for sustainable delivery of thymoquinone [295-297]. Thymoquinone-assembled PEGylated chitosan nanocapsules have been found to be a non-toxic formulation toward normal cells with improved stability and bioavailability of thymoquinone [298]. Thymoquinone-loaded gum rosin nanocapsules have been found to reverse hyperglycaemia, dyslipidaemia, and glycosylation of haemoglobin more efficiently at a much lower dose than metformin, metformin nanoformulation, and free thymoquinone [153]. In addition, thymoquinone nanoformulation achieved a sustained release profile of thymoquinone to improve the therapeutic efficacy [153]. However, the combination of glycyrrhizin and thymoquinone nanoparticles has been found to exhibit better therapeutic efficacy in the management of hyperglycaemia and dyslipidaemia in type 2 diabetic rats than 
thymoquinone nanoparticles [264]. Thymoquinone-loaded nanosized liposomes more efficiently alleviated hyperglycaemia, hepatoxicity, and nephrotoxicity in the diabetic mice than native thromboquinone [299]. The formulation restored the structural integrity of pancreatic $\beta$ cells [300]. In addition, thymoquinone liposomes were found to alleviate systemic candidiasis in diabetic mice [299]. Thymoquinone-encapsulated PLGA nanoparticles exhibited a sustained release of thymoquinone over a period of seven days and preserved the antioxidant profile of thymoquinone [300]. Thus, thymoquinone-PLGA nanoparticles would be efficient to deliver thymoquinone to mitigate diabetic complications.

\subsection{Ferulic Acid}

The pharmaceutical strategies in developing ferulic acid nanoformulation have been found to mitigate physicochemical, biopharmaceutical, and pharmacokinetic incompetence of ferulic acid. Ferulic-acid-assembled chitosan-coated PLGA nanoparticles have been found to improve intestinal permeability, gastrointestinal stability, biological half-life, and oral bioavailability of ferulic acid [301]. The mucoadhesive property of ferulic-acid-chitosan-PLGA nanoparticles allowed their greater association with the intestinal epithelium [301]. In addition, ferulic-acid-chitosan-PLGA nanoparticles achieved a sustained release pattern of ferulic acid following oral administration [301]. Ferulic-acid-assembled zein-casein-lysine nanoparticles were claimed to be an efficient oral formulation of ferulic acid offering better intestinal permeability, low toxicity, and sustained release profile [302]. Ethyl-oleate-containing nanostructured lipid carriers have been reported to improve the oral bioavailability of ferulic acid compared with ferulic acid-conjugated solid lipid nanoparticles [303]. Ferulic-acid-assembled chitosan-tri-poly phosphate nanoparticles achieved an improvement in the pharmacokinetic profile of ferulic acid [155]. Ferulic acid-loaded chitosan nanoparticles have been found to be biocompatible, non-toxic, and target specific oral formulation [155]. Ferulic acid-chitosan nanoparticles achieved a sustained release profile and a $\sim$ four-fold escalation of oral bioavailability of ferulic acid than free ferulic acid [155]. In addition, ferulic acid-chitosan nanoparticles showed excellent therapeutic effect in the reduction of blood glucose levels and enhancement of plasma insulin levels in diabetic rats compared to native ferulic acid [155]. Bairagi and co-workers claimed that both ferulic acid-PLGA nanoparticles and ferulic acid-PLGA nanoparticles-loaded carbopol 980 hydrogel exhibited a sustained release of ferulic acid from the respective formulations [304]. Oral administration of ferulic acid-PLGA nanosuspension was found to reciprocate hyperglycaemia more efficiently than free ferulic acid in wound-bearing diabetic rats [304]. In addition, ferulic-acid-PLGA nanosuspension treatment was also found to heal the diabetic wound [304]. Topical ferulic-acid-PLGA nanogel could significantly heal the diabetic wound without improving glycaemic status [304]. However, simultaneous treatment with oral ferulic-acid-PLGA nanosuspension and topical ferulic acid-PLGA nanogel was found to attenuate diabetic wound more effectively than that of any single treatment with either nanoformulation or free ferulic acid [304]. Thus, co-treatment of ferulic-acid-PLGA nanosuspension and ferulic acid-PLGA nanogel has been found to be an emerging approach to mitigate hyperglycaemia and diabetic wound.

\subsection{Other Plant-Derived Antidiabetic Nanoformulations}

Betulin nanoparticles prepared by antisolvent precipitation method were found to enhance oral bioavailability ( 2.2-fold) and hypoglycaemic effect of betulin more efficiently in diabetic mice than native betulin [156]. Self-nanoemulsifying drug delivery of trans-cinnamic acid has been found to alleviate hyperglycaemia, hyperlipidaemia, and diabetes-provoked toxicity more efficiently in diabetic rats via improving oral absorption and bioavailability of trans-cinnamic acid than free drug [305]. Trigonelline nanoparticles were claimed to be an excellent nanoscale device to attenuate hyperglycaemia and diabetes-provoked oxidative stress in the liver and pancreas [306]. Crocetin, a carotenoid in saffron, have been found to alleviate hyperglycaemia and hyperglycaemia-triggered oxidative tissue injury [307]. Crocetin-loaded PLGA nanoparticles have been found to alleviate hyperglycaemia, haemoglobin 
glycation, and diabetic nephropathy more efficiently than free crocetin via improving oral bioavailability, stability, and tissue uptake of crocetin [161]. Crocetin-PLGA nanoparticle treatment caused a dramatic improvement in redox parameters, fibrotic markers, and inflammatory factors in the renal tissue of diabetic rats compared to native crocetin [161]. Rhein, a bioactive anthraquinone in rhubarb species, has been reported to reduce hyperglycaemia, improve glucose tolerance, protect pancreatic $\beta$ cells, and inhibit diabetic complications [308,309]. Rhein-loaded liponanoparticles comprising polycaprolactone-polyethyleneimine-based cores have been found to achieve an excellent capacity of targeting and accumulation of rhein in kidneys with minimal urinary excretion to achieve better therapeutic efficacy in the management of diabetic nephropathy in mice [310]. Rhein liponanoparticles exhibited good stability in the biological environment and a sustained release profile up to $48 \mathrm{~h}$ without producing any toxic effect to the renal cells [310]. 14-Deoxy 11, 12-didehydro andrographolide-loaded polycaprolactone (PCL) nanoparticles exhibited more stability, superior cellular uptake, and prolonged release profile to attain a dramatic improvement in glucose uptake by skeletal muscle cells than free drug [311]. An in vitro drug release study of this nanoformulation demonstrated an initial burst release at $24 \mathrm{~h}$ followed by a sustained release for up to 11 days of 14-deoxy 11, 12-didehydro andrographolide [311]. Vicenin 2, naturally occurring flavonoid glycoside, is known for its potential antidiabetic effect via promoting AMPK/GLUT4-mediated glucose uptake and inhibiting $\alpha$-glucosidase, protein tyrosine phosphatase 1B (PTP1B), AGEs formation, aldose reductase, inflammation, and oxidative stress [312,313]. Vicenin-gold nanoparticles have been reported to improve glucose uptake by 3T3-L1 adipocytes than free drug via improving the stability of vicenin 2 [314]. Fisetin, a dietary flavonol, is known to improve glucose homeostasis and mitigates diabetic complications [43]. Several nanoformulations, such as fisetin-PLGA-hyroxypropyl $\beta$-cyclodextrin nanoparticles, fisetin-assembled solid lipid nanoparticles, and fisetin-loaded nanoemulsion, were reported to improve oral bioavailability and gastrointestinal stability of fisetin $[165,315,316]$. Fisetin-PCL-PLGA-PEG-COOH nanoparticles have been claimed to be an attractive formulation with an improved pharmacokinetic profile for efficient management of hyperglycaemia and oxidative stress [317]. Astaxanthin, a naturally occurring keto-carotenoid, exhibits strong antioxidant and antidiabetic effects [318]. Astaxanthin-assembled nanostructured lipid carriers demonstrated the capability of improving the stability and enhancing the antioxidant activity of astaxanthin [168]. Astaxanthin-loaded chitosan oligosaccharides-PLGA core-shell nanoparticles have been found to improve the water solubility, stability, bioavailability, cytocompatibility, and sustained release profile of astaxanthin as compared to native astaxanthin [319]. Chitosan-oligosaccharides (chitooligosaccharides) can consequently exhibit a hypoglycaemic effect [320]. Astaxanthin-chitooligosaccharides-PLGA nanoparticles would be an efficacious antidiabetic formulation to mitigate hyperglycaemia and associated complications. Transdermal delivery of astaxanthin- $\alpha$-tocopherol-k-carrageenan nanoemulsion was found to reduce blood glucose levels, improve glucose tolerance, and accelerate wound healing in diabetic mice [321]. Lycopene is a red-colored carotenoid abundant in tomatoes and other red fruits. It possesses antidiabetic and antioxidant properties. However, stability is the most critical issue with lycopene. In order to improve its stability, Sharma and co-workers formulated lycopene-encapsulated niosomes [322]. Lycopene niosomes were found to enhance the stability and prolong the release of lycopene up

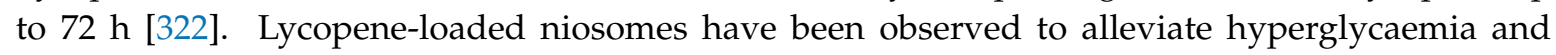
dyslipidaemia more efficiently than the native lycopene in diabetic rats [322]. Bixin, a red coloured apocarotenoid, possesses hypoglycaemic activity [10]. Like lycopene, poor stability is a major limitation of bixin. Bixin-assembled solid lipid nanoparticles were reported to improve its clinical applications by enhancing the stability, localization at targeted tissues, sustained drug release by passive diffusion, and cellular uptake of bixin [323]. Bixin-loaded PCL nanofibers were found to be a biocompatible formulation and exhibited an initial burst release $(30 \%-40 \%$, in the first $10 \mathrm{~h})$ followed by a sustained release $(100 \%$ in day 14$)$ of bixin. Bixin-PCL nanofibers exhibited the excellent ability of tissue regeneration and wound repair to promote the healing of diabetic wounds in mice [324]. Lutein, a xanthophyll carotenoid, has been reported to be useful in preventing hyperglycaemia-induced oxidative 
stress, inflammation, and cataract development without affecting glycaemic status [325,326]. Lutein nanoformulations indeed corrected the pharmaceutical incompetence of lutein [327,328]. Lutein-PVA nanoparticles alleviated hyperglycaemia, hyperlipidaemia, and hepato-renal oxidative stress in diabetic rats more efficiently at much lower doses than the native lutein [329]. In addition, free lutein failed to impress with its hypoglycaemic effect [329]. Fucoxanthin, a marine xanthophyll, exhibits antidiabetic effect through promoting insulin responsiveness and glucose uptake by skeletal muscle via triggering PPAR- $\gamma$ co-activator 1- $\alpha$ (PGC-1 $\alpha$ ) and Akt/GLUT4 activation [330]. Simultaneously, it prevents obesity and diabetes-related disorders [331]. Fucoxanthin-casein-chitosan, fucoxanthin-zein-caseinate, fucoxanthin-pinolenic acid, fucoxanthin-chitosan-glycolipid nanoformulations were reported to enhance stability, safety, bioavailability, and therapeutic efficacy of fucoxanthin [331-334]. However, the exact effect of fucoxanthin nanoparticles on diabetic animals is yet to be explored. 16-hydroxycleroda-3,13-dine-16,15-olide, a naturally occurring DPP-4 inhibitor from Polyalthia longifolia, exhibits hypoglycaemic activity. 16-Hydroxycleroda-3,13-dine-16,15-olide in mesoporous silica nanoparticles reciprocated hyperglycaemia, insulin resistance, dyslipidaemia and obesity in diabetic mice more efficiently than native drug [174]. $\gamma$-Oryzanol, a mixture of phytosterol ferulates and triterpene alcohol extracted from rice bran oil, is a PPAR $-\gamma$ agonist and can promote glucose utilization via IRS-1/PI3K/Akt/GLUT4 activation [335]. $\gamma$-Oryzanol-loaded PLGA nanoparticles have been found to improve absorption efficiency and therapeutic efficacy of $\gamma$-oryzanol [336]. Nano- $\gamma$-oryzanol effectively ameliorated blood glucose and lipid metabolism at a 1000-fold lower dose than native $\gamma$-oryzanol in type 2 diabetic mice [336]. In addition, a noticeable impact has been achieved through its dosing once every two weeks. $\gamma$-Oryzanol nanoparticles were found to exhibit a significant decrease in toxicosis in hypothalamus, pancreatic islets, liver, and adipose tissue [337]. Nicotinamide has been reported to stimulate pancreatic $\beta$ cells to produce insulin [337]. Nicotinamide-functionalized multi-walled carbon nanotubes have been found to restore cell viability of insulin-producing $\beta$ cells and increase insulin production more significantly than free nicotinamide via triggering macrophage migration inhibitory factor (MIF) pathway [337]. Propanoic acid 2-(3-acetoxy-4,4,14-trimethylandrost-8-en-17-yl), a antidiabetic lead in Cassia auriculata flower, showed significant antidiabetic activity [338]. However, propanoic acid 2-(3-acetoxy-4,4,14-trimethylandrost-8-en-17-yl)-fabricated gold nanoparticle treatment for four weeks has been found to reduce hyperglycaemia, suppress hyperlipidaemia, improve insulin level, and inhibit loss of body weight more efficiently than free drug in type 1 diabetic rats [338,339]. In addition, propanoic acid 2-(3-acetoxy-4,4,14-trimethylandrost-8-en-17-yl)-gold nanoparticles significantly attenuated PTP1B activity in vitro at a much lower concentration [340]. In another report, propanoic-acid-functionalized gold nanoparticles have been found to elicit antidiabetic potential in vitro via promoting glucose uptake by skeletal muscle, suppressing PTP1B, and inhibiting glucose absorption through $\alpha$-glucosidase and $\alpha$-glucosidase inhibition [339]. Escin, a bioactive mixture of saponins in horse chestnut seeds, is known for its hypoglycaemic and anti-inflammatory effects [340,341]. To improve therapeutic efficacy and biocompatibility, Shamprasad and co-workers formulated escin-fabricated gold nanoparticles via natural sunlight-mediated synthesis [342]. Escin-gold nanoparticles have been found to possess better pharmacological efficacy in improving glucose uptake by skeletal muscle and promoting radical scavenging effect in vitro than native escin [342]. Guavanoic acid, an antidiabetic lead from Psidium guajava leaves, has been formulated as guavanoic-acid-gold nanoparticles and separated by the classical chromatographic methods [343]. Guavanoic acid-gold nanoparticles were found to be a stable formulation with better PTP1B inhibitory capacity $\left(\mathrm{IC}_{50} \sim 2.2 \mu \mathrm{M}\right)$ than RK-682 $\left(\mathrm{IC}_{50} \sim 5\right.$ $\mu \mathrm{M})$, a well-known phosphatase inhibitor [343]. Docosahexaenoic acid, a long-chain polyunsaturated fatty acid, possesses antidiabetic effect via multiple mechanisms [179]. However, instability, poor pharmacokinetic profile, and age-related differential responses compromise its therapeutic utility [344]. Thus, suitable formulations of docosahexaenoic acid need to be developed to enhance its therapeutic efficacy. Gum-arabic-capped docosahexaenoic-acid-loaded zinc oxide nanoparticles have been found to be a reliable oral formulation to treat diabetes. Docosahexaenoic-acid-zinc-oxide nanoparticles could more efficiently attenuate diabetes than free docosahexaenoic acid evidenced from superior 
control against hyperglycaemia, insulin resistance, hyperlipidaemia, hypoinsulinaemia, and oxidative stress in diabetic rats [345]. Similarly, Docosahexaenoic-acid-silver nanoparticles could more efficiently reduce hyperglycaemia, insulin resistance, hyperlipidaemia, hypoinsulinaemia, oxidative stress, and endothelial dysfunction than native docosahexaenoic acid [346].

\subsection{Green-Synthesized Nanoformulations as Antidiabetic Phytotherapeuticals}

The global interest toward natural medicines is continuously increasing, especially to treat chronic diseases. Natural medicines include nature-derived products with nominal processing [347]. Nature-derived therapeutic agents have been regarded as eco-friendly, safe, and cost-effective healthcare agents [348]. Herbal drugs occupy the principal share in nature-derived medicines. Herbal medicines have a long and successful history in the management of diabetes and diabetic complications $[349,350]$. Several medicinal plants, such as Gymnema sylvestre, Momordica charantia, Azadirachta indica, Trigonella foenum gracecum, Tinospora cordifolia, Inula racemosa, Allium sativum, Eugenia jambolana, Syzygium cumini, Pterocarpus marsupium, Emblica officinalis, Asparagus racemosus, Boerhavia diffusa etc., have been reported to be clinically useful in the management of diabetes [349]. Green synthesis of herbal product-assembled polymeric or metallic nanoparticles has been found to achieve better therapeutic output in the management of diabetes than native crude products [351-354]. Phyto-nanotherapy offers better biopharmaceutical attributes and is revealed to be clinically equivalent to many commercially available antidiabetic drugs [353]. In addition, plant-metal nanoparticles can achieve unique therapeutic properties via a synergistic effect [353]. Green synthesis of gold, silver, and zinc oxide nanoformulations of herbal drugs has got considerable attention through improving the stability, pharmacokinetic attributes, and biopharmaceutical properties of comprising phytochemicals to achieve better therapeutic efficacy in the management of diabetes [353]. Several phyto-nanoformulations developed in recent years have been claimed to be effective in alleviating diabetes (Supplementary Table S1). However, a substantial amount of research is required in developing novel antidiabetic phyto-nanoformulation(s) to be clinically useful against diabetes.

\section{Present Scenario and Future Perspective}

Nanotechnology has appreciably emerged in the medicinal field in recent years. Patient compliance has been regarded as an important aspect in the treatment of diabetes, where prolonged or continuous treatment is required. Nanoformulations have been found to improve patient compliance by offering various routes of administration, regulating release, improving biological stability, achieving target specificity, and reducing toxicity. Thus, interest in developing nanoformulations against diabetes has been increasing dramatically, as evidenced by the published documents in the last 20 years (Supplementary Figure S1). Similarly, natural-product-based different nanoformulations and natural-product-based antidiabetic nanoformulations have fetched the interest of the researchers over the years (Supplementary Figure S1). Considering these, it would be said that there would have the possibility of developing suitable nanoformulations to attenuate diabetes and associated complications using naturally occurring antidiabetic agents or crude herbal products.

Several naturally occurring agents with well-established antidiabetic potential have been nanoformulated to improve their pharmacokinetic and therapeutic efficacy in the management of diabetes mellitus. However, the majority of these studies have been constrained due to inadequate data and lack of long term experimental statistics, particularly, regarding the prolonged stability profiling, long-term therapeutic effectiveness, and toxicological characteristics of the developed antidiabetic nanoformulations of plant-derived molecules. Thus, most of the findings are confined within the laboratory scale. Thus, significant attention must be paid to resolve this issue. On the other hand, several nanoformulations of plant-derived molecules also possessing antidiabetic effects have also been developed and reported to be effective against other diseases etiologically similar or different from diabetes [111,278,355-359]. Thus, dose manipulation of these nanoformulations would have the prospects in the therapeutic management of diabetes. Presently, around 51 FDA-approved 
nanoformulations are applied clinically as medicines and all these nanoformulations have been initially designed to improve physicochemical, pharmaceutical, and pharmacokinetic attributes of comprising drug molecules [360]. Considering these, it would be expected that the nanoformulations of naturally occurring hypoglycaemic agents will offer huge prospects through improving patient compliance, ensuring cost-effectiveness, and reducing toxicity in diabetes therapy in the future.

\section{Interpretation and Conclusion}

In the case of chronic metabolic syndrome like diabetes, long-term treatment is required. Thus, patient compliance is the most needed criterion in developing the formulation of pharmacotherapeutic agents for diabetes management. In this regard, oral formulation is mostly preferred. Plant-derived antidiabetic molecules offer excellent prospects to attenuate diabetes and associated complications. However, the poor biopharmaceutical and pharmacokinetic profiles of phytochemicals largely limit their therapeutic efficacy. Over the years, several antidiabetic nanoformulations of plant-derived molecules, such as polymeric nanoparticles, nano-emulsion, nanocarrier-assembled nanoparticles, nanoliposomes, solid lipid nanoparticles, nanostructured lipid carriers, nanomicelles, solid dispersions, and nanocrystals have been developed.

PLGA has been claimed as the potential nanocarrier for the oral delivery of most of the plant-based compounds, including curcumin, resveratrol, quercetin, silymarin, pelargonidin, thromboquinone, ferulic acid, crocetin, and $\gamma$-oryzanol [193,221,272,273,292,300]. Although PLGA-loaded nanoformulations have been claimed to improve oral bioavailability and antidiabetic efficacy of aforementioned plant-derived small molecules, PLGA is very much susceptible to the hydrolytic degradation in gastrointestinal environment. In this regard, the PLA/PGA ratio in PLGA is a critical factor and the effects of different grades of PLGA as nanocarriers need to be specifically addressed. Chitosan has been regarded as a suitable nanocarrier for the oral delivery of curcumin, naringenin, quercetin, gymnemic acid, rosmarinic acid, scutellarin, silybin, and others, which improves compliance and pharmacokinetic attributes of the aforementioned antidiabetic phytochemicals [200,220,224,240,247,268]. Pluronic has also been found to be another suitable nanocarrier in developing curcumin, apigenin, baicalin, stevioside, silymarin, silybin, and thymoquinone nanoformulations [121,138,148,196,232,269,295,297].

Fabrication of nanocarriers can offer better drug loading capacity, gradual release, low toxicity, and antidiabetic efficacy of the formulations [192]. Development of different block polymers such as nanocarriers using PLGA, PEG, PCL, poly( $\varepsilon$-caprolactone), polyacrylamide, chitosan, pluronic etc. as di- or tri-blocks has also been shown to improve the therapeutic efficacy of phytochemicals as antidiabetic agents with better pharmacokinetic attributes. PLGA-PVA, Poly( $\varepsilon$-caprolactone)-PLGA, pluronic-PLGA, PLGA-PEG, chitosan-PLGA, chitosan-gum arabic, chitosan-alginate, PCL-PLGA-PEG-COOH, and chitooligosaccharides-PLGA, polycaprolactone-polyethyleneimine, polyacrylamide-chitosan-PLGA, chitooligosaccharides-PLGA, and PEG-block-[poly-(ethylenediaminel- glutamate)-graft-poly-( $\varepsilon$-benzyloxy-carbonyl-1-lysine)] have been revealed to be attractive nanocarriers to improve pharmacokinetic profile and antidiabetic efficacy of curcumin, luteolin, silybin, thymoquinone, ferulic acid, fisetin, and astaxanthin, respectively $[195,223,237,244,269,317,321]$. In addition, block polymer can improve the target specificity of the nanoformulations [361]. Chemical modifications of polymeric nanocarriers can also improve the pharmacokinetic profile and compliance over unmodified polymers. Galactosylation of PLGA can yield superior nanocarrier in terms of improvement in transepithelial transport, oral bioavailability, and therapeutic efficacy of resveratrol than the unmodified PLGA [214]. Similarly, succinylated chitosan-alginate and o-hexadecyl-dextran blocks have been regarded as suitable nanocarriers for the oral delivery of naturally occurring antidiabetic molecules [224,256].

In conclusion, the nanoscale formulations of plant-derived antidiabetic molecules have been found to improve the compliance and clinical efficacy by overturning the pharmacokinetic and biopharmaceutical obstacles associated with them. Thus, the development of nanoformulations 
could be anticipated as a potential solution to achieve the best clinical output of plant-derived antidiabetic molecules. However, more research is required to deliver clinically effective therapeutic nanoformulations of plant-derived antidiabetic molecules to control diabetes and associated complications.

Supplementary Materials: The following are available online at http:/www.mdpi.com/1422-0067/21/6/2217/s1, Table S1: Antidiabetic nanoformulations of crude natural products. Figure S1: Statistics of research in the field of nanotechnology-based formulation development accessed in scopus on 08.03.2020.

Author Contributions: S.D. and P.C. designed and structured the manuscript. S.D. and P.C. performed the literature search and wrote the first draft of the manuscript. S.D., B.M., and V.D.F. revised and edited the final version of the manuscript. All authors read and approved the final manuscript.

Funding: This work was financially supported by Council of Scientific and Industrial Research, New Delhi, India, grant number 02(0275)/16/EMR-II to S.D.

Acknowledgments: Authors sincerely acknowledge Jadavpur University, India, and University of Salerno, Italy.

Conflicts of Interest: The authors declare no conflict of interest.

\section{References}

1. Kesharwani, P.; Gorain, B.; Low, S.Y.; Tan, S.A.; Ling, E.C.S.; Lim, Y.K.; Chin, C.M.; Lee, P.Y.; Lee, C.M.; Ooi, C.H.; et al. Nanotechnology based approaches for anti-diabetic drugs delivery. Diabetes Res. Clin. Pract. 2018, 136, 52-77. [CrossRef] [PubMed]

2. Patra, J.K.; Das, G.; Fraceto, L.F.; Campos, E.V.R.; Rodriguez-Torres, M.D.P.; Acosta-Torres, L.S.; Diaz-Torres, L.A.; Grillo, R.; Swamy, M.K.; Sharma, S.; et al. Nano based drug delivery systems: Recent developments and future prospects. J. Nanobiotechnol. 2018, 16, 71. [CrossRef] [PubMed]

3. Aryaeian, N.; Sedehi, S.K.; Arablou, T. Polyphenols and their effects on diabetes management: A review. Med. J. Islam. Repub. Iran. 2017, 31, 134. [CrossRef]

4. Brglez Mojzer, E.; Knez Hrnčič, M.; Škerget, M.; Knez, Ž.; Bren, U. Polyphenols: Extraction methods, antioxidative action, bioavailability and anticarcinogenic effects. Molecules 2016, 21, 901. [CrossRef] [PubMed]

5. Khurana, R.K.; Gaspar, B.L.; Welsby, G.; Katare, O.P.; Singh, K.K.; Singh, B. Improving the biopharmaceutical attributes of mangiferin using vitamin E-TPGS co-loaded self-assembled phosholipidic nano-mixed micellar systems. Drug Deliv. Transl. Res. 2018, 8, 617-632. [CrossRef]

6. Sharma, M.; Sharma, R.; Jain, D.K. Nanotechnology based approaches for enhancing oral bioavailability of poorly water soluble antihypertensive drugs. Scientifica 2016, 2016, 8525679. [CrossRef]

7. Hu, F.B. Globalization of diabetes: The role of diet, lifestyle, and genes. Diabetes Care 2011, 34, $1249-1257$. [CrossRef]

8. Li, Y.; Zhang, J.; Gu, J.; Chen, S.; Wang, C.; Jia, W. Biosynthesis of polyphenol-stabilised nanoparticles and assessment of anti-diabetic activity. J. Photochem. Photobiol. B 2017, 169, 96-100. [CrossRef]

9. Bhattacharjee, N.; Dua, T.K.; Khanra, R.; Joardar, S.; Nandy, A.; Saha, A.; De Feo, V.; Dewanjee, S. Protocatechuic acid, a phenolic from Sansevieria roxburghiana leaves, suppresses diabetic cardiomyopathy via stimulating glucose metabolism, ameliorating oxidative stress, and inhibiting inflammation. Front. Pharmacol. 2017, 8, 251. [CrossRef]

10. Gothai, S.; Ganesan, P.; Park, S.Y.; Fakurazi, S.; Choi, D.K.; Arulselvan, P. Natural phyto-bioactive compounds for the treatment of type 2 diabetes: Inflammation as a target. Nutrients 2016, 8, 461. [CrossRef]

11. Qaseem, A.; Humphrey, L.L.; Sweet, D.E.; Starkey, M.; Shekelle, P. Oral pharmacologic treatment of type 2 diabetes mellitus: A clinical practice guideline from the American College of Physicians. Ann. Intern. Med. 2012, 156, 218-231. [CrossRef] [PubMed]

12. Dewanjee, S.; Das, S.; Das, A.K.; Bhattacharjee, N.; Dihingia, A.; Dua, T.K.; Kalita, J.; Manna, P. Molecular mechanism of diabetic neuropathy and its pharmacotherapeutic targets. Eur. J. Pharmacol. 2018, 833, 472-523. [CrossRef] [PubMed]

13. Dewanjee, S.; Bhattacharjee, N. MicroRNA: A new generation therapeutic target in diabetic nephropathy. Biochem. Pharmacol. 2018, 155, 32-47. [CrossRef] [PubMed] 
14. Bhattacharjee, N.; Barma, S.; Konwar, N.; Dewanjee, S.; Manna, P. Mechanistic insight of diabetic nephropathy and its pharmacotherapeutic targets: An update. Eur. J. Pharmacol. 2016, 791, 8-24. [CrossRef] [PubMed]

15. Khanra, R.; Bhattacharjee, N.; Dua, T.K.; Nandy, A.; Saha, A.; Kalita, J.; Manna, P.; Dewanjee, S. Taraxerol, a pentacyclic triterpenoid, from Abroma augusta leaf attenuates diabetic nephropathy in type 2 diabetic rats. Biomed. Pharmacother. 2017, 94, 726-741. [CrossRef]

16. Xavier, G.D.S. The cells of the islets of langerhans. J. Clin. Med. 2018, 7, 54. [CrossRef]

17. Berenson, D.F.; Weiss, A.R.; Wan, Z.L.; Weiss, M.A. Insulin analogs for the treatment of diabetes mellitus: Therapeutic applications of protein engineering. Ann. N. Y. Acad. Sci. 2011, 1243, E40-E54. [CrossRef]

18. Tadera, K.; Minami, Y.; Takamatsu, K.; Matsuoka, T. Inhibition of alpha-glucosidase and alpha-amylase by flavonoids. J. Nutr. Sci. Vitaminol. (Tokyo) 2006, 52, 149-153. [CrossRef]

19. Kamiyama, O.; Sanae, F.; Ikeda, K.; Higashi, Y.; Minami, Y.; Asano, N.; Adachi, I.; Kato, A. In vitro inhibition of a-glucosidases and glycogen phosphorylase by catechin gallates in green tea. Food Chem. 2010, 122, 1061-1066. [CrossRef]

20. Arumugam, B.; Palanisamy, U.D.; Chua, K.H.; Kuppusamy, U.R. Potential antihyperglycaemic effect of myricetin derivatives from Syzygium malaccense. J. Funct. Foods 2016, 22, 325-336. [CrossRef]

21. Rasouli, H.; Hosseini-Ghazvini, S.M.; Adibi, H.; Khodarahmi, R. Differential $\alpha$-amylase/ $\alpha$-glucosidase inhibitory activities of plant-derived phenolic compounds: A virtual screening perspective for the treatment of obesity and diabetes. Food Funct. 2017, 8, 1942-1954. [CrossRef] [PubMed]

22. Ngo, Y.L.; Lau, C.H.; Chua, L.S. Review on rosmarinic acid extraction, fractionation and its anti-diabetic potential. Food Chem. Toxicol. 2018, 121, 687-700. [CrossRef] [PubMed]

23. Li, K.; Yao, F.; Xue, Q.; Fan, H.; Yang, L.; Li, X.; Sun, L.; Liu, Y. Inhibitory effects against $\alpha$-glucosidase and $\alpha$-amylase of the flavonoids-rich extract from Scutellaria baicalensis shoots and interpretation of structure-activity relationship of its eight flavonoids by a refined assign-score method. Chem. Cent. J. 2018, 12, 82. [CrossRef] [PubMed]

24. Thadhani, V.M. Resveratrol in Management of Diabetes and Obesity: Clinical Applications, Bioavailability, and Nanotherapy. In Resveratrol-Adding Life to Years, Not Adding Years to Life; IntechOpen: Rijeka, Croatia, 2019; pp. 139-156.

25. Oh, Y.S. Plant-derived compounds targeting pancreatic beta cells for the treatment of diabetes. Evid. Based Complement. Altern. Med. 2015, 2015, 629863. [CrossRef]

26. Rouse, M.; Younès, A.; Egan, J.M. Resveratrol and curcumin enhance pancreatic $\beta$-cell function by inhibiting phosphodiesterase activity. J. Endocrinol. 2014, 223, 107-117. [CrossRef]

27. Wu, L.; Zhou, L.; Lu, Y.; Zhang, J.; Jian, F.; Liu, Y.; Li, F.; Li, W.; Wang, X.; Li, G. Activation of SIRT1 protects pancreatic $\beta$-cells against palmitate-induced dysfunction. Biochim. Biophys. Acta 2012, 1822, 1815-1825. [CrossRef]

28. Suman, R.K.; Mohanty, I.R.; Maheshwari, U.; Borde, M.K.; Deshmukh, Y.A. Natural dipeptidyl peptidase-IV inhibitor mangiferin mitigates diabetes- and metabolic syndrome-induced changes in experimental rats. Diabetes Metab. Syndr. Obes. 2016, 9, 261-272. [CrossRef]

29. Shenoy, R.S.; Prashanth, K.V.H.; Manonmani, H.K. In Vitro antidiabetic effects of isolated triterpene glycoside fraction from gymnema sylvestre. Evid. Based Complement. Altern. Med. 2018, 2018, 7154702. [CrossRef]

30. Jeppesen, P.B.; Gregersen, S.; Poulsen, C.R.; Hermansen, K. Stevioside acts directly on pancreatic beta cells to secrete insulin: Actions independent of cyclic adenosine monophosphate and adenosine triphosphate-sensitive K+-channel activity. Metabolism 2000, 49, 208-214. [CrossRef]

31. Philippaert, K.; Pironet, A.; Mesuere, M.; Sones, W.; Vermeiren, L.; Kerselaers, S.; Pinto, S.; Segal, A.; Antoine, N.; Gysemans, C.; et al. Steviol glycosides enhance pancreatic beta-cell function and taste sensation by potentiation of TRPM5 channel activity. Nat. Commun. 2017, 8, 14733. [CrossRef]

32. Liu, J.; He, T.; Lu, Q.; Shang, J.; Sun, H.; Zhang, L. Asiatic acid preserves beta cell mass and mitigates hyperglycaemia in streptozocin-induced diabetic rats. Diabetes Metab. Res. Rev. 2010, 26, 448-454. [CrossRef] [PubMed]

33. Ghorbani, A.; Rashidi, R.; Shafiee-Nick, R. Flavonoids for preserving pancreatic beta cell survival and function: A mechanistic review. Biomed. Pharmacother. 2019, 111, 947-957. [CrossRef] [PubMed]

34. Den Hartogh, D.J.; Tsiani, E. Antidiabetic properties of naringenin: A citrus fruit polyphenol. Biomolecules 2019, 9, 99. [CrossRef] [PubMed] 
35. Soto, C.; Raya, L.; Pérez, J.; González, I.; Pérez, S. Silymarin induces expression of pancreatic Nkx6.1 transcription factor and $\beta$-cells neogenesis in a pancreatectomy model. Molecules 2014, 19, 4654-4668. [CrossRef]

36. Sameermahmood, Z.; Raji, L.; Saravanan, T.; Vaidya, A.; Mohan, V.; Balasubramanyam, M. Gallic acid protects RINm5F beta-cells from glucolipotoxicity by its antiapoptotic and insulin-secretagogue actions. Phytother. Res. 2010, 24, S83-S94. [CrossRef]

37. Boucher, J.; Kleinridders, A.; Kahn, C.R. Insulin receptor signaling in normal and insulin-resistant states. Cold Spring Harb. Perspect. Biol. 2014, 6, a009191. [CrossRef]

38. Puigserver, P.; Rhee, J.; Donovan, J.; Walkey, C.J.; Yoon, J.C.; Oriente, F.; Kitamura, Y.; Altomonte, J.; Dong, H.; Accili, D.; et al. Insulin-regulated hepatic gluconeogenesis through FOXO1-PGC-1alpha interaction. Nature 2003, 423, 550-555. [CrossRef]

39. Eid, S.; Boutary, S.; Braych, K.; Sabra, R.; Massaad, C.; Hamdy, A.; Rashid, A.; Moodad, S.; Block, K.; Gorin, Y.; et al. mTORC2 signaling regulates Nox4-induced podocyte depletion in diabetes. Antioxid. Redox Signal. 2016, 25, 703-719. [CrossRef]

40. Sayem, A.S.M.; Arya, A.; Karimian, H.; Krishnasamy, N.; Ashok Hasamnis, A.; Hossain, C.F. Action of phytochemicals on insulin signaling pathways accelerating glucose transporter (GLUT4) protein translocation. Molecules 2018, 23, 258. [CrossRef]

41. Wong, R.H.X.; Howe, P.R.C. Resveratrol counteracts insulin resistance-potential role of the circulation. Nutrients 2018, 10, 1160. [CrossRef]

42. Zhang, D.W.; Fu, M.; Gao, S.H.; Liu, J.L. Curcumin and diabetes: A systematic review. Evid. Based Complement. Altern. Med. 2013, 2013, 636053. [CrossRef] [PubMed]

43. Al-Ishaq, R.K.; Abotaleb, M.; Kubatka, P.; Kajo, K.; Büsselberg, D. Flavonoids and their anti-diabetic effects: Cellular mechanisms and effects to improve blood sugar levels. Biomolecules 2019, 9, 430. [CrossRef] [PubMed]

44. Kawser Hossain, M.; Abdal Dayem, A.; Han, J.; Yin, Y.; Kim, K.; Kumar Saha, S.; Yang, G.M.; Choi, H.Y.; Cho, S.G. Molecular mechanisms of the anti-obesity and anti-diabetic properties of flavonoids. Int. J. Mol. Sci. 2016, 17, 569. [CrossRef] [PubMed]

45. Yin, J.; Ye, J.; Jia, W. Effects and mechanisms of berberine in diabetes treatment. Acta Pharm. Sin. 2012, 2, 327-334. [CrossRef]

46. Rizzo, B.; Zambonin, L.; Angeloni, C.; Leoncini, E.; Dalla Sega, F.V.; Prata, C.; Fiorentini, D.; Hrelia, S. Steviol glycosides modulate glucose transport in different cell types. Oxid. Med. Cell. Longev. 2013, 2013, 348169. [CrossRef] [PubMed]

47. Ramachandran, V.; Saravanan, R. Glucose uptake through translocation and activation of GLUT4 in PI3K/Akt signaling pathway by asiatic acid in diabetic rats. Hum. Exp. Toxicol. 2015, 34, 884-893. [CrossRef]

48. Sil, R.; Ray, D.; Chakraborti, A.S. Glycyrrhizin ameliorates insulin resistance, hyperglycaemia, dyslipidemia and oxidative stress in fructose-induced metabolic syndrome- $X$ in rat model. Indian J. Exp. Biol. 2013, 51, 129-138.

49. Variya, B.C.; Bakrania, A.K.; Patel, S.S. Antidiabetic potential of gallic acid from Emblica officinalis: Improved glucose transporters and insulin sensitivity through PPAR- $\gamma$ and Akt signaling. Phytomedicine 2019, 152906. [CrossRef]

50. Badr, G.; Mahmoud, M.H.; Farhat, K.; Waly, H.; Al-Abdin, O.Z.; Rabah, D.M. Maternal supplementation of diabetic mice with thymoquinone protects their offspring from abnormal obesity and diabetes by modulating their lipid profile and free radical production and restoring lymphocyte proliferation via PI3K/AKT signaling. Lipids Health Dis. 2013, 12, 37. [CrossRef]

51. Jay, M.A.; Ren, J. Peroxisome proliferator-activated receptor (PPAR) in metabolic syndrome and type 2 diabetes mellitus. Curr. Diabetes Rev. 2007, 3, 33-39. [CrossRef]

52. Pan, Y.; Zhao, D.; Yu, N.; An, T.; Miao, J.; Mo, F.; Gu, Y.; Zhang, D.; Gao, S.; Jiang, G. Curcumin improves glycolipid metabolism through regulating peroxisome proliferator activated receptor $\gamma$ signalling pathway in high-fat diet-induced obese mice and 3T3-L1 adipocytes. R. Soc. Open Sci. 2017, 4, 170917. [CrossRef] [PubMed]

53. Zhang, Q.; Xiao, X.; Feng, K.; Wang, T.; Li, W.; Yuan, T.; Sun, X.; Sun, Q.; Xiang, H.; Wang, H. Berberine moderates glucose and lipid metabolism through multipathway mechanism. Evid. Based Complement. Altern. Med. 2011, 2011, 924851. [CrossRef] [PubMed] 
54. Eu, C.H.; Lim, W.Y.; Ton, S.H.; bin Abdul Kadir, K. Glycyrrhizic acid improved lipoprotein lipase expression, insulin sensitivity, serum lipid and lipid deposition in high-fat diet-induced obese rats. Lipids Health Dis. 2010, 9, 81. [CrossRef] [PubMed]

55. Lu, K.; Han, M.; Ting, H.L.; Liu, Z.; Zhang, D. Scutellarin from Scutellaria baicalensis suppresses adipogenesis by upregulating PPAR $\alpha$ in 3T3-L1 cells. J. Nat. Prod. 2013, 76, 672-678. [CrossRef] [PubMed]

56. Cho, K.W.; Kim, Y.O.; Andrade, J.E.; Burgess, J.R.; Kim, Y.C. Dietary naringenin increases hepatic peroxisome proliferators-activated receptor $\alpha$ protein expression and decreases plasma triglyceride and adiposity in rats. Eur. J. Nutr. 2011, 50, 81-88. [CrossRef] [PubMed]

57. Chang, C.J.; Tzeng, T.F.; Liou, S.S.; Chang, Y.S.; Liu, I.M. Myricetin increases hepatic peroxisome proliferator-activated receptor $\alpha$ protein expression and decreases plasma lipids and adiposity in rats. Evid. Based Complement. Altern. Med. 2012, 2012, 787152. [CrossRef]

58. Wang, M.I.; Xiao, F.L.; Mao, Y.J.; Ying, L.L.; Zhou, B.; Li, Y. Quercetin decreases the triglyceride content through the PPAR signalling pathway in primary hepatocytes of broiler chickens. Biotechnol. Biotechnol. Equip. 2019, 33, 1000-1010. [CrossRef]

59. Fomenko, E.V.; Chi, Y. Mangiferin modulation of metabolism and metabolic syndrome. Biofactors 2016, 42, 492-503. [CrossRef]

60. Naowaboot, J.; Piyabhan, P.; Munkong, N.; Parklak, W.; Pannangpetch, P. Ferulic acid improves lipid and glucose homeostasis in high-fat diet-induced obese mice. Clin. Exp. Pharmacol. Physiol. 2016, 43, 242-250. [CrossRef]

61. Goto, T.; Takahashi, N.; Kato, S.; Kim, Y.I.; Kusudo, T.; Taimatsu, A.; Egawa, K.; Kang, M.S.; Hiramatsu, T.; Sakamoto, T.; et al. Bixin activates PPAR $\alpha$ and improves obesity-induced abnormalities of carbohydrate and lipid metabolism in mice. J. Agric. Food Chem. 2012, 60, 11952-11958. [CrossRef]

62. Gu, M.; Zhao, P.; Huang, J.; Zhao, Y.; Wang, Y.; Li, Y.; Li, Y.; Fan, S.; Ma, Y.M.; Tong, Q.; et al. Silymarin ameliorates metabolic dysfunction associated with diet-induced obesity via activation of farnesyl $\mathrm{X}$ receptor. Front. Pharmacol. 2016, 7, 345. [CrossRef] [PubMed]

63. Chen, Y.; Li, J.; Yan, Y.; Shen, X. Diabetic macular morphology changes may occur in the early stage of diabetes. BMC Ophthalmol. 2016, 16, 12. [CrossRef]

64. Xu, G.; Sun, W.; Guo, X.; Wu, L.; Hou, Y.; Ma, X.; Qin, L.; Gao, M.; Liu, T. Asiatic acid promotes liver fatty acid metabolism in diabetic models. Int. J. Clin. Exp. Med. 2018, 11, 11837-11845.

65. Li, Y.; Sun, M.; Liu, Y.; Liang, J.; Wang, T.; Zhang, Z. Gymnemic acid alleviates type 2 diabetes mellitus and suppresses endoplasmic reticulum stress in vivo and in vitro. J. Agric. Food Chem. 2019, 67, 3662-3669. [CrossRef] [PubMed]

66. Domínguez-Avila, J.A.; González-Aguilar, G.A.; Alvarez-Parrilla, E.; de la Rosa, L.A. Modulation of PPAR expression and activity in response to polyphenolic compounds in high fat diets. Int. J. Mol. Sci. 2016, 17, 1002. [CrossRef] [PubMed]

67. Floyd, Z.E.; Wang, Z.Q.; Kilroy, G.; Cefalu, W.T. Modulation of peroxisome proliferator-activated receptor gamma stability and transcriptional activity in adipocytes by resveratrol. Metabolism 2008, 57, S32-S38. [CrossRef]

68. Bing, S.; Haoqiang, Z.; Chunyu, M.; Yali, Y.; Jing, W.; Yumeng, G.; Hongwei, Z.; Xuezheng, L. The effects of emodin on insulin resistance in KKAy mice with diabetes mellitus. Pharmacogn. Mag. 2018, 14, 344-350.

69. Pang, B.; Zhao, L.H.; Zhou, Q.; Zhao, T.Y.; Wang, H.; Gu, C.J.; Tong, X.L. Application of berberine on treating type 2 diabetes mellitus. Int. J. Endocrinol. 2015, 2015, 905749. [CrossRef]

70. Chae, B.S. Protective effect of baicalin on the TNF- $\alpha$-mediated development of insulin resistance in differentiated 3T3-L1 cells. Nat. Prod. Sci. 2013, 19, 316-323.

71. Cho, S.Y.; Park, P.J.; Shin, H.J.; Kim, Y.K.; Shin, D.W.; Shin, E.S.; Lee, H.H.; Lee, B.G.; Baik, J.H.; Lee, T.R. (-)-Catechin suppresses expression of Kruppel-like factor 7 and increases expression and secretion of adiponectin protein in 3T3-L1 cells. Am. J. Physiol. Endocrinol. Metab. 2007, 292, E1166-E1172. [CrossRef]

72. Dodda, D.; Ciddi, V. Plants used in the management of diabetic complications. Indian J. Pharm Sci. 2014, 76, 97-106. [PubMed]

73. Parsamanesh, N.; Moossavi, M.; Bahrami, A.; Butler, A.E.; Sahebkar, A. Therapeutic potential of curcumin in diabetic complications. Pharmacol. Res. 2018, 136, 181-193. [CrossRef] [PubMed]

74. Oyenihi, O.R.; Oyenihi, A.B.; Adeyanju, A.A.; Oguntibeju, O.O. Antidiabetic effects of resveratrol: The way forward in its clinical utility. J. Diabetes Res. 2016, 2016, 9737483. [CrossRef] [PubMed] 
75. Shi, G.J.; Li, Y.; Cao, Q.H.; Wu, H.X.; Tang, X.Y.; Gao, X.H.; Yu, J.Q.; Chen, Z.; Yang, Y. In vitro and in vivo evidence that quercetin protects against diabetes and its complications: A systematic review of the literature. Biomed. Pharmacother. 2019, 109, 1085-1099. [CrossRef] [PubMed]

76. Mao, X.Y.; Yu, J.; Liu, Z.Q.; Zhou, H.H. Apigenin attenuates diabetes-associated cognitive decline in rats via suppressing oxidative stress and nitric oxide synthase pathway. Int. J. Clin. Exp. Med. 2015, 8, 15506-15513. [PubMed]

77. Malik, S.; Suchal, K.; Khan, S.I.; Bhatia, J.; Kishore, K.; Dinda, A.K.; Arya, D.S. Apigenin ameliorates streptozotocin-induced diabetic nephropathy in rats via MAPK-NF-KB-TNF- $\alpha$ and TGF- $\beta 1$-MAPK-fibronectin pathways. Am. J. Physiol. Ren. Physiol. 2017, 313, F414-F422. [CrossRef] [PubMed]

78. Zhang, B.; Shen, Q.; Chen, Y.; Pan, R.; Kuang, S.; Liu, G.; Sun, G.; Sun, X. Myricitrin alleviates oxidative stress-induced inflammation and apoptosis and protects mice against diabetic cardiomyopathy. Sci. Rep. 2017, 7, 44239. [CrossRef]

79. Ahangarpour, A.; Oroojan, A.A.; Khorsandi, L.; Kouchak, M.; Badavi, M. Solid lipid nanoparticles of myricitrin have antioxidant and antidiabetic effects on streptozotocin-nicotinamide-induced diabetic model and myotube cell of male mouse. Oxid. Med. Cell. Longev. 2018, 2018, 7496936. [CrossRef]

80. Ku, S.K.; Bae, J.S. Baicalin, baicalein and wogonin inhibits high glucose-induced vascular inflammation in vitro and in vivo. BMB Rep. 2015, 48, 519-524. [CrossRef]

81. Wang, G.; Liang, J.; Gao, L.R.; Si, Z.P.; Zhang, X.T.; Liang, G.; Yan, Y.; Li, K.; Cheng, X.; Bao, Y.; et al. Baicalin administration attenuates hyperglycaemia-induced malformation of cardiovascular system. Cell Death Dis. 2018, 9, 234. [CrossRef]

82. Wang, G.G.; Lu, X.H.; Li, W.; Zhao, X.; Zhang, C. Protective effects of luteolin on diabetic nephropathy in STZ-induced diabetic rats. Evid. Based Complement. Altern. Med. 2011, 2011, 323171. [CrossRef] [PubMed]

83. Wang, G.; Li, W.; Lu, X.; Bao, P.; Zhao, X. Luteolin ameliorates cardiac failure in type I diabetic cardiomyopathy. J. Diabetes Complicat. 2012, 26, 259-265. [CrossRef] [PubMed]

84. Pal, P.B.; Sinha, K.; Sil, P.C. Mangiferin attenuates diabetic nephropathy by inhibiting oxidative stress mediated signaling cascade, TNF $\alpha$ related and mitochondrial dependent apoptotic pathways in streptozotocin-induced diabetic rats. PLoS ONE 2014, 9, e107220. [CrossRef] [PubMed]

85. Du, S.; Liu, H.; Lei, T.; Xie, X.; Wang, H.; He, X.; Tong, R.; Wang, Y. Mangiferin: An effective therapeutic agent against several disorders (Review). Mol. Med. Rep. 2018, 18, 4775-4786. [CrossRef]

86. Wu, Z.; Chen, Q.; Ke, D.; Li, G.; Deng, W. Emodin protects against diabetic cardiomyopathy by regulating the AKT/GSK-3 $\beta$ signaling pathway in the rat model. Molecules 2014, 19, 14782-14793. [CrossRef]

87. Gao, J.; Wang, F.; Wang, W.; Su, Z.; Guo, C.; Cao, S. Emodin suppresses hyperglycaemia-induced proliferation and fibronectin expression in mesangial cells via inhibiting cFLIP. PLoS ONE 2014, 9, e93588.

88. Hasanein, P.; Mohammad Zaheri, L. Effects of rosmarinic acid on an experimental model of painful diabetic neuropathy in rats. Pharm. Biol. 2014, 52, 1398-1402. [CrossRef]

89. Chang, W.; Chen, L.; Hatch, G.M. Berberine as a therapy for type 2 diabetes and its complications: From mechanism of action to clinical studies. Biochem. Cell Biol. 2015, 93, 479-486. [CrossRef]

90. Prata, C.; Zambonin, L.; Rizzo, B.; Maraldi, T.; Angeloni, C.; Vieceli Dalla Sega, F.; Fiorentini, D.; Hrelia, S. Glycosides from Stevia rebaudiana Bertoni possess insulin-mimetic and antioxidant activities in rat cardiac fibroblasts. Oxid. Med. Cell. Longev. 2017, 2017, 3724545. [CrossRef]

91. Rotimi, S.O.; Rotimi, O.A.; Adelani, I.B.; Onuzulu, C.; Obi, P.; Okungbaye, R. Stevioside modulates oxidative damage in the liver and kidney of high fat/low streptozocin diabetic rats. Heliyon 2018, 4, e00640. [CrossRef]

92. Nagoor Meeran, M.F.; Goyal, S.N.; Suchal, K.; Sharma, C.; Patil, C.R.; Ojha, S.K. Pharmacological properties, molecular mechanisms, and pharmaceutical development of asiatic acid: A pentacyclic triterpenoid of therapeutic promise. Front. Pharmacol. 2018, 9, 892. [CrossRef] [PubMed]

93. Dai, Y.; Wang, Z.; Quan, M.; Lv, Y.; Li, Y.; Xin, H.B.; Qian, Y. Asiatic acid protests against myocardial ischemia/reperfusion injury via modulation of glycometabolism in rat cardiomyocyte. Drug Des. Dev. Ther. 2018, 12, 3573-3582. [CrossRef] [PubMed]

94. Chen, Y.N.; Wu, C.G.; Shi, B.M.; Qian, K.; Ding, Y. The protective effect of asiatic acid on podocytes in the kidney of diabetic rats. Am. J. Transl. Res. 2018, 10, 3733-3741. [PubMed]

95. Kim, A.; Lee, W.; Yun, J.M. Luteolin and fisetin suppress oxidative stress by modulating sirtuins and forkhead box O3a expression under in vitro diabetic conditions. Nutr. Res. Pract. 2017, 11, 430-434. [CrossRef] [PubMed] 
96. Thakur, V.; Nargis, S.; Gonzalez, M.; Pradhan, S.; Terreros, D.; Chattopadhyay, M. Role of glycyrrhizin in the reduction of inflammation in diabetic kidney disease. Nephron 2017, 137, 137-147. [CrossRef]

97. Akutagawa, K.; Fujita, T.; Ouhara, K.; Takemura, T.; Tari, M.; Kajiya, M.; Matsuda, S.; Kuramitsu, S.; Mizuno, N.; Shiba, H.; et al. Glycyrrhizic acid suppresses inflammation and reduces the increased glucose levels induced by the combination of Porphyromonas gulae and ligature placement in diabetic model mice. Int. Immunopharmacol. 2019, 68, 30-38. [CrossRef]

98. Liu, L.; Jiang, Y.; Steinle, J.J. Glycyrrhizin protects the diabetic retina against permeability, neuronal, and vascular damage through anti-inflammatory mechanisms. J. Clin. Med. 2019, 8, 957. [CrossRef]

99. Long, L.; Wang, J.; Lu, X.; Xu, Y.; Zheng, S.; Luo, C.; Li, Y. Protective effects of scutellarin on type II diabetes mellitus-induced testicular damages related to reactive oxygen species/Bcl-2/Bax and reactive oxygen species/microcirculation/staving pathway in diabetic rat. J. Diabetes Res. 2015, 2015, 252530. [CrossRef]

100. Liu, Y.; Wang, J.; Zhang, X.; Wang, L.; Hao, T.; Cheng, Y.; Wang, D. Scutellarin exerts hypoglycaemic and renal protective effects in $\mathrm{db} / \mathrm{db}$ mice via the $\mathrm{Nrf} 2 / \mathrm{HO}-1$ signaling pathway. Oxid. Med. Cell. Longev. 2019, 2019, 1354345.

101. Voroneanu, L.; Nistor, I.; Dumea, R.; Apetrii, M.; Covic, A. Silymarin in type 2 diabetes mellitus: A systematic review and meta-analysis of randomized controlled trials. J. Diabetes Res. 2016, 2016, 5147468. [CrossRef]

102. Patel, S.S.; Goyal, R.K. Cardioprotective effects of gallic acid in diabetes-induced myocardial dysfunction in rats. Pharmacogn. Res. 2011, 3, 239-245.

103. Ramkumar, K.M.; Vijayakumar, R.S.; Vanitha, P.; Suganya, N.; Manjula, C.; Rajaguru, P.; Sivasubramanian, S.; Gunasekaran, P. Protective effect of gallic acid on alloxan-induced oxidative stress and osmotic fragility in rats. Hum. Exp. Toxicol. 2014, 33, 638-649. [CrossRef] [PubMed]

104. Abdel-Moneim, A.; El-Twab, S.M.A.; Ashour, M.B.; Yousef, A.I. Hepato-renal protective effects of gallic acid and p-coumaric acid in nicotinamide/streptozotocin-induced diabetic rats. Int. J. Bioassays 2016, 5, 4641-4649. [CrossRef]

105. Zhu, D.; Wang, L.; Zhou, Q.; Yan, S.; Li, Z.; Sheng, J.; Zhang, W. (+)-Catechin ameliorates diabetic nephropathy by trapping methylglyoxal in type 2 diabetic mice. Mol. Nutr. Food Res. 2014, 58, 2249-2260. [CrossRef]

106. Addepalli, V.; Suryavanshi, S.V. Catechin attenuates diabetic autonomic neuropathy in streptozotocin induced diabetic rats. Biomed. Pharmacother. 2018, 108, 1517-1523. [CrossRef]

107. Sankaranarayanan, C. Thymoquinone, a panacea for diabetic complications-an overview. EC Diabetes Metab. Res. 2019, 3, 120-126.

108. Choi, R.; Kim, B.H.; Naowaboot, J.; Lee, M.Y.; Hyun, M.R.; Cho, E.J.; Lee, E.S.; Lee, E.Y.; Yang, Y.C.; Chung, C.H. Effects of ferulic acid on diabetic nephropathy in a rat model of type 2 diabetes. Exp. Mol. Med. 2011, 43, 676-683. [CrossRef]

109. Song, Y.; Wen, L.; Sun, J.; Bai, W.; Jiao, R.; Hu, Y.; Peng, X.; He, Y.; Ou, S. Cytoprotective mechanism of ferulic acid against high glucose-induced oxidative stress in cardiomyocytes and hepatocytes. Food Nutr. Res. 2016, 60, 30323. [CrossRef]

110. Chowdhury, S.; Ghosh, S.; Das, A.K.; Sil, P.C. Ferulic acid protects hyperglycaemia-induced kidney damage by regulating oxidative insult, inflammation and autophagy. Front. Pharmacol. 2019, 10, 27. [CrossRef]

111. Taghipour, Y.D.; Hajialyani, M.; Naseri, R.; Hesari, M.; Mohammadi, P.; Stefanucci, A.; Mollica, A.; Farzaei, M.H.; Abdollahi, M. Nanoformulations of natural products for management of metabolic syndrome. Int. J. Nanomed. 2019, 14, 5303-5321. [CrossRef]

112. Suresh, K.; Nangia, A. Curcumin: Pharmaceutical solids as a platform to improve solubility and bioavailability. CrystEngComm 2018, 24, 3277-3296. [CrossRef]

113. Ernest, U.; Chen, H.Y.; Xu, M.J.; Taghipour, Y.; Asad, M.; Rahimi, R.; Murtaza, G. Anti-cancerous potential of polyphenol-loaded polymeric nanotherapeutics. Molecules 2018, 23, 2787. [CrossRef] [PubMed]

114. Metzler, M.; Pfeiffer, E.; Schulz, S.I.; Dempe, J.S. Curcumin uptake and metabolism. Biofactors 2013, 39, 14-20. [CrossRef] [PubMed]

115. Peñalva, R.; Morales, J.; González-Navarro, C.J.; Larrañeta, E.; Quincoces, G.; Peñuelas, I.; Irache, J.M. Increased oral bioavailability of resveratrol by its encapsulation in casein nanoparticles. Int. J. Mol. Sci. 2018, 19, 2816. [CrossRef] [PubMed]

116. Chimento, A.; De Amicis, F.; Sirianni, R.; Sinicropi, M.S.; Puoci, F.; Casaburi, I.; Saturnino, C.; Pezzi, V. Progress to improve oral bioavailability and beneficial effects of resveratrol. Int. J. Mol. Sci. 2019, 20, 1381. [CrossRef] 
117. Gera, S.; Talluri, S.; Rangaraj, N.; Sampathi, S. Formulation and evaluation of naringenin nanosuspensions for bioavailability enhancement. AAPS PharmSciTech 2017, 18, 3151-3162. [CrossRef]

118. Song, I.; Cha, J.; Choi, M. Enhanced oral bioavailability of naringenin administered in a mixed micelle formulation with Pluronic F127 and Tween 80 in rats. J. Pharm. Investig. 2015, 45, 633-640. [CrossRef]

119. Jeong, S.M.; Kang, M.J.; Choi, H.N.; Kim, J.H.; Kim, J.I. Quercetin ameliorates hyperglycaemia and dyslipidaemia and improves antioxidant status in type 2 diabetic db/db mice. Nutr. Res. Pract. 2012, 6, 201-207. [CrossRef]

120. Mukhopadhyay, P.; Prajapati, A.K. Quercetin in anti-diabetic research and strategies for improved quercetin bioavailability using polymer-based carriers-A review. RSC Adv. 2015, 5, 97547-97562. [CrossRef]

121. Alshehri, S.M.; Shakeel, F.; Ibrahim, M.A.; Elzayat, E.M.; Altamimi, M.; Mohsin, K.; Almeanazel, O.T.; Alkholief, M.; Alshetaili, A.; Alsulays, B.; et al. Dissolution and bioavailability improvement of bioactive apigenin using solid dispersions prepared by different techniques. Saudi Pharm. J. 2019, 27, 264-273. [CrossRef]

122. Fernandez, S.P.; Nguyen, M.; Yow, T.T.; Chu, C.; Johnston, G.A.R.; Hanrahan, J.R.; Chebib, M. The flavonoid glycosides, myricitrin, gossypin and naringin exert anxiolytic action in mice. Neurochem. Res. 2009, 34, 1867-1875. [CrossRef] [PubMed]

123. Man, N.; Wang, Q.; Li, H.; Adu-Frimpong, M.; Sun, C.; Zhang, K.; Yang, Q.; Wei, Q.; Ji, H.; Toreniyazov, E.; et al. Improved oral bioavailability of myricitrin by liquid self-microemulsifying drug delivery systems. $J$. Drug Deliv. Sci. Technol. 2019, 52, 597-606. [CrossRef]

124. Cui, L.; Sune, E.; Song, J.; Wang, J.; Jia, X.B.; Zhang, Z.H. Characterization and bioavailability study of baicalin-mesoporous carbon nanopowder solid dispersion. Pharmacogn. Mag. 2016, 12, 326-332. [PubMed]

125. Huang, T.; Liu, Y.; Zhang, C. Pharmacokinetics and bioavailability enhancement of baicalin: A Review. Eur. J. Drug Metab. Pharmacokinet. 2019, 44, 159-168. [CrossRef]

126. Sarawek, S.; Derendorf, H.; Butterweck, V. Pharmacokinetics of luteolin and metabolites in rats. Nat. Prod. Commun. 2008, 3, 2019-2036. [CrossRef]

127. Khurana, R.K.; Bansal, A.K.; Beg, S.; Burrow, A.J.; Katare, O.P.; Singh, K.K.; Singh, B. Enhancing biopharmaceutical attributes of phospholipid complex-loaded nanostructured lipidic carriers of mangiferin: Systematic development, characterization and evaluation. Int. J. Pharm. 2017, 518, 289-306. [CrossRef]

128. Tiwari, P.; Mishra, B.N.; Sangwan, N.S. Phytochemical and pharmacological properties of Gymnema sylvestre: An important medicinal plant. Biomed. Res. Int. 2014, 2014, 830285. [CrossRef]

129. Ravichandran, R. Studies on gymnemic acids nanoparticulate formulations against diabetes mellitus. In Nanotechnology: Concepts, Methodologies, Tools, and Applications; IGI Global: Hershey, PA, USA, 2014; pp. 1276-1288.

130. Janković-Tomanić, M.; Todorović, D.; Stanivuković, Z.; Perić Mataruga, V.; Wessjohann, L.A.; Kaluđerović, G.N. Mesoporous silica nanoparticles SBA-15 loaded with emodin upregulate the antioxidative defense of Euproctis chrysorrhoea (L.) larvae. Turk. J. Biol. 2017, 41, 935-942. [CrossRef]

131. Ban, E.; Park, M.; Jeong, S.; Kwon, T.; Kim, E.H.; Jung, K.; Kim, A. Poloxamer-based thermoreversible gel for topical delivery of emodin: Influence of P407 and P188 on solubility of emodin and its application in cellular activity screening. Molecules 2017, 22, 246. [CrossRef]

132. Madureira, A.R.; Nunes, S.; Campos, D.A.; Fernandes, J.C.; Marques, C.; Zuzarte, M.; Gullón, B.; Rodríguez-Alcalá, L.M.; Calhau, C.; Sarmento, B.; et al. Safety profile of solid lipid nanoparticles loaded with rosmarinic acid for oral use: In vitro and animal approaches. Int. J. Nanomed. 2016, 11, 3621-3640.

133. Wang, J.; Li, G.; Rui, T.; Kang, A.; Li, G.; Fu, T.; Li, J.; Di, L.; Cai, B. Pharmacokinetics of rosmarinic acid in rats by LC-MS/MS: Absolute bioavailability and dose proportionality. RSC Adv. 2017, 7, 9057-9063. [CrossRef]

134. Godugu, C.; Patel, A.R.; Doddapaneni, R.; Somagoni, J.; Singh, M. Approaches to improve the oral bioavailability and effects of novel anticancer drugs berberine and betulinic acid. PLoS ONE 2014, 9, e89919. [CrossRef] [PubMed]

135. Liu, C.S.; Zheng, Y.R.; Zhang, Y.F.; Long, X.Y. Research progress on berberine with a special focus on its oral bioavailability. Fitoterapia 2016, 109, 274-282. [CrossRef] [PubMed]

136. Zhang, H.; Wang, X.; Wang, T.; Chen, K.; Wang, H.; Jia, Q.; Li, Y. Enhancement of berberine hypoglycaemic activity by oligomeric proanthocyanidins. Molecules 2018, 23, 3318. [CrossRef] 
137. Tian, X.; Liu, F.; Li, Z.; Lin, Y.; Liu, H.; Hu, P.; Chen, M.; Sun, Z.; Xu, Z.; Zhang, Y.; et al. Enhanced anti-diabetic effect of berberine combined with timosaponin $\mathrm{b} 2$ in goto-kakizaki rats, associated with increased variety and exposure of effective substances through intestinal absorption. Front. Pharmacol. 2019, 10, 19. [CrossRef]

138. Barwal, I.; Sood, A.; Sharma, M.; Singh, B.; Yadav, S.C. Development of stevioside Pluronic-F-68 copolymer based PLA-nanoparticles as an antidiabetic nanomedicine. Colloids Surf. B Biointerfaces 2013, 101, 510-516. [CrossRef]

139. EFSA Panel on Food Additives and Nutrient Sources (ANS). Scientific opinion on safety of steviol glycosides for the proposed uses as a food additive. EFSA J. 2010, 8, 1537. [CrossRef]

140. Bundgaard Anker, C.C.; Rafiq, S.; Jeppesen, P.B. Effect of steviol glycosides on human health with emphasis on type 2 diabetic biomarkers: A systematic review and meta-analysis of randomized controlled trials. Nutrients 2019, 11, 1965. [CrossRef]

141. Lingling, G.; Yuan, Z.; Weigen, L. Preparation, optimization, characterization and in vivo pharmacokinetic study of asiatic acid tromethamine salt-loaded solid lipid nanoparticles. Drug Dev. Ind. Pharm. 2016, 42, 1325-1333. [CrossRef] [PubMed]

142. Jin, S.; Fu, S.; Han, J.; Jin, S.; Lv, Q.; Lu, Y.; Qi, J.; Wu, W.; Yuan, H. Improvement of oral bioavailability of glycyrrhizin by sodium deoxycholate/phospholipid-mixed nanomicelles. J. Drug Target. 2012, 20, 615-622. [CrossRef]

143. Yuan, G.F.; Sinclair, A.J.; Zhou, C.Q.; Li, D. $\alpha$-eleostearic acid is more effectively metabolized into conjugated linoleic acid than punicic acid in mice. J. Sci. Food Agric. 2009, 89, 1006-1011. [CrossRef]

144. Paul, D.; Manna, K.; Sengupta, A.; Mukherjee, S.; Dey, S.; Bag, P.K.; Dhar, P. A novel nanoformulation of $\alpha$-eleostearic acid restores molecular pathogenesis of hypersensitivity. Nanomedicine (Lond.) 2019, 14, 529-552. [CrossRef] [PubMed]

145. Zhou, H.; Wan, J.; Wu, L.; Yi, T.; Liu, W.; Xu, H.; Yang, X. A new strategy for enhancing the oral bioavailability of drugs with poor water-solubility and low liposolubility based on phospholipid complex and supersaturated SEDDS. PLoS ONE 2013, 8, e84530. [CrossRef]

146. Liu, S.; Ho, P.C. Formulation optimization of scutellarin-loaded HP- $\beta-C D / c h i t o s a n$ nanoparticles using response surface methodology with Box-Behnken design. Asian J. Pharm. Sci. 2017, 12, 378-385. [CrossRef] [PubMed]

147. Di Costanzo, A.; Angelico, R. Formulation strategies for enhancing the bioavailability of silymarin: The state of the art. Molecules 2019, 24, 2155. [CrossRef] [PubMed]

148. El-Far, Y.M.; Zakaria, M.M.; Gabr, M.M.; El Gayar, A.M.; El-Sherbiny, I.M.; Eissa, L.A. A newly developed silymarin nanoformulation as a potential antidiabetic agent in experimental diabetes. Nanomedicine (Lond.) 2016, 11, 2581-2602. [CrossRef]

149. de Cristo Soares Alves, A.; Mainardes, R.M.; Khalil, N.M. Nanoencapsulation of gallic acid and evaluation of its cytotoxicity and antioxidant activity. Mater. Sci. Eng. C Mater. Biol. Appl. 2016, 60, 126-134. [CrossRef]

150. Cai, Z.Y.; Li, X.M.; Liang, J.P.; Xiang, L.P.; Wang, K.R.; Shi, Y.L.; Yang, R.; Shi, M.; Ye, J.H.; Lu, J.L.; et al. Bioavailability of tea catechins and its improvement. Molecules 2018, 23, 2346. [CrossRef]

151. El Mohsen, M.A.; Marks, J.; Kuhnle, G.; Moore, K.; Debnam, E.; Kaila Srai, S.; Rice-Evans, C.; Spencer, J.P. Absorption, tissue distribution and excretion of pelargonidin and its metabolites following oral administration to rats. Br. J. Nutr. 2006, 95, 51-58. [CrossRef]

152. Mohammadabadi, M.R.; Mozafari, M.R. Enhanced efficacy and bioavailability of thymoquinone using nanoliposomal dosage form. J. Drug Deliv. Sci. Technol. 2018, 47, 445-453. [CrossRef]

153. Rani, R.; Dahiya, S.; Dhingra, D.; Dilbaghi, N.; Kim, K.H.; Kumar, S. Improvement of antihyperglycaemic activity of nano-thymoquinone in rat model of type-2 diabetes. Chem. Biol. Interact. 2018, 295, 119-132. [CrossRef] [PubMed]

154. Anson, N.M.; den Berg, R.; Havenaar, R.; Bast, A.; Haenen, G.R.M.M. Bioavailability of ferulic acid is determined by its bioaccessibility. J. Cereal Sci. 2009, 49, 296-300. [CrossRef]

155. Panwar, R.; Raghuwanshi, N.; Srivastava, A.K.; Sharma, A.K.; Pruthi, V. In-vivo sustained release of nanoencapsulated ferulic acid and its impact in induced diabetes. Mater. Sci. Eng. C Mater. Biol. Appl. 2018, 92, 381-392. [CrossRef] [PubMed]

156. Zhao, X.; Wang, W.; Zu, Y.; Zhang, Y.; Li, Y.; Sun, W.; Shan, C.; Ge, Y. Preparation and characterization of betulin nanoparticles for oral hypoglycaemic drug by antisolvent precipitation. Drug Deliv. 2014, 21, 467-479. [CrossRef] 
157. Myz, S.A.; Shakhtshneider, T.P.; Mikhailenko, M.A.; Ogienko, A.G.; Bogdanova, E.G.; Ogienko, A.A.; Kuznetsova, S.A.; Boldyreva, E.V.; Boldyrev, V.V. Ultrafine betulin formulation with biocompatible carriers exhibiting improved dissolution rate. Nat. Prod. Commun. 2015, 10, 1345-1347. [CrossRef]

158. Chen, Y.; Ma, Y.; Ma, W. Pharmacokinetics and bioavailability of cinnamic acid after oral administration of Ramulus Cinnamomi in rats. Eur. J. Drug Metab. Pharmacokinet. 2009, 34, 51-56. [CrossRef]

159. Mohamadi, N.; Sharififar, F.; Pournamdari, M.; Ansari, M. A review on biosynthesis, analytical techniques, and pharmacological activities of trigonelline as a plant alkaloid. J. Diet. Suppl. 2018, 15, 207-222. [CrossRef]

160. Zhang, Y.; Fei, F.; Zhen, L.; Zhu, X.; Wang, J.; Li, S.; Geng, J.; Sun, R.; Yu, X.; Chen, T.; et al. Sensitive analysis and simultaneous assessment of pharmacokinetic properties of crocin and crocetin after oral administration in rats. J. Chromatogr. B Anal. Technol. Biomed. Life Sci. 2017, 1044-1045, 1-7. [CrossRef]

161. Yang, X. Design and optimization of crocetin loaded PLGA nanoparticles against diabetic nephropathy via suppression of inflammatory biomarkers: A formulation approach to preclinical study. Drug Deliv. 2019, 26, 849-859. [CrossRef]

162. Feng, H.; Zhu, Y.; Fu, Z.; Li, D. Preparation, characterization, and in vivo study of rhein solid lipid nanoparticles for oral delivery. Chem. Biol. Drug Des. 2017, 90, 867-872. [CrossRef]

163. Luo, J.; Sun, J.; Luo, X.; Wei, Y.; Zheng, H.; Mu, C.; Yao, W. Low molecular weight chitosan-based conjugates for efficient Rhein oral delivery: Synthesis, characterization, and pharmacokinetics. Drug Dev. Ind. Pharm. 2019, 45, 96-104. [CrossRef] [PubMed]

164. Yen, C.C.; Liu, Y.T.; Lin, Y.J.; Yang, Y.C.; Chen, C.C.; Yao, H.T.; Chen, H.W.; Lii, C.K. Bioavailability of the diterpenoid 14-deoxy-11,12-didehydroandrographolide in rats and up-regulation of hepatic drug-metabolizing enzyme and drug transporter expression. Phytomedicine 2019, 61, 152841. [CrossRef] [PubMed]

165. Kadari, A.; Gudem, S.; Kulhari, H.; Bhandi, M.M.; Borkar, R.M.; Kolapalli, V.R.; Sistla, R. Enhanced oral bioavailability and anticancer efficacy of fisetin by encapsulating as inclusion complex with HP $\beta C D$ in polymeric nanoparticles. Drug Deliv. 2017, 24, 224-232. [CrossRef]

166. Grynkiewicz, G.; Demchuk, O.M. New perspectives for fisetin. Front. Chem. 2019, 7, 697. [CrossRef] [PubMed]

167. Mercke Odeberg, J.; Lignell, A.; Pettersson, A.; Höglund, P. Oral bioavailability of the antioxidant astaxanthin in humans is enhanced by incorporation of lipid based formulations. Eur. J. Pharm. Sci. 2003, 19, 299-304. [CrossRef]

168. Rodriguez-Ruiz, V.; Salatti-Dorado, J.Á.; Barzegari, A.; Nicolas-Boluda, A.; Houaoui, A.; Caballo, C.; Caballero-Casero, N.; Sicilia, D.; Bastias Venegas, J.; Pauthe, E.; et al. Astaxanthin-loaded nanostructured lipid carriers for preservation of antioxidant activity. Molecules 2018, 23, 2601. [CrossRef]

169. Ross, A.B.; Vuong le, T.; Ruckle, J.; Synal, H.A.; Schulze-König, T.; Wertz, K.; Rümbeli, R.; Liberman, R.G.; Skipper, P.L.; Tannenbaum, S.R.; et al. Lycopene bioavailability and metabolism in humans: An accelerator mass spectrometry study. Am. J. Clin. Nutr. 2011, 93, 1263-1273. [CrossRef]

170. de Sousa Lobato, K.B.; Paese, K.; Forgearini, J.C.; Guterres, S.S.; Jablonski, A.; de Oliveira Rios, A. Evaluation of stability of bixin in nanocapsules in model systems of photosensitization and heating. LWT Food Sci. Technol. 2015, 60, 8-14. [CrossRef]

171. Amar, I.; Aserin, A.; Garti, N. Solubilization patterns of lutein and lutein esters in food grade nonionic microemulsions. J. Agric. Food Chem. 2003, 51, 4775-4781. [CrossRef]

172. Zhang, L.-H.; Xu, X.-D.; Shao, B.; Shen, Q.; Zhou, H.; Hong, Y.-M.; Yu, L-M. Physicochemical properties and bioavailability of lutein microencapsulation (LM). Food Sci. Technol. Res. 2015, 21, 503-507. [CrossRef]

173. Sun, X.; Xu, Y.; Zhao, L.; Yan, H.; Wang, S.; Wang, D. The stability and bioaccessibility of fucoxanthin in spray-dried microcapsules based on various biopolymers. RSC Adv. 2018, 8, 35139-35149. [CrossRef]

174. Huang, P.K.; Lin, S.X.; Tsai, M.J.; Leong, M.K.; Lin, S.R.; Kankala, R.K.; Lee, C.H.; Weng, C.F. Encapsulation of 16-hydroxycleroda-3,13-dine-16,15-olide in mesoporous silica nanoparticles as a natural dipeptidyl peptidase-4 inhibitor potentiated hypoglycaemia in diabetic mice. Nanomaterials 2017, 7, 112. [CrossRef]

175. Yang, K.M.; Chiang. P.Y. Preparation and evaluation of release formulation of $\gamma$-oryzanol/algae oil self-emulsified with alginate beads. Mar. Drugs 2019, 17, 156. [CrossRef]

176. Patlolla, J.M.R.; Rao, C.V. Anti-inflammatory and anti-cancer properties of $\beta$-escin, a triterpene saponin. Curr. Pharmacol. Rep. 2015, 1, 170-178. [CrossRef] 
177. Ren, Y.S.; Lei, L.; Deng, X.; Zheng, Y.; Li, Y.; Li, J.; Mei, Z.N. Novel application of neural network modelling for multicomponent herbal medicine optimization. Sci. Rep. 2019, 9, 15442. [CrossRef] [PubMed]

178. Libinaki, R.; Gavin, P.D. Changes in bioavailability of omega-3 (DHA) through Alpha-Tocopheryl Phosphate Mixture (TPM) after oral administration in rats. Nutrients 2017, 9, 1042. [CrossRef] [PubMed]

179. Petyaev, I.M.; Chalyk, N.E.; Klochkov, V.A.; Pristensky, D.V.; Chernyshova, M.P.; Kyle, N.H.; Bashmakov, Y.K. Pharmacokinetics and oxidation parameters in volunteers supplemented with microencapsulated docosahexaenoic acid. Int. J. Appl. Basic Med. Res. 2018, 8, 148-154. [PubMed]

180. LaVan, D.A.; Lynn, D.M.; Langer, R. Moving smaller in drug discovery and delivery. Nat. Rev. Drug Discov. 2002, 1, 77. [CrossRef]

181. Boulaiz, H.; Alvarez, P.J.; Ramirez, A.; Marchal, J.A.; Prados, J.; Rodríguez-Serrano, F.; Perán, M.; Melguizo, C.; Aranega, A. Nanomedicine: Application areas and development prospects. Int. J. Mol. Sci. 2011, 12, 3303-3321. [CrossRef]

182. Din, F.U.; Aman, W.; Ullah, I.; Qureshi, O.S.; Mustapha, O.; Shafique, S.; Zeb, A. Effective use of nanocarriers as drug delivery systems for the treatment of selected tumors. Int. J. Nanomed. 2017, 12, 7291-7309. [CrossRef]

183. Khursheed, R.; Singh, S.K.; Wadhwa, S.; Kapoor, B.; Gulati, M.; Kumar, R.; Ramanunny, A.K.; Awasthi, A.; Dua, K. Treatment strategies against diabetes: Success so far and challenges ahead. Eur. J. Pharmacol. 2019, 862, 172625. [CrossRef]

184. Hu, C.; Jia, W. Therapeutic medications against diabetes: What we have and what we expect. Adv. Drug Deliv. Rev. 2019, 139, 3-15. [CrossRef]

185. Kumar, P.; Kim, K.H.; Bansal, V.; Kumar. S.; Dilbaghi, N.; Kim, Y.H. Modern progress and future challenges in nanocarriers for probe applications. TrAC Trend. Anal. Chem. 2017, 86, 235-250. [CrossRef]

186. Veiseh, O.; Tang, B.C.; Whitehead, K.A.; Anderson, D.G.; Langer, R. Managing diabetes with nanomedicine: Challenges and opportunities. Nat. Rev. Drug Discov. 2015, 14, 45. [CrossRef]

187. des Rieux, A.; Fievez, V.; Garinot, M.; Schneider, Y.J.; Préat, V. Nanoparticles as potential oral delivery systems of proteins and vaccines: A mechanistic approach. J. Control. Release 2006, 116, 1-27. [CrossRef]

188. Chakraborty, S.; Dile, Z.; Chakraborty, S.; Roy, S.; Mukherjee, B.; Besra, S.E.; Dewanjee, S.; Mukherjee, A.; Ojha, P.K.; Kumar, V.; et al. Aptamer-functionalized drug-nanocarrier improves hepatocellular carcinoma towards normal by targeting neoplastic hepatocytes. Mol. Ther. Nucleic Acids 2020. [CrossRef]

189. Allam, A.N.; Komeil, I.A.; Fouda, M.A.; Abdallah, O.Y. Preparation, characterization and in vivo evaluation of curcumin self-nano phospholipid dispersion as an approach to enhance oral bioavailability. Int. J. Pharm. 2015, 489, 117-123. [CrossRef]

190. Gouda, W.; Hafiz, N.A.; Mageed, L.; Alazzouni, A.S.; Khalil, W.K.; Afify, M.; Abdelmaksoud, M.D. Effects of nano-curcumin on gene expression of insulin and insulin receptor. Bull. Natl. Res. Cent. 2019, 43, 128. [CrossRef]

191. Raslan, M.M.; Mohamed, S.; Abd El Maksoud, M.D.E.; El Nesr, K. Role of curcumin-zinc oxide composite nanoparticles on streptozotocin-induced diabetic rats. J. Biotechnol. Biomater. 2018, 8, 55.

192. Tong, F.; Chai, R.; Jiang, H.; Dong, B. In vitro/vivo drug release and anti-diabetic cardiomyopathy properties of curcumin/PBLG-PEG-PBLG nanoparticles. Int. J. Nanomed. 2018, 13, 1945. [CrossRef]

193. Xie, X.; Tao, Q.; Zou, Y.; Zhang, F.; Guo, M.; Wang, Y.; Wang, H.; Zhou, Q.; Yu, S. PLGA nanoparticles improve the oral bioavailability of curcumin in rats: Characterizations and mechanisms. J. Agric. Food Chem. 2011, 59, 9280-9289. [CrossRef]

194. Joshi, R.P.; Negi, G.; Kumar, A.; Pawar, Y.B.; Munjal, B.; Bansal, A.K.; Sharma, S.S. SNEDDS curcumin formulation leads to enhanced protection from pain and functional deficits associated with diabetic neuropathy: An insight into its mechanism for neuroprotection. Nanomedicine 2013, 9, 776-785. [CrossRef]

195. Grama, C.N.; Suryanarayana, P.; Patil, M.A.; Raghu, G.; Balakrishna, N.; Kumar, M.R.; Reddy, G.B. Efficacy of biodegradable curcumin nanoparticles in delaying cataract in diabetic rat model. PLoS ONE 2013, 8, e78217. [CrossRef]

196. El-Far, Y.M.; Zakaria, M.M.; Gabr, M.M.; El Gayar, A.M.; Eissa, L.A.; El-Sherbiny, I.M. Nanoformulated natural therapeutics for management of streptozotocin-induced diabetes: Potential use of curcumin nanoformulation. Nanomedicine 2017, 12, 1689-1711. [CrossRef]

197. Devadasu, V.R.; Wadsworth, R.M.; Kumar, M.R. Protective effects of nanoparticulate coenzyme Q 10 and curcumin on inflammatory markers and lipid metabolism in streptozotocin-induced diabetic rats: A possible remedy to diabetic complications. Drug Deliv. Transl. Res. 2011, 1, 448-455. [CrossRef] 
198. Jia, T.; Rao, J.; Zou, L.; Zhao, S.; Yi, Z.; Wu, B.; Li, L.; Yuan, H.; Shi, L.; Zhang, C.; et al. Nanoparticleencapsulated curcumin inhibits diabetic neuropathic pain involving the P2Y12 receptor in the dorsal root ganglia. Front. Neurosci. 2018, 11, 755. [CrossRef]

199. El-Naggar, M.E.; Al-Joufi, F.; Anwar, M.; Attia, M.F.; El-Bana, M.A. Curcumin-loaded PLA-PEG copolymer nanoparticles for treatment of liver inflammation in streptozotocin-induced diabetic rats. Colloids Surf. B Biointerfaces 2019, 177, 389-398. [CrossRef]

200. Chauhan, P.; Tamrakar, A.K.; Mahajan, S.; Prasad, G.B.K.S. Chitosan encapsulated nanocurcumin induces GLUT-4 translocation and exhibits enhanced anti-hyperglycaemic function. Life Sci. 2018, 213, 226-235. [CrossRef]

201. Kamar, S.S.; Abdel-Kader, D.H.; Rashed, L.A. Beneficial effect of Curcumin Nanoparticles-Hydrogel on excisional skin wound healing in type-I diabetic rat: Histological and immunohistochemical studies. Ann. Anat. 2019, 222, 94-102. [CrossRef]

202. Liu, J.; Chen, Z.; Wang, J.; Li, R.; Li, T.; Chang, M.; Yan, F.; Wang, Y. Encapsulation of curcumin nanoparticles with MMP9-responsive and thermos-sensitive hydrogel improves diabetic wound healing. ACS Appl. Mater. Interfaces 2018, 10, 16315-16326. [CrossRef]

203. Katas, H.; Wen, C.Y.; Siddique, M.I.; Hussain, Z.; Mohd Fadhil, F.H. Thermoresponsive curcumin/DsiRNA nanoparticle gels for the treatment of diabetic wounds: Synthesis and drug release. Ther. Deliv. 2017, 8, 137-150. [CrossRef]

204. Karri, V.V.; Kuppusamy, G.; Talluri, S.V.; Mannemala, S.S.; Kollipara, R.; Wadhwani, A.D.; Mulukutla, S.; Raju, K.R.; Malayandi, R. Curcumin loaded chitosan nanoparticles impregnated into collagen-alginate scaffolds for diabetic wound healing. Int. J. Biol. Macromol. 2016, 93, 1519-1529. [CrossRef]

205. Yallapu, M.M.; Nagesh, P.K.; Jaggi, M.; Chauhan, S.C. Therapeutic applications of curcumin nanoformulations. AAPS J. 2015, 17, 1341-1356. [CrossRef]

206. Rahimi, H.R.; Mohammadpour, A.H.; Dastani, M.; Jaafari, M.R.; Abnous, K.; Mobarhan, M.G.; Oskuee, R.K. The effect of nano-curcumin on $\mathrm{HbA1c}$, fasting blood glucose, and lipid profile in diabetic subjects: A randomized clinical trial. Avicenna J. Phytomed. 2016, 6, 567-577.

207. Na, L.X.; Li, Y.; Pan, H.Z.; Zhou, X.L.; Sun, D.J.; Meng, M.; Li, X.X.; Sun, C.H. Curcuminoids exert glucose-lowering effect in type 2 diabetes by decreasing serum free fatty acids: A double-blind, placebo-controlled trial. Mol. Nutr. Food Res. 2013, 57, 1569-1577. [CrossRef]

208. Santos, A.C.; Veiga, F.J.; Sequeira, J.A.D.; Fortuna, A.; Falcão, A.; Pereira, I.; Pattekari, P.; Fontes-Ribeiro, C.; Ribeiro, A.J. First-time oral administration of resveratrol-loaded layer-by-layer nanoparticles to rats-a pharmacokinetics study. Analyst 2019, 144, 2062-2079. [CrossRef]

209. Yücel, Ç.; Karatoprak, G.Ş.; Aktaş, Y. Nanoliposomal resveratrol as a novel approach to treatment of diabetes mellitus. J. Nanosci. Nanotechnol. 2018, 18, 3856-3864. [CrossRef]

210. Yücel, Ç.; Karatoprak, G.Ş.; Atmar, A. Novel resveratrol-loaded nanocochleates and effectiveness in the treatment of diabetes. Fabad J. Pharm. Sci. 2018, 43, 35-44.

211. Al-Bishri, W.M. Attenuating impacts of chromium and nano resveratrol against hyperglycaemia induced oxidative stress in diabetic rats. Int. J. Pharm. Res. Allied Sci. 2017, 6, 61-69.

212. Mohseni, R.; ArabSadeghabadi, Z.; Ziamajidi, N.; Abbasalipourkabir, R.; RezaeiFarimani, A. Oral administration of resveratrol-loaded solid lipid nanoparticle improves insulin resistance through targeting expression of SNARE proteins in adipose and muscle tissue in rats with type 2 diabetes. Nanoscale Res. Lett. 2019, 14, 227. [CrossRef]

213. Wan, S.; Zhang, L.; Quan, Y.; Wei, K. Resveratrol-loaded PLGA nanoparticles: Enhanced stability, solubility and bioactivity of resveratrol for non-alcoholic fatty liver disease therapy. R. Soc. Open Sci. 2018, 5, 181457. [CrossRef]

214. Siu, F.Y.; Ye, S.; Lin, H.; Li, S. Galactosylated PLGA nanoparticles for the oral delivery of resveratrol: Enhanced bioavailability and in vitro anti-inflammatory activity. Int. J. Nanomed. 2018, 13, 4133-4144. [CrossRef]

215. Dong, Y.; Wan, G.; Yan, P.; Qian, C.; Li, F.; Peng, G. Fabrication of resveratrol coated gold nanoparticles and investigation of their effect on diabetic retinopathy in streptozotocin induced diabetic rats. J. Photochem. Photobiol. B 2019, 195, 51-57. [CrossRef]

216. Khan, A.W.; Kotta, S.; Ansari, S.H.; Sharma, R.K.; Ali, J. Self-nanoemulsifying drug delivery system (SNEDDS) of the poorly water-soluble grapefruit flavonoid Naringenin: Design, characterization, in vitro and in vivo evaluation. Drug Deliv. 2015, 22, 552-561. [CrossRef] 
217. Chaurasia, S.; Patel, R.R.; Vure, P.; Mishra, B. Oral naringenin nanocarriers: Fabrication, optimization, pharmacokinetic and chemotherapeutic efficacy assessments. Nanomedicine (Lond.) 2017, 12, 1243-1260. [CrossRef]

218. Wang, Y.; Wang, S.; Firempong, C.K.; Zhang, H.; Wang, M.; Zhang, Y.; Zhu, Y.; Yu, J.; Xu, X. Enhanced solubility and bioavailability of naringenin via liposomal nanoformulation: Preparation and in vitro and in vivo evaluations. AAPS PharmSciTech 2017, 18, 586-594. [CrossRef]

219. Ganesan, P.; Arulselvan, P.; Choi, D.K. Phytobioactive compound-based nanodelivery systems for the treatment of type 2 diabetes mellitus-current status. Int. J. Nanomed. 2017, 12, 1097-1111. [CrossRef]

220. Maity, S.; Mukhopadhyay, P.; Kundu, P.P.; Chakraborti, A.S. Alginate coated chitosan core-shell nanoparticles for efficient oral delivery of naringenin in diabetic animals-An in vitro and in vivo approach. Carbohydr. Polym. 2017, 170, 124-132. [CrossRef]

221. Chitkara, D.; Nikalaje, S.K.; Mittal, A.; Chand, M.; Kumar, N. Development of quercetin nanoformulation and in vivo evaluation using streptozotocin induced diabetic rat model. Drug Deliv. Transl. Res. 2012, 2, 112-123. [CrossRef]

222. Alam, M.M.; Abdullah, K.M.; Singh, B.R.; Naqvi, A.H.; Naseem, I. Ameliorative effect of quercetin nanorods on diabetic mice: Mechanistic and therapeutic strategies. RSC Adv. 2016, 6, 55092-55103. [CrossRef]

223. Li, H.; Zhao, X.; Ma, Y.; Zhai, G.; Li, L.; Lou, H. Enhancement of gastrointestinal absorption of quercetin by solid lipid nanoparticles. J. Control. Release 2009, 133, 238-244. [CrossRef]

224. Mukhopadhyay, P.; Maity, S.; Mandal, S.; Chakraborti, A.S.; Prajapati, A.K.; Kundu, P.P. Preparation, characterization and in vivo evaluation of $\mathrm{pH}$ sensitive, safe quercetin-succinylated chitosan-alginate core-shell-corona nanoparticle for diabetes treatment. Carbohydr. Polym. 2018, 182, 42-51. [CrossRef]

225. Singh, J.; Mittal, P.; Vasant Bonde, G.; Ajmal, G.; Mishra, B. Design, optimization, characterization and in-vivo evaluation of Quercetin enveloped Soluplus ${ }^{\circledR} / \mathrm{P} 407$ micelles in diabetes treatment. Artif. Cells Nanomed. Biotechnol. 2018, 46, S546-S555. [CrossRef]

226. Ebrahimpour, S.; Esmaeili, A.; Beheshti, S. Effect of quercetin-conjugated superparamagnetic iron oxide nanoparticles on diabetes-induced learning and memory impairment in rats. Int. J. Nanomed. 2018, 13, 6311-6324. [CrossRef]

227. Zhang, Z.; Cui, C.; Wei, F.; Lv, H. Improved solubility and oral bioavailability of apigenin via soluplus/pluronic F127 binary mixed micelles system. Drug Dev. Ind. Pharm. 2017, 43, 1276-1282. [CrossRef]

228. Ding, S.M.; Zhang, Z.H.; Song, J.; Cheng, X.D.; Jiang, J.; Jia, X.B. Enhanced bioavailability of apigenin via preparation of a carbon nanopowder solid dispersion. Int. J. Nanomed. 2014, 9, 2327-2333. [CrossRef]

229. Zhang, Y. Effect of apigenin-loaded nanoliposomes on myocardial cells apoptosis induced by diabetic cardiomyopathy. Her. Med. 2019, 38, 555-559.

230. Chen, H.; Gao, Y.; Wu, J.; Chen, Y.; Chen, B.; Hu, J.; Zhou, J. Exploring therapeutic potentials of baicalin and its aglycone baicalein for hematological malignancies. Cancer Lett. 2014, 354, 5-11. [CrossRef]

231. Wei, Y.; Guo, J.; Zheng, X.; Wu, J.; Zhou, Y.; Yu, Y.; Ye, Y.; Zhang, L.; Zhao, L. Preparation, pharmacokinetics and biodistribution of baicalin-loaded liposomes. Int. J. Nanomed. 2014, 9, 3623-3630.

232. Shi, F.; Wei, Z.; Zhao, Y.; Xu, X. Nanostructured lipid carriers loaded with baicalin: An efficient carrier for enhanced antidiabetic effects. Pharmacogn. Mag. 2016, 12, 198-202.

233. Puhl, A.C.; Fagundes, M.; dos Santos, K.C.; Polikarpov, I.; das Graças, M.F.; da Silva, F.; Fernandes, J.B.; Vieira, P.C.; Forim, M.R. Preparation and characterization of polymeric nanoparticles loaded with the flavonoid luteolin, by using factorial design. Int. J. Drug Deliv. 2011, 3, 683-698.

234. Majumdar, D.; Jung, K.H.; Zhang, H.; Nannapaneni, S.; Wang, X.; Amin, A.R.; Chen, Z.; Chen, Z.G.; Shin, D.M. Luteolin nanoparticle in chemoprevention: In vitro and in vivo anticancer activity. Cancer Prev. Res. (Phila.) 2014, 7, 65-73. [CrossRef]

235. Dang, H.; Meng, M.H.W.; Zhao, H.; Iqbal, J.; Dai, R.; Deng, Y.; Lv, F. Luteolin-loaded solid lipid nanoparticles synthesis, characterization, \& improvement of bioavailability, pharmacokinetics in vitro and vivo studies. J. Nanopart. Res. 2014, 16, 2347.

236. Samadarsi, R.; Dutta, D. Design and characterization of mangiferin nanoparticles for oral delivery. J. Food. Eng. 2019, 247, 80-94. [CrossRef]

237. Ravichandran, R. Physico-chemical evaluation of gymnemic acids nanocrystals. Int. J. Nanopart. 2010, 3, 280-296. [CrossRef] 
238. Ravichandran, R. Formulation of nanosuspensions of gymnemic acids for oral administration. Int. J. Nanopart. 2010, 3, 309-324. [CrossRef]

239. Rajarajeshwari, T.; Shivashria, C.; Rajasekar, P. Synthesis and characterization of biocompatible gymnemic acid-gold nanoparticles: A study on glucose uptake stimulatory effect in 3T3-L1 adipocytes. RSC Adv. 2014, 4, 63285-63295. [CrossRef]

240. Senthilnathan, B.; Vivekanandan, K.; Bhavya, E.; Masilamani; Swarna, P. B. Impact of nanoparticulate drug delivery system of herbal drug in control of diabetes mellitus. Res. J. Pharm. Technol. 2019, 12, 1688-1694. [CrossRef]

241. Shi, Y.; Li, J.; Ren, Y.; Wang, H.; Cong, Z.; Wu, G.; Du, L.; Li, H.; Zhang, X. Pharmacokinetics and tissue distribution of emodin loaded nanoemulsion in rats. J. Drug Deliv. Sci. Technol. 2015, 30, 242-249. [CrossRef]

242. Li, L.; Sheng, X.; Zhao, S.; Zou, L.; Han, X.; Gong, Y.; Yuan, H.; Shi, L.; Guo, L.; Jia, T.; et al. Nanoparticle-encapsulated emodin decreases diabetic neuropathic pain probably via a mechanism involving P2X3 receptor in the dorsal root ganglia. Purinergic Signal. 2017, 13, 559-568. [CrossRef]

243. Kuo, Y.-C.; Tsai, H-C. Rosmarinic acid and curcumin-loaded polyacrylamide-cardiolipin-poly(lactide -co-glycolide) nanoparticles with conjugated 83-14 monoclonal antibody to protect $\beta$-amyloid-insulted neurons. J. Alzheimers Dis. Parkinsonism. 2018, 8, 41. [CrossRef]

244. Kuo, Y.-C.; Rajesh, R. Targeted delivery of rosmarinic acid across the blood-brain barrier for neuronal rescue using polyacrylamide-chitosan-poly(lactide-co-glycolide) nanoparticles with surface cross-reacting material 197 and apolipoprotein E. Int. J. Pharm. 2017, 528, 228-241. [CrossRef]

245. Grote, C.W.; Wright, D.E. A role for insulin in diabetic neuropathy. Front. Neurosci. 2016, 10, 581. [CrossRef] [PubMed]

246. Campos, D.A.; Madureira, A.R.; Gomes, A.M.; Sarmento, B.; Pintado, M.M. Optimization of the production of solid Witepsol nanoparticles loaded with rosmarinic acid. Colloids Surf. B Biointerfaces 2014, 115, 109-117. [CrossRef] [PubMed]

247. da Silva, S.B.; Ferreira, D.; Pintado, M.; Sarmento, B. Chitosan-based nanoparticles for rosmarinic acid ocular delivery-in vitro tests. Int. J. Biol. Macromol. 2016, 84, 112-120. [CrossRef]

248. Wani, T.U.; Raza, S.N.; Khan, N.A. Rosmarinic acid loaded chitosan nanoparticles for wound healing in rats. Int. J. Pharm. Sci. Res. 2019, 10, 1126-1135.

249. Li, Z.; Zheng, J.; Zhang, N.; Li, C. Berberine improves airway inflammation and inhibits NF-кB signaling pathway in an ovalbumin-induced rat model of asthma. J. Asthma 2016, 53, 999-1005. [CrossRef]

250. Nguyen, T.X.; Huang, L.; Liu, L.; Abdalla, A.M.E.; Gauthier, M.; Yang, G. Chitosan-coated nano-liposomes for the oral delivery of berberine hydrochloride. J. Mater. Chem. B 2014, 2, 7149-7159. [CrossRef]

251. Gupta, L.; Sharma, A.K.; Gothwal, A.; Khan, M.S.; Khinchi, M.P.; Qayum, A.; Singh, S.K.; Gupta, U. Dendrimer encapsulated and conjugated delivery of berberine: A novel approach mitigating toxicity and improving in vivo pharmacokinetics. Int. J. Pharm. 2017, 528, 88-99. [CrossRef]

252. Yu, F.; Ao, M.; Zheng, X.; Li, N.; Xia, J.; Li, Y.; Li, D.; Hou, Z.; Qi, Z.; Chen, X.D. PEG-lipid-PLGA hybrid nanoparticles loaded with berberine-phospholipid complex to facilitate the oral delivery efficiency. Drug Deliv. 2017, 24, 825-833. [CrossRef]

253. Wang, T.; Wang, N.; Song, H.; Xi, X.; Wang, J.; Hao, A.; Li, T. Preparation of an anhydrous reverse micelle delivery system to enhance oral bioavailability and anti-diabetic efficacy of berberine. Eur. J. Pharm. Sci. 2011, 44, 127-135. [CrossRef]

254. Xue, M.; Yang, M.X.; Zhang, W.; Li, X.M.; Gao, D.H.; Ou, Z.M.; Li, Z.P.; Liu, S.H.; Li, X.J.; Yang, S.Y. Characterization, pharmacokinetics, and hypoglycaemic effect of berberine loaded solid lipid nanoparticles. Int. J. Nanomed. 2013, 8, 4677-4687. [CrossRef]

255. Xue, M.; Zhang, L.; Yang, M.X.; Zhang, W.; Li, X.M.; Ou, Z.M.; Li, Z.P.; Liu, S.H.; Li, X.J.; Yang, S.Y. Berberine-loaded solid lipid nanoparticles are concentrated in the liver and ameliorate hepatosteatosis in db/db mice. Int. J. Nanomed. 2015, 10, 5049-5057. [CrossRef]

256. Kapoor, R.; Singh, S.; Tripathi, M.; Bhatnagar, P.; Kakkar, P.; Gupta, K.C. O-hexadecyl-dextran entrapped berberine nanoparticles abrogate high glucose stress induced apoptosis in primary rat hepatocytes. PLoS ONE 2014, 9, e89124.2. [CrossRef]

257. Wang, Z.; Wu, J.; Zhou, Q.; Wang, Y.; Chen, T. Berberine nanosuspension enhances hypoglycaemic efficacy on streptozotocin induced diabetic C57BL/6 mice. Evid. Based Complement. Altern. Med. 2015, 2015, 239749. 
258. Yin, J.; Hou, Y.; Yin, Y.; Song, X. Selenium-coated nanostructured lipid carriers used for oral delivery of berberine to accomplish a synergic hypoglycaemic effect. Int. J. Nanomed. 2017, 12, 8671-8680. [CrossRef] [PubMed]

259. Barwal, I.; Yadav, S.C. Rebaudioside A loaded PLA-nanoparticles as an anti-diabetic nanomedicine. J. Bionanosci. 2014, 8, 137-140. [CrossRef]

260. Hou, Y.; Wang, H.; Zhang, F.; Sun, F.; Xin, M.; Li, M.; Li, J.; Wu, X. Novel self-nanomicellizing solid dispersion based on rebaudioside A: A potential nanoplatform for oral delivery of curcumin. Int. J. Nanomed. 2019, 14, 557-571. [CrossRef] [PubMed]

261. Zhang, Y.W.; Yin, L.N.; Huang, X.Y.; Liang, Z.H.; Chen, X.X.; Wang, S.H. Oral absorption of asiatic acid nanoparticles modified with PEG. Zhongguo Zhong Yao Za Zhi 2017, 42, 2784-2788.

262. Radwant, M.A.; Aboul-Enein, H.Y. The effect of oral absorption enhancers on the in vivo performance of insulin-loaded poly(ethylcyanoacrylate) nanospheres in diabetic rats. J. Microencapsul. 2002, 19, 225-235. [CrossRef]

263. Rani, R.; Dahiya, S.; Dhingra, D.; Dilbaghi, N.; Kim, K.H.; Kumar, S. Evaluation of anti-diabetic activity of glycyrrhizin-loaded nanoparticles in nicotinamide-streptozotocin-induced diabetic rats. Eur. J. Pharm. Sci. 2017, 106, 220-230. [CrossRef] [PubMed]

264. Rani, R.; Dahiya, S.; Dhingra, D.; Dilbaghi, N.; Kaushik, A.; Kim, K.H.; Kumar, S. Antidiabetic activity enhancement in streptozotocin + nicotinamide-induced diabetic rats through combinational polymeric nanoformulation. Int. J. Nanomed. 2019, 14, 4383-4395. [CrossRef] [PubMed]

265. Paul, D.; Dey, T.K.; Mukherjee, S.; Ghosh, M.; Dhar, P. Comparative prophylactic effects of $\alpha$-eleostearic acid rich nano and conventional emulsions in induced diabetic rats. J. Food Sci. Technol. 2014, 51, 1724-1736. [CrossRef] [PubMed]

266. Paul, D.; Mukherjee, S.; Chakraborty, R.; Mallick, S.K.; Dhar, P. Comparative real-time study of cellular uptake of a formulated conjugated linolenic acid rich nano and conventional macro emulsions and their bioactivity in ex vivo models for parenteral applications. Colloids Surf. B Biointerfaces 2015, 126, 426-436. [CrossRef]

267. Wei, Y.; Li, L.; Xi, Y.; Qian, S.; Gao, Y.; Zhang, J. Sustained release and enhanced bioavailability of injectable scutellarin-loaded bovine serum albumin nanoparticles. Int. J. Pharm. 2014, 476, 142-148. [CrossRef]

268. Wang, J.; Tan, J.; Luo, J.; Huang, P.; Zhou, W.; Chen, L.; Long, L.; Zhang, L.M.; Zhu, B.; Yang, L.; et al. Enhancement of scutellarin oral delivery efficacy by vitamin B12-modified amphiphilic chitosan derivatives to treat type II diabetes induced-retinopathy. J. Nanobiotechnol. 2017, 15, 18. [CrossRef]

269. Das, S.; Roy, P.; Pal, R.; Auddy, R.G.; Chakraborti, A.S.; Mukherjee, A. Engineered silybin nanoparticles educe efficient control in experimental diabetes. PLoS ONE 2014, 9, e101818. [CrossRef]

270. Javed, S.; Kohli, K.; Ali, M. Reassessing bioavailability of silymarin. Altern. Med. Rev. 2011, 16, $239-249$.

271. Piazzini, V.; D'Ambrosio, M.; Luceri, C.; Cinci, L.; Landucci, E.; Bilia, A.R.; Bergonzi, M.C. Formulation of nanomicelles to improve the solubility and the oral absorption of silymarin. Molecules 2019, $24,1688$. [CrossRef]

272. Shangguan, M.; Qi, J.; Lu, Y.; Wu, W. Comparison of the oral bioavailability of silymarin-loaded lipid nanoparticles with their artificial lipolysate counterparts: Implications on the contribution of integral structure. Int. J. Pharm. 2015, 489, 195-202. [CrossRef]

273. Xie, Y.; Yi, Y.; Hu, X.; Shangguan, M.; Wang, L.; Lu, Y.; Qi, J.; Wu, W. Synchronous microencapsulation of multiple components in silymarin into PLGA nanoparticles by an emulsification/solvent evaporation method. Pharm. Dev. Technol. 2016, 21, 672-679. [CrossRef] [PubMed]

274. Piazzini, V.; Cinci, L.; D’Ambrosio, M.; Luceri, C.; Bilia, A.R.; Bergonzi, M.C. Solid lipid nanoparticles and chitosan-coated solid lipid nanoparticles as promising tool for silybin delivery: Formulation, characterization, and in vitro evaluation. Curr. Drug Deliv. 2019, 16, 142-152. [CrossRef] [PubMed]

275. Tan, J.M.; Karthivashan, G.; Arulselvan, P.; Fakuraz, S.; Hussein, M.Z. Characterization and in vitro sustained release of silibinin from $\mathrm{pH}$ responsive carbon nanotube-based drug delivery system. J. Nanomater. 2014, $2014,439873$.

276. Мa, Y.; He, H.; Xia, F.; Li, Y.; Lu, Y.; Chen, D.; Qi, J.; Lu, Y.; Zhang, W.; Wu, W. In vivo fate of lipid-silybin conjugate nanoparticles: Implications on enhanced oral bioavailability. Nanomedicine 2017, 13, 2643-2654. [CrossRef] 
277. Nagpal, K.; Singh, S.K.; Mishra, D.N. Nanoparticle mediated brain targeted delivery of gallic acid: In vivo behavioral and biochemical studies for protection against scopolamine-induced amnesia. Drug Deliv. 2013, 20, 112-119. [CrossRef]

278. Martakov, I.S.; Shevchenko, O.G.; Torlopov, M.A.; Gerasimov, E.Y.; Sitnikov, P.A. Formation of gallic acid layer on $\gamma$-AlOOH nanoparticles surface and their antioxidant and membrane-protective activity. J. Inorg. Biochem. 2019, 199, 110782. [CrossRef]

279. Purbowatiningrum; Ngadiwiyana; Ismiyarto; Fachriyah, E.; Eviana, I.; Eldiana, O.; Amaliyah, N.; Sektianingrum, A.N. Antidiabetic activity from gallic acid encapsulated nanochitosan. IOP Conf. Ser. Mater. Sci. Eng. 2017, 172, 012042. [CrossRef]

280. Zhang, Y.; Zhang, L.; Ban, Q.; Li, J.; Li, C.H.; Guan, Y.Q. Preparation and characterization of hydroxyapatite nanoparticles carrying insulin and gallic acid for insulin oral delivery. Nanomedicine 2018, 14, 353-364. [CrossRef]

281. Yadav, R.; Kumar, D.; Kumari, A.; Yadav, S.K. Encapsulation of catechin and epicatechin on BSA NPS improved their stability and antioxidant potential. EXCLI J. 2014, 13, 331-346.

282. Samanta, A.; Bandopadhyay, B.; Das, N. Formulation of catechin hydrate nanocapsule and study of its bioavailability. Med. Chem. 2016, 6, 6. [CrossRef]

283. Liang, J.; Yan, H.; Puligunda, P.; Gao, X.; Zhou, Y.; Wan, X. Applications of chitosan nanoparticles to enhance absorption and bioavailability of tea polyphenols: A review. Food Hydrocoll. 2017, 69, 286-292. [CrossRef]

284. Granja, A.; Frias, I.; Neves, A.R.; Pinheiro, M.; Reis, S. Therapeutic potential of epigallocatechin gallate nanodelivery systems. Biomed. Res. Int. 2017, 2017, 5813793. [CrossRef] [PubMed]

285. Sistanipour, E.; Meshkini, A.; Oveisi, H. Catechin-conjugated mesoporous hydroxyapatite nanoparticle: A novel nano-antioxidant with enhanced osteogenic property. Colloids Surf. B Biointerfaces 2018, 169, 329-339. [CrossRef] [PubMed]

286. Liu, J.; Lu, J.F.; Kan, J.; Wen, X.Y.; Jin, C.H. Synthesis, characterization and in vitro anti-diabetic activity of catechin grafted inulin. Int. J. Biol. Macromol. 2014, 64, 76-83. [CrossRef] [PubMed]

287. Zhu, W.; Zhang, Z. Preparation and characterization of catechin-grafted chitosan with antioxidant and antidiabetic potential. Int. J. Biol. Macromol. 2014, 70, 150-155. [CrossRef] [PubMed]

288. Frias, I.; Neves, A.R.; Pinheiro, M.; Reis, S. Design, development, and characterization of lipid nanocarriers-based epigallocatechin gallate delivery system for preventive and therapeutic supplementation. Drug Des. Dev. Ther. 2016, 10, 3519-3528. [CrossRef]

289. Hu, B.; Ting, Y.; Zeng, X.; Huang, Q. Bioactive peptides/chitosan nanoparticles enhance cellular antioxidant activity of (-)-epigallocatechin-3-gallate. J. Agric. Food Chem. 2013, 61, 875-881. [CrossRef]

290. Fangueiro, J.F.; Calpena, A.C.; Clares, B.; Andreani, T.; Egea, M.A.; Veiga, F.J.; Garcia, M.L.; Silva, A.M.; Souto, E.B. Biopharmaceutical evaluation of epigallocatechin gallate-loaded cationic lipid nanoparticles (EGCG-LNs): In vivo, in vitro and ex vivo studies. Int. J. Pharm. 2016, 502, 161-169. [CrossRef]

291. Chang, C.Y.; Wang, M.C.; Miyagawa, T.; Chen, Z.Y.; Lin, F.H.; Chen, K.H.; Liu, G.S.; Tseng, C.L. Preparation of arginine-glycine-aspartic acid-modified biopolymeric nanoparticles containing epigalloccatechin-3-gallate for targeting vascular endothelial cells to inhibit corneal neovascularization. Int. J. Nanomed. 2016, 12, 279-294. [CrossRef]

292. Roy, M.; Sen, S.; Chakraborti, A.S. Pelargonidin-PLGA nanoparticles: Fabrication, characterization, and their effect on streptozotocin induced diabetic rats. Ind. J. Exp. Biol. 2017, 55, 819-830.

293. Samadder, A.; Abraham, S.K.; Khuda-Bukhsh, A.R. Nanopharmaceutical approach using pelargonidin towards enhancement of efficacy for prevention of alloxan-induced DNA damage in L6 cells via activation of PARP and p53. Environ. Toxicol. Pharmacol. 2016, 43, 27-37. [CrossRef] [PubMed]

294. Samadder, A.; Tarafdar, D.; Abraham, S.K.; Ghosh, K.; Khuda-Bukhsh, A.R. Nano-pelargonidin protects hyperglycaemic-induced L6 cells against mitochondrial dysfunction. Planta Med. 2017, 83, 468-475. [PubMed]

295. Shaarani, S.; Hamid, S.S.; Mohd Kaus, N.H. The influence of pluronic F68 and F127 nanocarrier on physicochemical properties, in vitro release, and antiproliferative activity of thymoquinone drug. Pharmacogn. Res. 2017, 9, 12-20.

296. Ahmad, R.; Kaus, N.H.M.; Hamid, S. Synthesis and characterization of PLGA-PEG thymoquinone nanoparticles and its cytotoxicity effects in tamoxifen-resistant breast cancer cells. In Advances in Experimental Medicine and Biology; Springer: New York, NY, USA, 2018; pp. 1-18. 
297. Shahein, S.A.; Aboul-Enein, A.M.; Higazy, I.M.; Abou-Elella, F.; Lojkowski, W.; Ahmed, E.R.; Mousa, S.A.; AbouAitah, K. Targeted anticancer potential against glioma cells of thymoquinone delivered by mesoporous silica core-shell nanoformulations with pH-dependent release. Int. J. Nanomed. 2019, 14, 5503-5526. [CrossRef] [PubMed]

298. Vignesh Kumar, S.; Renuka Devi, P.; Hemananthan, E. In vitro studies to analyze the stability and bioavailability of thymoquinone encapsulated in the developed nanocarrier. J. Disper. Sci. Technol. 2020, 41, 243-256.

299. Khan, M.A.; Aldebasi, Y.H.; Alsuhaibani, S.A.; AlSahli, M.A.; Alzohairy, M.A.; Khan, A.; Younus, H. Therapeutic potential of thymoquinone liposomes against the systemic infection of Candida albicans in diabetic mice. PLoS ONE 2018, 13, e0208951. [CrossRef]

300. Nallamuthu, I.; Parthasarathi, A.; Khanum, F. Thymoquinone-loaded PLGA nanoparticles: Antioxidant and anti-microbial properties. Int. Curr. Pharm. J. 2013, 2, 202-207. [CrossRef]

301. de Lima, I.A.; Khalil, N.M.; Tominaga, T.T.; Lechanteur, A.; Sarmento, B.; Mainardes, R.M. Mucoadhesive chitosan-coated PLGA nanoparticles for oral delivery of ferulic acid. Artif. Cell Nanomed. B 2018, 46, S993-S1002. [CrossRef]

302. Heep, G.; Almeida, A.; Marcano, R.; Vieira, D.; Mainardes, R.M.; Khalil, N.M.; Sarmento, B. Zein-casein-lysine multicomposite nanoparticles are effective in modulate the intestinal permeability of ferulic acid. Int. J. Biol. Macromol. 2019, 138, 244-251. [CrossRef]

303. Zhang, Y.; Li, Z.; Zhang, K.; Yang, G.; Wang, Z.; Zhao, J.; Hu, R.; Feng, N. Ethyl oleate-containing nanostructured lipid carriers improve oral bioavailability of trans-ferulic acid ascompared with conventional solid lipid nanoparticles. Int. J. Pharm. 2016, 511, 57-64. [CrossRef]

304. Bairagi, U.; Mittal, P.; Singh, J.; Mishra, B. Preparation, characterization, and in vivo evaluation of nano formulations of ferulic acid in diabetic wound healing. Drug Dev. Ind. Pharm. 2018, 44, 1783-1796. [CrossRef] [PubMed]

305. Wang, H.; Li, Q.; Deng, W.; Omari-Siaw, E.; Wang, Q.; Wang, S.; Wang, S.; Cao, X.; Xu, X.; Yu, J. Self-nanoemulsifying drug delivery system of trans-cinnamic acid: Formulation development and pharmacodynamic evaluation in alloxan-induced type 2 diabetic rat model. Drug Dev. Res. 2015, 76, 82-93. [CrossRef] [PubMed]

306. Daunde, J.A.; Desai, S.S.; Desai, P.J.; Kamble, P.S.; Bhoi, A.V.; Gaiwad, P.R.; Walvekar, M.V. Nano-scaling of trigonelline improves antioxidative status of hfd-stz induced diabetic mice. Int. J. Res. Appl. Sci. Eng. Technol. 2018, 6, 2547-2552.

307. Farkhondeh, T.; Samarghandian, S. The effect of saffron (Crocus sativus L.) and its ingredients on the management of diabetes mellitus and dyslipidaemia. Afr. J. Pharm. Pharmacol. 2014, 8, 541-549.

308. Jia, Z.; Guo, X.; Wang, J.; Liu, Z. Beneficial effect of rhein on the treatment of diabetic nephropathy in nonobese diabetic (NOD) mice. J. Nephrol. Ther. 2012, 2, 112. [CrossRef]

309. Liu, J.; Chen, Z.; Zhang, Y.; Zhang, M.; Zhu, X.; Fan, Y.; Shi, S.; Zen, K.; Liu, Z. Rhein protects pancreatic $\beta$-cells from dynamin-related protein-1-mediated mitochondrial fission and cell apoptosis under hyperglycaemia. Diabetes 2013, 62, 3927-3935. [CrossRef]

310. Wang, G.; Li, Q.; Chen, D.; Wu, B.; Wu, Y.; Tong, W.; Huang, P. Kidney-targeted rhein-loaded liponanoparticles for diabetic nephropathy therapy via size control and enhancement of renal cellular uptake. Theranostics 2019, 9, 6191-6208. [CrossRef]

311. Kamaraj, N.; Rajaguru, P.Y.; Issac, P.K.; Sundaresan, S. Fabrication, characterization, in vitro drug release and glucose uptake activity of 14-deoxy, 11, 12-didehydroandrographolide loaded polycaprolactone nanoparticles. Asian J. Pharm. Sci. 2017, 12, 353-362. [CrossRef]

312. Islam, M.N.; Ishita, I.J.; Jung, H.A.; Choi, J.S. Vicenin 2 isolated from Artemisia capillaris exhibited potent anti-glycation properties. Food Chem. Toxicol. 2014, 69, 55-62. [CrossRef]

313. Ku, S.-K.; Bae, J-S. Vicenin-2 and scolymoside inhibit high-glucose-induced vascular inflammation in vitro and in vivo. Can. J. Physiol. Pharm. 2016, 94, 287-295. [CrossRef]

314. Chockalingam, S.; Thada, R.; Dhandapani, R.K.; Panchamoorthy, R. Biogenesis, characterization, and the effect of vicenin-gold nanoparticles on glucose utilization in 3T3-L1 adipocytes: A bioinformatic approach to illuminate its interaction with PTP 1B and AMPK. Biotechnol. Prog. 2015, 31, 1096-1106. [CrossRef] [PubMed] 
315. Ragelle, H.; Crauste-Manciet, S.; Seguin, J.; Brossard, D.; Scherman, D.; Arnaud, P.; Chabot, G.G. Nanoemulsion formulation of fisetin improves bioavailability and antitumour activity in mice. Int. J. Pharm. 2012, 427, 452-459. [CrossRef] [PubMed]

316. Das, S.; Maity, A.; Purkayastha, P. Effect of environment $\mathrm{pH}$ on the photophysics of fisetin in solid lipid nanoparticles. J. Photochem. Photobiol. B 2015, 153, 305-310. [CrossRef] [PubMed]

317. Sechi, M.; Syed, D.N.; Pala, N.; Mariani, A.; Marceddu, S.; Brunetti, A.; Mukhtar, H.; Sanna, V. Nanoencapsulation of dietary flavonoid fisetin: Formulation and in vitro antioxidant and $\alpha$-glucosidase inhibition activities. Mater. Sci. Eng. C Mater. Biol. Appl. 2016, 68, 594-602. [CrossRef]

318. Bhuvaneswari, S.; Anuradha, C.V. Astaxanthin prevents loss of insulin signaling and improves glucose metabolism in liver of insulin resistant mice. Can. J. Physiol. Pharmacol. 2012, 90, 1544-1552. [CrossRef]

319. Liu, C.; Zhang, S.; McClements, D.J.; Wang, D.; Xu, Y. Design of astaxanthin-loaded core-shell nanoparticles consisting of chitosan oligosaccharides and poly(lactic- co-glycolic acid): Enhancement of water solubility, stability, and bioavailability. J. Agric. Food Chem. 2019, 67, 5113-5121. [CrossRef]

320. Liu, B.; Liu, W.S.; Han, B.Q.; Sun, Y.Y. Antidiabetic effects of chitooligosaccharides on pancreatic islet cells in streptozotocin-induced diabetic rats. World J. Gastroenterol. 2007, 13, 725-731. [CrossRef]

321. Shanmugapriya, K.; Kim, H.; Kang, H.W. A new alternative insight of nanoemulsion conjugated with K-carrageenan for wound healing study in diabetic mice: In vitro and in vivo evaluation. Eur. J. Pharm. Sci. 2019, 133, 236-250. [CrossRef]

322. Sharma, P.K.; Saxena, P.; Jaswanth, A.; Chalamaiah, M.; Balasubramaniam, A. Anti-diabetic activity of lycopene niosomes: Experimental observation. J. Pharm. Drug Dev. 2017, 4, 103.

323. Rao, M.P.; Manjunath, K.; Bhagawati, S.T.; Thippeswamy, B.S. Bixin loaded solid lipid nanoparticles for enhanced hepatoprotection-Preparation, characterisation and in vivo evaluation. Int. J. Pharm. 2014, 473, 485-492. [CrossRef]

324. Pinzón-García, A.D.; Cassini-Vieira, P.; Ribeiro, C.C.; de Matos Jensen, C.E.; Barcelos, L.S.; Cortes, M.E.; Sinisterra, R.D. Efficient cutaneous wound healing using bixin-loaded PCL nanofibers in diabetic mice. J. Biomed. Mater. Res. B Appl. Biomater. 2017, 105, 1938-1949. [CrossRef] [PubMed]

325. Muriach, M.; Bosch-Morell, F.; Arnal, E.; Alexander, G.; Blomhoff, R.; Romero, F.J. Lutein prevents the effect of high glucose levels on immune system cells in vivo and in vitro. J. Physiol. Biochem. 2008, 64, 149-157. [CrossRef]

326. Arnal, E.; Miranda, M.; Almansa, I.; Muriach, M.; Barcia, J.M.; Romero, F.J.; Diaz-Llopis, M.; Bosch-Morell, F. Lutein prevents cataract development and progression in diabetic rats. Graefes Arch. Clin. Exp. Ophthalmol. 2009, 247, 115-120. [CrossRef] [PubMed]

327. Yoo, J.H.; Shanmugam, S.; Thapa, P.; Lee, E.S.; Balakrishnan, P.; Baskaran, R.; Yoon, S.K.; Choi, H.G.; Yong, C.S.; Yoo, B.K.; et al. Novel self-nanoemulsifying drug delivery system for enhanced solubility and dissolution of lutein. Arch. Pharm. Res. 2010, 33, 417-426. [CrossRef] [PubMed]

328. Zhao, C.; Shen, X.; Guo, M. Stability of lutein encapsulated whey protein nano-emulsion during storage. PLoS ONE 2018, 13, e0192511. [CrossRef] [PubMed]

329. Mishra, S.B.; Malaviya, J.; Mukerjee, A. Attenuation of oxidative stress and glucose toxicity by lutein loaded nanoparticles from Spinacia oleracea leaves. J. Pharm. Sci. Pharmacol. 2015, 2, 242-249. [CrossRef]

330. Nishikawa, S.; Hosokawa, M.; Miyashita, K. Fucoxanthin promotes translocation and induction of glucose transporter 4 in skeletal muscles of diabetic/obese KK-A(y) mice. Phytomedicine 2012, 19, 389-394. [CrossRef]

331. Koo, S.Y.; Mok, I.K.; Pan, C.H.; Kim, S.M. Preparation of fucoxanthin-loaded nanoparticles composed of casein and chitosan with improved fucoxanthin bioavailability. J. Agric. Food Chem. 2016, 64, 9428-9435. [CrossRef]

332. Ravi, H.; Arunkumar, R.; Baskaran, V. Chitosan-glycolipid nanogels loaded with anti-obese marine carotenoid fucoxanthin: Acute and sub-acute toxicity evaluation in rodent model. J. Biomater. Appl. 2015, 30, 420-434. [CrossRef]

333. Li, H.; Xu, Y.; Sun, X.; Wang, S.; Wang, J.; Zhu, J.; Wang, D.; Zhao, L. Stability, bioactivity, and bioaccessibility of fucoxanthin in zein-caseinate composite nanoparticles fabricated at neutral $\mathrm{pH}$ by antisolvent precipitation. Food Hydrocoll. 2018, 84, 379-388. [CrossRef]

334. Huang, Z.; Xu, L.; Zhu, X.; Hu, J.; Hailong, P.; Zeng, Z.; Xiong, H. Stability and bioaccessibility of fucoxanthin in nanoemulsions prepared from pinolenic acid-contained structured lipid. Int. J. Food Eng. 2017, 13, 20160273. [CrossRef] 
335. Jung, C.H.; Lee, D.H.; Ahn, J.; Lee, H.; Choi, W.H.; Jang, Y.J.; Ha, T.Y. $\gamma$-oryzanol enhances adipocyte differentiation and glucose uptake. Nutrients 2015, 7, 4851-4861. [CrossRef] [PubMed]

336. Kozuka, C.; Shimizu-Okabe, C.; Takayama, C.; Nakano, K.; Morinaga, H.; Kinjo, A.; Fukuda, K.; Kamei, A.; Yasuoka, A.; Kondo, T.; et al. Marked augmentation of PLGA nanoparticle-induced metabolically beneficial impact of $\gamma$-oryzanol on fuel dyshomeostasis in genetically obese-diabetic ob/ob mice. Drug Deliv. 2017, 24, 558-568. [CrossRef] [PubMed]

337. Ilie, I.; Ilie, R.; Mocan, T.; Tabaran, F.; Iancu, C.; Mocan, L. Nicotinamide-functionalized multiwalled carbon nanotubes increase insulin production in pancreatic beta cells via MIF pathway. Int. J. Nanomed. 2013, 8, 3345-3353.

338. Venkatachalam, M.; Govindaraju, K.; Mohamed Sadiq, A.; Tamilselvan, S.; Ganesh Kumar, V.; Singaravelu, G. Functionalization of gold nanoparticles as antidiabetic nanomaterial. Spectrochim. Acta A Mol. Biomol. Spectrosc. 2013, 116, 331-338. [CrossRef] [PubMed]

339. Uma Suganya, K.S.; Govindaraju, K.; Veena Vani, C.; Premanathan, M.; Ganesh Kumar, V.K. In vitro biological evaluation of anti-diabetic activity of organic-inorganic hybrid gold nanoparticles. IET Nanobiotechnol. 2019, 13, 226-229. [CrossRef]

340. Yoshikawa, M.; Matsuda, H. Chemical and Pharmacological Studies on Triterpene Saponins, Escins, from Horse Chestnut Seeds. In Saponins in Food, Feedstuffs and Medicinal Plants; Oleszek, W., Marston, A., Eds.; Springer: Dordrecht, The Netherlands, 2000.

341. Wang, H.; Zhang, L.; Jiang, N.; Wang, Z.; Chong, Y.; Fu, F. Anti-inflammatory effects of escin are correlated with the glucocorticoid receptor/NF-kB signaling pathway, but not the COX/PGF2 $\alpha$ signaling pathway. Exp. Ther. Med. 2013, 6, 19-422. [CrossRef]

342. Shamprasad, B.R.; Keerthana, S.; Megarajan, S.; Lotha, R.; Aravind, S.; Veerappan, A. Photosynthesized escin stabilized gold nanoparticles exhibit antidiabetic activity in L6 rat skeletal muscle cells. Mater. Lett. 2019, 241, 198-201. [CrossRef]

343. Khaleel Basha, S.; Govindaraju, K.; Manikandan, R.; Ahn, J.S.; Bae, E.Y.; Singaravelu, G. Phytochemical mediated gold nanoparticles and their PTP 1B inhibitory activity. Colloids Surf. B Biointerfaces 2010, 75, 405-409. [CrossRef]

344. Li, P.; Zhang, L.; Tian, X.; Xing, J. Docosahexaenoic acid has an anti-diabetic effect in streptozotocin-induced diabetic mice. Int. J. Clin. Exp. Med. 2014, 7, 3021-3029.

345. Hussein, J.; Attia, M.F.; El Bana, M.; El-Daly, S.M.; Mohamed, N.; El-Khayat, Z.; El-Naggar, M.E. Solid state synthesis of docosahexaenoic acid-loaded zinc oxide nanoparticles as a potential antidiabetic agent in rats. Int. J. Biol. Macromol. 2019, 140, 1305-1314. [CrossRef] [PubMed]

346. Hussein, J.S.; Rasheed, W.; Ramzy, T.; Nabeeh, M.; Harvy, M.; El-Toukhy, S.; Ali, O.; Raafat, J.; El-Naggar, M. Synthesis of docosahexaenoic acid-loaded silver nanoparticles for improving endothelial dysfunctions in experimental diabetes. Hum. Exp. Toxicol. 2019, 38, 962-973. [CrossRef] [PubMed]

347. Tilburt, J.C.; Kaptchuk, T.J. Herbal medicine research and global health: An ethical analysis. Bull. World Health Organ. 2008, 86, 594-599. [CrossRef] [PubMed]

348. Ekor, M. The growing use of herbal medicines: Issues relating to adverse reactions and challenges in monitoring safety. Front. Pharmacol. 2013, 4, 177. [CrossRef]

349. Modak, M.; Dixit, P.; Londhe, J.; Ghaskadbi, S.; Devasagayam, T.P. Indian herbs and herbal drugs used for the treatment of diabetes. J. Clin. Biochem. Nutr. 2007, 40, 163-173. [CrossRef]

350. Khan, V.; Najmi, A.K.; Akhtar, M.; Aqil, M.; Mujeeb, M.; Pillai, K.K. A pharmacological appraisal of medicinal plants with antidiabetic potential. J. Pharm. Bioallied Sci. 2012, 4, $27-42$.

351. Alamoudi, E.F.; Khalil, W.K.B.; Ghaly, I.S.; Hassan, N.H.A.; Ahmed, E.S. Nanoparticles from of Costus speciosus extract improves the antidiabetic and antilipidaemic effects against STZ-induced diabetes mellitus in albino rats. Int. J. Pharm. Sci. Rev. Res. 2014, 29, 279-288.

352. Al Rashid, H. Preparation and characterization of plga loaded nanoparticles obtained from D. melanoxylon Roxb. leaves for their antiproliferative and antidiabetic activity. Int. J. Green Pharm. 2017, 11, S438-S447.

353. Anand, K.; Tiloke, C.; Naidoo, P.; Chuturgoon, A.A. Phytonanotherapy for management of diabetes using green synthesis nanoparticles. J. Photochem. Photobiol. B 2017, 173, 626-639. [CrossRef]

354. Deng, W.; Wang, H.; Wu, B.; Zhang, X. Selenium-layered nanoparticles serving for oral delivery of phytomedicines with hypoglycaemic activity to synergistically potentiate the antidiabetic effect. Acta Pharm. Sin. B 2019, 9, 74-86. [CrossRef] 
355. Lombardo, D.; Kiselev, M.A.; Caccam, M.T. Smart nanoparticles for drug delivery application: Development of versatile nanocarrier platforms in biotechnology and nanomedicine. J. Nanomater. 2019, 2019, 3702518. [CrossRef]

356. Khan, T.; Gurav, P. PhytoNanotechnology: Enhancing delivery of plant based anti-cancer drugs. Front. Pharmacol. 2018, 8, 1002. [CrossRef] [PubMed]

357. Martínez-Ballesta, M.; Gil-Izquierdo, Á.; García-Viguera, C.; Domínguez-Perles, R. Nanoparticles and controlled delivery for bioactive compounds: Outlining challenges for new "smart-foods" for health. Foods 2018, 7, 72. [CrossRef] [PubMed]

358. Pérez-Herrero, E.; Fernández-Medarde, A. Advanced targeted therapies in cancer: Drug nanocarriers, the future of chemotherapy. Eur. J. Pharm. Biopharm. 2015, 93, 52-79. [CrossRef] [PubMed]

359. Bilia, A.R.; Piazzini, V.; Guccione, C.; Risaliti, L.; Asprea, M.; Capecchi, G.; Bergonzi, M.C. Improving on nature: The role of nanomedicine in the development of clinical natural drugs. Planta Med. 2017, 83, 366-381. [CrossRef]

360. Patra, N.; Kar, D.; Pal, A.; Behera, A. Antibacterial, anticancer, anti-diabetic and catalytic activity of bio-conjugated metal nanoparticles. Adv. Nat. Sci. Nanosci. Nanotechnol. 2018, 9, 035001. [CrossRef]

361. Makadia, H.K.; Siegel, S.J. Poly lactic-co-glycolic acid (PLGA) as biodegradable controlled drug delivery carrier. Polymers 2011, 3, 1377-1397. [CrossRef]

(C) 2020 by the authors. Licensee MDPI, Basel, Switzerland. This article is an open access article distributed under the terms and conditions of the Creative Commons Attribution (CC BY) license (http://creativecommons.org/licenses/by/4.0/). 